\author{
UNIVERSIDADE DE SÃO PAULO \\ ESCOLA DE ENGENHARIA DE SÃO CARLOS
}

JAMILLE LAYS MARRARA

\title{
PADRÃO VISUAL DA DINÂMICA VOCAL COMO INSTRUMENTO PARA O DIAGNÓSTICO DA DISFAGIA EM PACIENTES COM ALTERAÇÕES NEUROLÓGICAS
}




\section{PADRÃO VISUAL DA DINÂMICA VOCAL COMO INSTRUMENTO PARA O DIAGNÓSTICO DA DISFAGIA EM PACIENTES COM ALTERAÇÕES NEUROLÓGICAS}

Dissertação apresentada ao Programa de Pós Graduação de Engenharia Elétrica/ Escola de Engenharia de São Carlos/Universidade de São Paulo para obtenção do Título de Mestre em Engenharia Elétrica.

Orientador: Prof. Dr. José Carlos Pereira Área de concentração: Processamento de Sinais e Instrumentação 
FOLHA DE JULGAMENTO

\section{Candidato: Bacharel JAMILLE LAYS MARRARA.}

Dissertação defendida e julgada em 31/03/2010 perante a Comissão Julgadora:

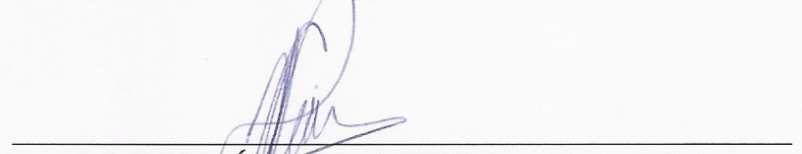

Prof. Titular JOSÉ CARLOS PEREIRA - (Orientador)

(Escola de Engenharia de São Carlos/USP)

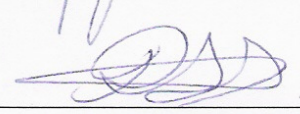

Prof. Associado ROBERTO OLIVEIRA DANTAS

(Faculdade de Medicina de Ribeirão Preto/USP)

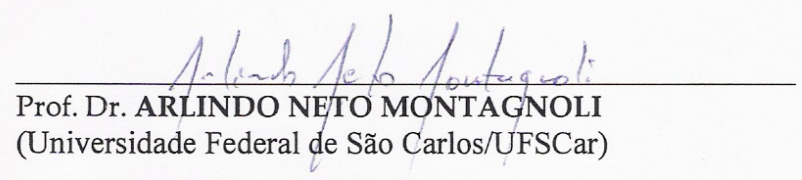

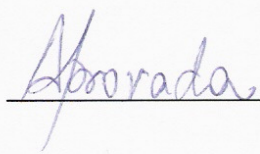
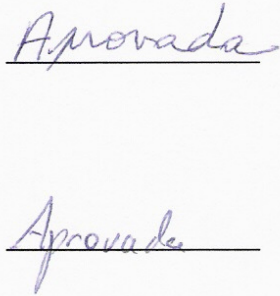

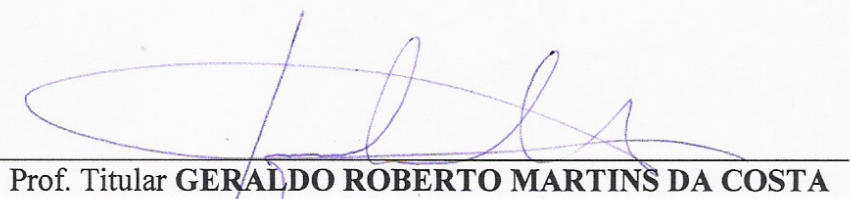

Coordenador do Programa de Pós-Graduação em Engenharia Elétrica e Presidente da Comissão de Pós-Graduação 



\section{DEDICATÓRIA}

A Deus, por me permitir superar todos os obstáculos e concretizar os meus sonhos.

À minha querida mãe, pelo total apoio, carinho, compreensão e amor, essenciais para que eu vencesse mais esta etapa da minha vida. Aos meus irmãos Kamilla e Douglas, e cunhado Diego, pelo carinho e por sempre me apoiaram nas horas difíceis.

Ao meu pai (in memorian), pois sua presença vive em meu coração e viver no coração dos que ficam não é partir.

Ao meu noivo Fábio, pelo amor, carinho, compreensão, incentivo e dedicação constante, estando sempre ao meu lado em todas as situações. 
A Deus, por absolutamente tudo.

Ao meu orientador, Prof. Dr. José Carlos Pereira, meu carinho e gratidão, por sua dedicação, ensinamento e amizade, orientando-me com responsabilidade e companheirismo.

Ao Prof. Dr. Roberto Oliveira Dantas, por sua colaboração como pesquisador, além da confiança e amizade.

As Fonoaudiólogas Paula e Daniele pelo incentivo, troca de informações e pela prontidão na realização da videofluoroscopia da deglutição.

A toda a equipe de pesquisa do Laboratório, em especial aos que contribuíram diretamente para a execução desse estudo: Maria Eugênia, Paulo, Lianet e Regina.

Aos professores da banca examinadora, obrigada pelas sugestões valiosas.

Aos pacientes, que tiveram participação fundamental neste trabalho. Acolheram-me com carinho, amizade e ajudaram-me a compreender suas dificuldades.

A todos aqueles que participaram direta ou indiretamente, os meus sinceros agradecimentos. 



\section{RESUMO}

Marrara, JL. Padrão visual da dinâmica vocal como instrumento para o diagnóstico da disfagia em pacientes com alterações neurológicas. 2010. Pgs 93. Dissertação (Mestrado)Escola de Engenharia de São Carlos, Universidade de São Paulo, São Carlos, 2010.

A disfunção da deglutição (disfagia) é muito comum em indivíduos com alterações neurológicas. Muitos estudos examinaram a presença de tosse após a deglutição e/ou desordens na fonação como a "rouquidão" que tem mostrado que a alteração na voz e desordens laríngeas podem estar relacionadas com penetração/aspiração. Embora a Análise Acústica tenha sido utilizada para avaliar vozes patológicas, este uso pode não estar sendo apropriado para vozes com desordens severas. Nos últimos anos, técnicas de dinâmica nãolinear têm se mostrado como um valioso meio para a análise de sinais com segmentos aperiódicos. O objetivo deste estudo foi caracterizar a amostra vocal de pacientes disfágicos, antes e após a deglutição de $3 \mathrm{ml}$ e $7 \mathrm{ml}$ das consistências pastosa e líquida, utilizando as técnicas de análise perceptivo-auditiva, análise acústica tradicional e do padrão visual da dinâmica vocal (PDVD). Cinco indivíduos sem alteração neurológica e vinte e seis pacientes, com alterações neurológicas de diferentes etiologias, foram submetidos à videofluoroscopia da deglutição, no Hospital das Clínicas da Faculdade de Medicina de Ribeirão Preto (HCFMRP). Cinco gravações de amostras vocais foram realizadas em cada sujeito, sendo uma antes da videofluoroscopia e quatro durante o procedimento. Estas quatro últimas aquisições foram realizadas imediatamente após a primeira deglutição de pastoso $(3 \mathrm{ml}$ e de $7 \mathrm{ml}$ ) e para a deglutição de líquido, respectivamente. Os pacientes produziram a vogal /a/ sustentada, sendo caracterizada pela Análise Perceptivo-auditiva, Análise Acústica Tradicional e pelos Padrões Visuais de Dinâmica Vocal. Na análise perceptivo-auditiva, tensão e instabilidade foram mais sensíveis a resíduo e penetração laríngea; e para aspiração a rugosidade. Utilizando a Análise Acústica Tradicional, nenhuma diferença significativa nos valores médios dos parâmetros acústicos foi observada entre os grupos. Para o PVDV, podese verificar o comportamento de toda a amostra, através da presença de irregularidades no traçado, alteração no número de loops e também pelo espalhamento das órbitas. O PVDV mostrou-se como uma técnica apropriada para a visualização ponto a ponto do sinal de voz, fornecendo informações mais precisas do comportamento vocal.

Palavras-chave: Transtorno da Deglutição; Voz; Padrão Visual da Dinâmica Vocal; Análise Acústica. 


\begin{abstract}
Marrara, JL.. Vocal Dynamic Visual Patterns (VDVP) for swallowing dysfunctions analysis in patients with neurological diseases. 2010. Pgs 93. M.Sc. Dissertation - Escola de Engenharia de São Carlos, Universidade de São Paulo, São Carlos, 2010

Swallowing dysfunction (dysphagia) is very common in individuals with neurological impairment. Most studies examining the presence of coughing after swallowing, and/or disorders of phonation such as "hoarseness" have shown that a variety of voice and laryngeal disorders can be positively related to penetration or aspiration. Although, acoustic analysis has been used to assess pathologic voices, it may be unsuitable for severely disordered voices. Over the last years, nonlinear dynamic techniques have shown to be a valuable way to analyze signals with aperiodic segments. The objective of this study is to characterize dysphagic patient voice samples, before and after swallowing solutions with different consistencies, with traditional acoustic analysis, perceptual analysis and Vocal Dynamic Visual Patterns (VDVP). Five volunteer without neurological disorders and twenty six patients, with neurological disorders of different etiologies, were subjected to a video-fluoroscopic swallowing study (VFSS), in the Speech Pathology Service at Clinics Hospital of Ribeirão Preto USP (HCFMRP). Five voice samples of each patient were recorded, one sample before the videofluoroscopic, and the other four during the procedure. The last four acquisitions were performed immediately after the first pasty $(3 \mathrm{ml}$ and $7 \mathrm{ml})$ and liquid solutions swallowing, respectively. Patients were asked to produce a sustained vowel /a/, which were characterized using traditional acoustic analysis, perceptual analysis and Vocal Dynamic Visual Patterns. For perceptual analysis, strained and instability qualities were more susceptible to residue and laryngeal penetration; roughness quality was more susceptible to aspiration. Acoustic Analysis showed none significance differences for mean values of the acoustic parameters among the five groups. For VDVP, all samples presented irregular trajectories, different numbers of loops, and divergent trajectory lines. Results demonstrate that PVDV seems to be a suitable technique for characterizing voice signals with neurological disturbance.
\end{abstract}

Key Words: Dysphagia and Voice; Vocal Dynamic Visual Patterns (VDVP); Acoustic Analysis. 


\section{LISTA DE TABELAS}

Tabela 1 - Dados do grupo de pacientes com alteração neurológica. 32

Tabela 2 - Relação de pacientes que apresentaram resíduo, penetração laríngea e/ou aspiração laringotraqueal

Tabela 3 - Porcentagem dos pacientes que apresentaram alteração na videofluoroscopia da deglutição.

Tabela 4 - Análise perceptivo-auditiva do grupo de referência.

Tabela 5 - $\quad$ Análise perceptivo-auditiva da rugosidade

Tabela 6 - $\quad$ Análise perceptivo-auditiva da soprosidade. .48

Tabela 7 - Análise perceptivo-auditiva da tensão.

Tabela 8 - Análise perceptivo-auditiva da instabilidade.

Tabela 9 - $\quad$ Análise perceptivo-auditiva de qualidade vocal molhada. .50

Tabela 10 - Valores em média e desvio padrão da Frequência Fundamental (Fo) para o sexo feminino do grupo de referência,

Tabela 11 - Valor médio e desvio padrão do jitter antes da deglutição, após a deglutição de $3 \mathrm{ml}$ e $7 \mathrm{ml}$ das consistências pastosa e líquida do grupo de

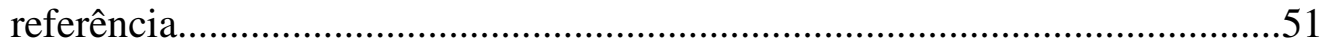

Tabela 12 - Valor médio e desvio padrão do shimmer antes da deglutição, após a deglutição de $3 \mathrm{ml}$ e $7 \mathrm{ml}$ das consistências pastosa e líquida para o grupo de referência.

Tabela 13 - Valores em média e desvio padrão da Frequência Fundamental (Fo) para o sexo feminino

Tabela 14 - Valores em média e desvio padrão da Frequência Fundamental para o sexo masculino. 
Tabela 15 - Valor médio e desvio padrão do jitter antes da deglutição, após a deglutição de $3 \mathrm{ml}$ e $7 \mathrm{ml}$ das consistências pastosa e líquida.

Tabela 16 - Valor em média e desvio padrão do shimmer antes da deglutição, após a deglutição de $3 \mathrm{ml} \mathrm{e} 7 \mathrm{ml}$ das consistências pastosa e líquida.

Tabela 17 - Padrão visual do número de loops, antes da deglutição, após a deglutição de pastoso e líquido

Tabela 18 - Comparação da proporção (em porcentagem) do número de loops antes da deglutição com as consistências pastosa e líquida e com os volumes de 3 e $7 \mathrm{ml}$; comparação entre as consistências e os

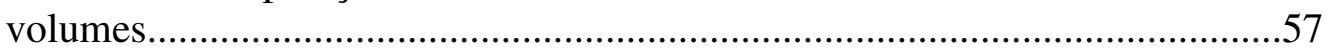

Tabela 19 - Número de loops dos pacientes com resíduo .58

Tabela 20 - Número de loops dos pacientes com penetração e/ou aspiração laringotraqueal..

Tabela 21 - Grau de comparação do traçado (em porcentagem) antes da deglutição com as consistências pastosa e líquida e com os volumes de 3 e $7 \mathrm{ml}$; comparação entre as consistências e os volumes dos indivíduos sem alteração

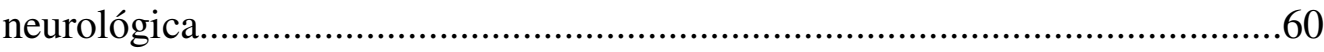

Tabela 22 - Regularidade do traçado, antes da deglutição, após a deglutição de pastoso e líquido.

Tabela 23 - Grau da regularidade dos traçados dos pacientes com resíduo em hipofaringe

Tabela 24 - Grau do traçado dos pacientes com penetração e/ou aspiração laringotraqueal..

Tabela 25 - Comparação do grau de irregularidade do traçado (em porcentagem) antes da deglutição com as consistências pastosa e líquida e com os volumes de 3 e 7ml; comparação entre as consistências $\mathrm{e}$ volumes 62

Tabela 26 - Grau de convergência das trajetórias antes da deglutição, após a deglutição de pastoso e de líquido. 
Tabela 27 - Grau de comparação da convergência do traçado(em porcentagem) antes da deglutição com as consistências pastosa e líquida e com os volumes de 3 e 7ml; comparação entre as consistências e os

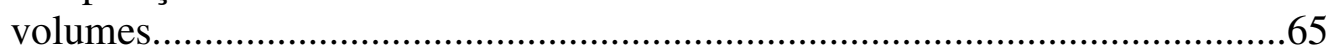

Tabela 28 - Grau de convergência do traçado dos pacientes com resíduo em hipofaringe.66

Tabela 29 - Grau da convergência do traçado dos pacientes com penetração e/ou aspiração

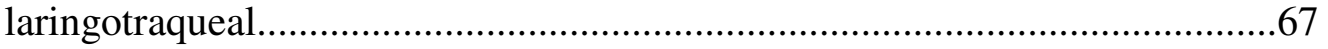




\section{LISTA DE FIGURAS}

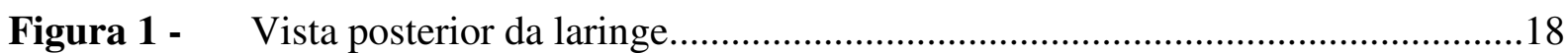

Figura 2 - Imagens das pregas vocais em posição respiratória (A) e fonatória (B)...........19

Figura 3 - Cartilagens, ligamentos e músculos da laringe...........................................20

Figura 4 - Representação esquemática do ciclo glótico..................................................21

Figura 5 - Desenho esquemático do espectro de frequiências do som fundamental, seguido da curva de ressonância do trato vocal e do espectro resultante da frequiência fundamental com a ressonância do trato vocal...............................................22

Figura 6 - Representação do jitter e shimmer..............................................................28

Figura 7 - Exemplo de um sinal de voz completo (vogal /a/), excluindo-se o início e fim

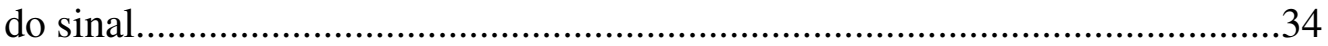

Figura 8 - Tela do programa Voice Analysis 2009 utilizado para análise dos parâmetros acústicos.

Figura 9 - Exemplo da série temporal simples (A); e gráfico bidimensional da reconstrução do espaço de fase $(\mathrm{B})$

Figura 10 - Exemplo de um sinal periódico com uma frequência fundamental (A); uma frequência e uma harmônica $(\mathrm{B})$; uma frequência e dois harmônicos $(\mathrm{C})$; uma frequência e três harmônicas (D) e na parte inferior o padrão visual da dinâmica vocal do sinal. Adaptada de Dajer (2006).......................................38

Figura 11 - (A) Padrão Visual da Dinâmica Vocal com shimmer; (B) Padrão Visual da Dinâmica Vocal com jitter. Adaptada de Dajer, 2006.

Figura 12 - Trecho selecionado do sinal de voz da vogal /a/ na parte superior (A). As imagens B, C e D são os trechos selecionados em 50 milissegundos

Figura 13 - Na parte superior verifica-se o sinal em amplitude em função do tempo e na parte inferior um exemplo do PVDV do trecho de 50 milissegundos; A) shimmer e B) o jitter. 
Figura 14 - Exemplos de PVDV com os 5 graus de número de loops; A) número indefinido de loops; B) 1 loop; C) 2 loops; D) 3 loops e D) 4 ou mais loops

Figura 15 - Exemplos de PVDV com os 5 graus de regularidade do traçado; A) regular; B) regular com porção irregular; C) irregularidade intermitente; D) levemente irregular e E) irregular.

Figura 16 - Classificação da convergência das órbitas; A) forte; B) forte a média; C) média; D) média a fraca e E) fraca convergência

Figura 17 - Padrão visual da dinâmica vocal de um sinal, de um individuo sem alteração vocal.

Figura 18 - Distribuição para a Fo dos sexos feminino e masculino.

Figura 19 - Gráficos de Distribuição para jitter e shimmer. 55

Figura 20 - Padrão Visual da Dinâmica Vocal de um indivíduo do grupo de referência, (A) antes da deglutição; (B) após deglutição de $3 \mathrm{ml}$ de pastoso; (C) após deglutição de $7 \mathrm{ml}$ de pastoso; (D) após a deglutição de $3 \mathrm{ml}$ de líquido e (E) após a deglutição de $7 \mathrm{ml}$ de líquido

Figura 21 - Padrão Visual da Dinâmica Vocal com amostras de 50 milissegundos; (A) antes da deglutição; (B) após deglutição de 3ml de pastoso; (C) após deglutição de $7 \mathrm{ml}$ de pastoso; (D) após a deglutição de $3 \mathrm{ml}$ de líquido e (E) após a deglutição de $7 \mathrm{ml}$ de líquido 


\section{SUMÁRIO}

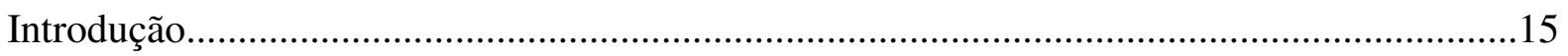

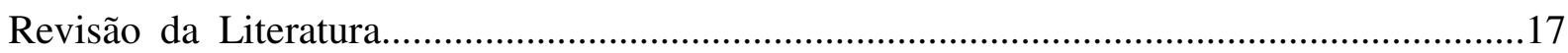

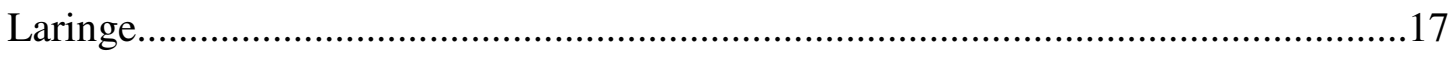

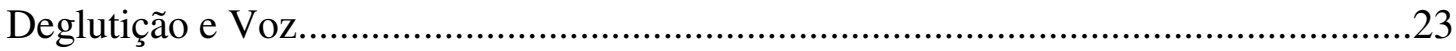

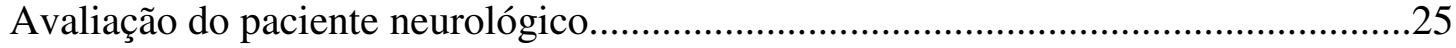

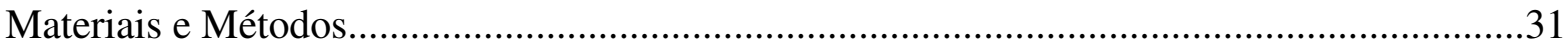

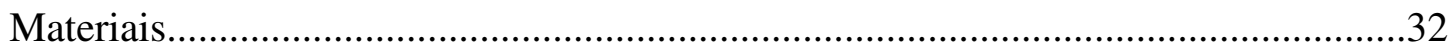

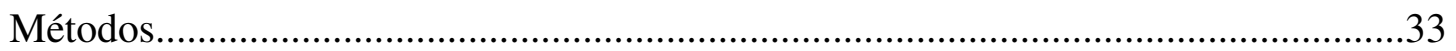

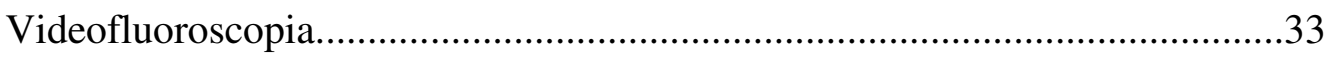

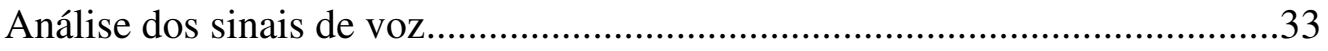

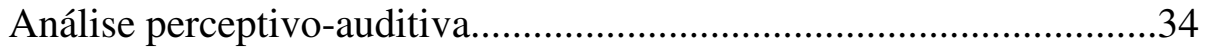

Análise acústica tradicional..............................................................34

Padrão Visual da Dinâmica Vocal (PVDV)........................................36

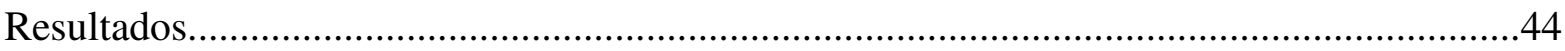

Videofluoroscopia da deglutição.........................................44

Análise Perceptivo-Auditiva.............................................46

Análise Acústica Tradicional.....................................................................................50

Análise qualitativa dos padrões visuais da dinâmica vocal.........................................56

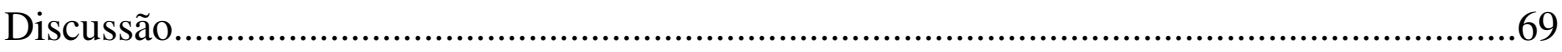

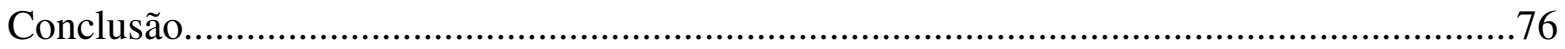

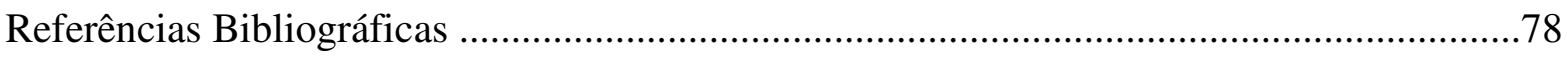

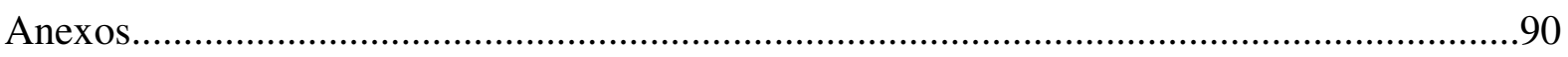




\section{1- INTRODUÇÃO}

A produção de voz é uma atividade complexa que necessita da mobilização de várias estruturas, especialmente daquelas relacionadas ao aparelho respiratório e digestivo, as quais mudam da função de respiração para deglutição e também para a fonação em curtos intervalos de tempo, implicando numa atividade altamente coordenada. Sendo a faringe considerada como um canal comum para a passagem do alimento e do ar inspirado, apresentando um cruzamento das vias seguidas pelo bolo alimentar e pela corrente aérea. Portanto, a orofaringe está envolvida com deglutição, respiração e também fonação (ANDRADE; CAMARGO, 2004). A coordenação respiração/deglutição é vital durante a alimentação devido à utilização da mesma via de passagem e a aspiração é evitada (VALIM et al., 2007).

O mecanismo funcional da laringe é complexo, apresentando um sofisticado sistema de controle neurológico, não sendo surpresa que distúrbios neurológicos provoquem alterações no mecanismo de respiração e deglutição assim como efeitos na voz (CERVANTES, 2002). Geralmente para avaliar e diagnosticar sintomas de desordens vocais os médicos utilizam técnicas invasivas, como a vídeo- laringoscopia ou a laringoestroboscopia. Essas técnicas embora modernas apresentam várias desvantagens, como por exemplo: são invasivas, de alto custo, causam desconforto ao paciente e em alguns casos são contra-indicadas. Para contornar estas desvantagens, vários métodos de analise acústicos e ferramentas computacionais têm sido desenvolvidos.

A avaliação vocal utilizada como instrumento complementar fornece parâmetros de comparação e cuidados por meio da análise acústica vocal e da análise perceptivo-auditiva em relação à avaliação da disfagia e suas complicações (VALIM et al., 2007). Características clínicas do comportamento vocal, como qualidade vocal molhada, são importantes para o levantamento de hipóteses relacionadas à presença de penetração laríngea e/ou aspiração laringotraqueal (ANDRADE; CAMARGO, 2004), sendo mencionado em muitos trabalhos nesta área.

Medidas como jitter e shimmer têm sido aplicadas como alguns métodos tradicionais, mas quando aplicadas em vozes aperiódicas mostram-se contestáveis. Nos últimos anos, diversas técnicas baseadas em modelos não lineares tem sido um meio valioso para a análise destes sinais. Segundo Titze (1994) as técnicas não-lineares se apresentam como ferramentas promissoras para analisar sinais com aperiodicidades como é o sinal de voz. 
Uma dessas técnicas é a análise dos Padrões Visuais de Dinâmica Vocal (PVDV) que permite a visualização da complexidade dinâmica do sinal de voz. Com esta técnica a vibração das pregas vocais pode ser mostrada como trajetórias num espaço de fase reconstruído evidenciando a dinâmica do sistema (DAJER; PEREIRA; MACIEL, 2005).

O objetivo deste trabalho é caracterizar a voz de indivíduos com alterações neurológicas através da correlação de análises vocais, utilizando a Análise perceptivoauditiva, Análise Acústica tradicional e análise dos Padrões Visuais da Dinâmica Vocal (PVDV), com achados da videofluoroscopia da deglutição - estase alimentar, penetração e/ou aspiração laringotraqueal; e verificar se estas ferramentas podem ser utilizadas como métodos auxiliares no diagnóstico de penetração e/ou aspiração laringotraqueal. 


\section{2- REVISÃO DE LITERATURA}

A produção da voz envolve órgãos e sistemas, tornando-se um mecanismo complexo que produz um único e individual sinal acústico, este sinal de voz tem origem na laringe, onde estão localizadas as pregas vocais, e sendo esta voz a principal responsável para a comunicação humana (DAJER, PEREIRA, MACIEL; 2005).

\subsection{LARINGE}

A laringe é um órgão que comunica a faringe com a traquéia, constituída por cartilagens unidas entre si por membranas e ligamentos; movimentadas por ações musculares, e coberta internamente por mucosa. Os ligamentos e membranas laríngeas são considerados extrínsecos quando unem uma cartilagem ao osso hióide ou traquéia - exercendo função de suporte- e são considerados intrínsecos quando unem as cartilagens laríngeas entre si (DEDIVITIS, 2002).

Os músculos extrínsecos da laringe podem ser divididos, segundo sua localização, em supra-hióides (digástrico, gênio-hióideo, milo-hióide e estilo-hióide) e os infra-hióides (tirohióideo, esterno-hióideo, omo-hióideo e esternotiróideo), apresentando suas fixações laríngeas a partir do osso hióideo. Já os músculos intrínsecos que controlam os movimentos de abertura e fechamento das pregas durante a respiração, fonação e deglutição são: cricotireídeo (CT), cricoaritenóideo posterior (CAP), aritenóideo (IA), tireoaritenóideo (TA) - músculo vocal - e ariepiglótico (DEDIVITIS, 2002).

A laringe também é formada por três cartilagens ímpares - epiglote, tireóide e cricóide - e três cartilagens pares - aritenóides, corniculadas e cuneiformes - apresentadas em detalhe a continuação:

- Epiglote: fina lâmina de cartilagem do tipo elástica, com formato de folha e com o eixo maior vertical. Está localizada dorsalmente à base da língua e verticalmente ao adito laríngeo. 
Sua extremidade cranial ou base é livre e o extremo caudal é longo e estreito. A valécula ou fossa glossoepiglótica é a depressão entre a epiglote e a base da língua. As áreas posterior e inferior da epiglote são chamadas de vestíbulo laríngeo, que termina na superfície superior das pregas vestibulares (MARCHESAN, 2004);

- Tireóide: maior cartilagem da laringe, composta de duas lâminas com disposição vertical, fundidas ventralmente na linha média do pescoço, estabelecendo um ângulo diedro e projetando a chamada proeminência laríngea;

- Cricóide: anel cartilaginoso, que forma os aspectos caudal e dorsal da laringe, e serve de suporte para as demais cartilagens;

- Aritenóides: par de cartilagens localizadas na borda cranial da lâmina da cricóide, no dorso da laringe;

- Corniculadas: também conhecidas como cartilagens de Santorini. Apresentam formato cônico, constituídas por cartilagem do tipo elástico e se articulam com o ápice das aritenóides e em alguns casos podem estar fundidas a elas;

- Cuneiformes: também conhecidas como cartilagens de Wrisberg. Não são constantes, apresentando variações em suas dimensões quando presentes. São compostas de cartilagem elástica, localizando-se uma de cada lado, sobre a prega ariepiglótica.

A figura 1 ilustra algumas das estruturas cartilaginosas e musculares da laringe.

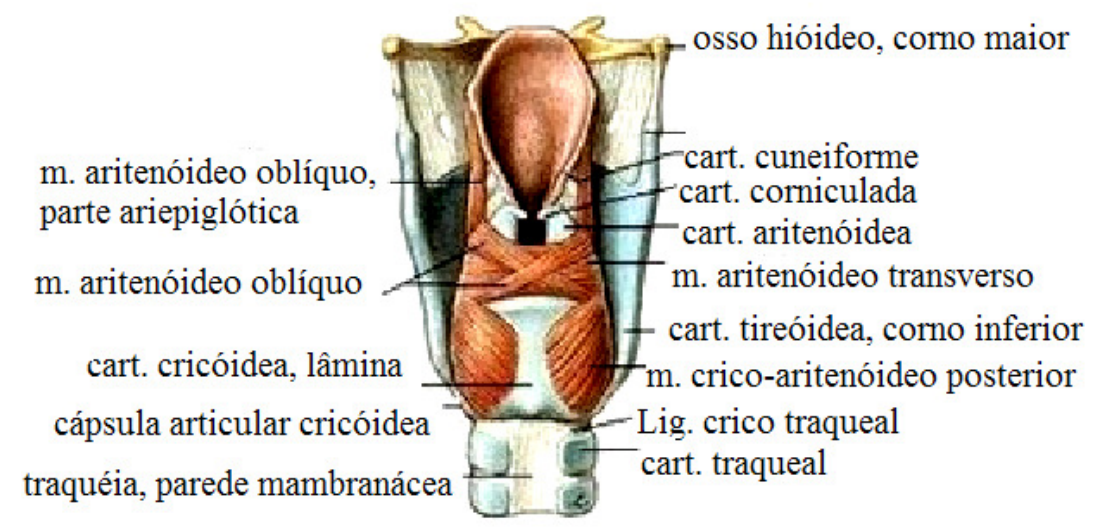

Figura 1 - Vista posterior da laringe

Figura modificada: http://pt.wikipedia.org/wiki/Sistema_respiratorio 
A laringe possui três funções básicas, sendo elas a função respiratória, a qual permite a passagem do ar, função esfincteriana, que previne a aspiração de saliva e alimentos e função fonatória por meio da vibração de lâminas elásticas devido à passagem do ar, produzindo o som fundamental (DEDIVITIS, 2002). Para cada uma dessas funções, diferentes movimentos das pregas vocais são requeridos: abertura máxima durante a respiração, abertura parcial durante as consoantes surdas, como /s/, fechamento na linha média para a vibração das pregas vocais durante a produção de voz e fechamento esfincteriano de ambas pregas vocais e pregas ventriculares durante a deglutição (LUDLOW, 2005).

\section{- Função Respiratória}

A musculatura da laringe proporciona a atividade das pregas vocais para a passagem do fluxo de ar durante a inspiração e fechamento parcial para reduzir o fluxo de ar durante a expiração (BRANCATISANO; DODD; ENGEL, 1991). A figura 2A ilustra a imagem da prega vocal em posição respiratória. Durante a inspiração a laringe desce ligeiramente, passando a ser tracionada para cima na expiração, a amplitude desse movimento esta relacionada à intensidade e força da respiração (DEDIVITIS; BARROS, 2002). A traquéia e o diafragma participam da descida laríngea, contribuindo junto ao músculo cricoaritenóideo posterior com função de abdução das pregas vocais. Na descida da cartilagem tiróide e conseqüente abertura da laringe há contribuição dos músculos infra-hióideos.

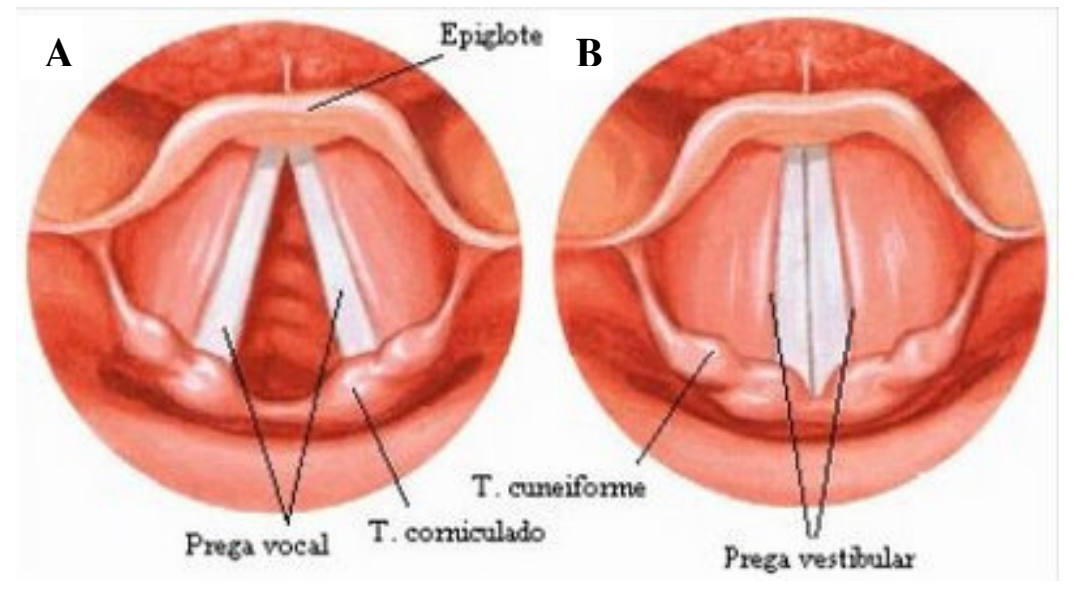

Figura 2 - Imagens das pregas vocais em posição respiratória (A) e fonatória (B) 


\section{- Função Esfincteriana}

A alimentação é o principal suporte para a manutenção da vida, como também esta relacionada com um dos maiores prazeres experimentados pelo homem, parecendo natural e sempre prazeroso, degustar uma boa comida, somente é valorizada esta situação quando se percebe alguma dificuldade para deglutir os alimentos (ESTRELA, MOTTA, ELIAS, 2009).

A deglutição constitui um processo fisiológico, resultante de um complexo mecanismo neuromotor, tendo como principal função o transporte do material ingerido e da saliva da boca até o estômago (MACEDO-FILHO, 1999). Ela pode ser dividida nas seguintes fases: antecipatória, oral, faríngea e esofágica. $\mathrm{Na}$ fase antecipatória ocorrem mecanismos organizacionais para o ato da alimentação; na fase oral há captação do alimento, qualificação e o seu preparo (FURKIM; MATTANA, 2004). A fase faríngea inicia-se com o disparo do reflexo de deglutição, e irá durar enquanto o movimento posterior do bolo não for completado (TANIGUTE, 1998), nesta fase a laringe e o osso hióide são movidos anterior e superiormente pelos músculos extrínsecos, auxiliando a inversão da epiglote, protegendo a via aérea durante o fechamento das pregas vocais (KAWASAKI et al., 2001).

Para cobrir a entrada superior da laringe as pregas ariepiglóticas se aproximam, sendo neste nível mais alto que o espaço anterior é preenchido pelo movimento descendente da epiglote, já o espaço posterior é preenchido pela cartilagem aritenóidea (SASAKI; IAACSON, 1988). O segundo nível de proteção são as pregas vestibulares que formam o teto do ventrículo laríngeo, e o terceiro corresponde às pregas vocais, com o feixe interno dos músculos tireoaritenóideos (MARCHESAN, 2004), como ilustra a figura 3.

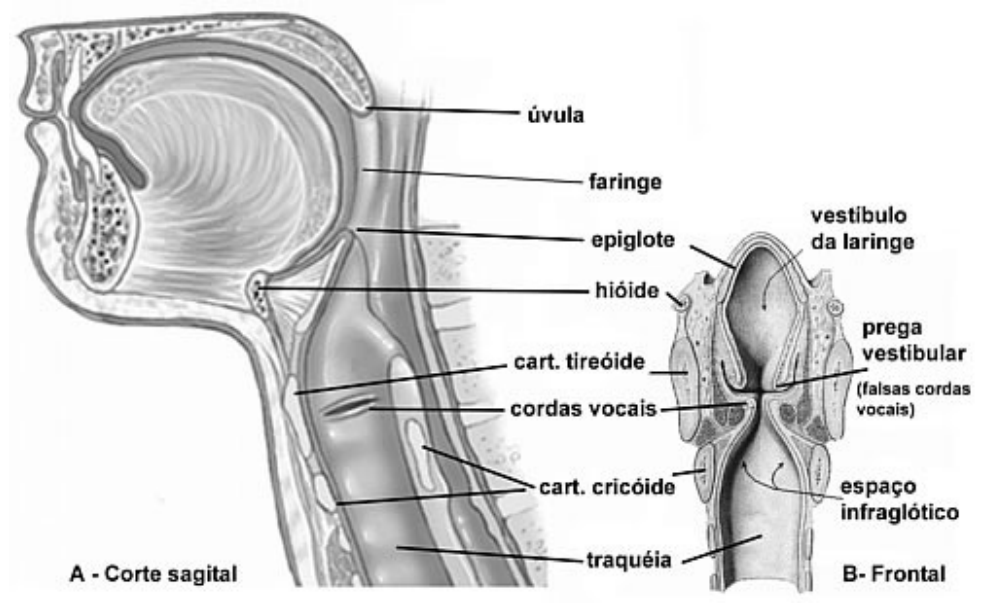

Figura 3 - Cartilagens, ligamentos e músculos da laringe 
$\mathrm{Na}$ fase esofágica o alimento que passou pelo esfíncter superior é direcionado para o esôfago por meio de ondas peristálticas e, posteriormente, para o estômago (MENEGHELLI; OLIVEIRA; FERNANDES, 1996).

Shaker et al. (1993) refere que um perfeito sincronismo de eventos permite que ocorra a deglutição sem aspirar às vias respiratórias o bolo alimentar e não permite o refluxo desse bolo proveniente do esôfago, pois envolve a interação entre os tratos respiratório e digestório. Complexos distúrbios podem ocorrer por alterações da deglutição, sendo um deles a disfagia, denominada como dificuldade de deglutição (FURKIM; SILVA, 1999).

\section{- Função Fonatória}

Para que ocorra a produção vocal é necessário que o ar, vindo dos pulmões, passe pelos brônquios e traquéia até atingir a laringe, onde estão localizadas as pregas vocais formadas pela porção cartilaginosa e outra membranosa - que ao serem ativadas pela pressão subglótica de ar vibram em movimentos muco-ondulatórios sucessivos produzindo o som laríngeo (COTES et al., 2001). Quando as pregas vocais se abrem, o ar passa entre as pregas reduzindo a pressão entre elas (efeito Bernoulli) e a tensão retorna com o fechamento das pregas na linha média, permitindo que este processo cíclico continue (TITZE, 1994), conforme ilustrado na figura 4.

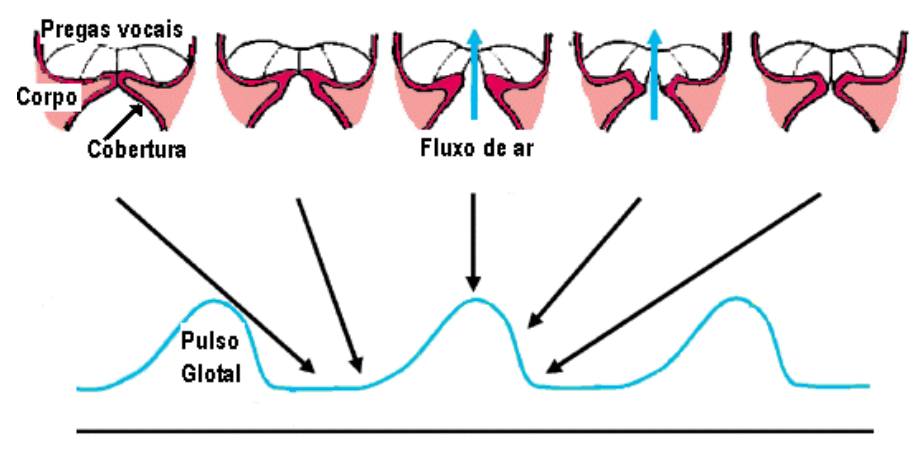

Figura 4 - Representação esquemática do ciclo glótico biorobotics.harvard.edu/ research/heather2

Para que esta produção ocorra é necessário um controle neurofisiológico altamente integrado, sendo que as pregas vocais devem aproximar-se na linha média e manter um perfeito equilíbrio do tono muscular adutor e abdutor, devendo a abertura e fechamento 
glótico ocorrer com extrema precisão, estando às pregas vocais aduzidas no momento do início da produção das vogais e sons sonoros; e abduzidas para os sons surdos (COTES et al., 2001).

Para Andrade e Camargo (2004), durante a produção da fala, as estruturas dos sistemas respiratório e digestivo estão envolvidas em várias atividades, sendo que o sistema respiratório exerce a função de gerar a fonte de energia devido a modulação do suporte ventilatório e por sua vez, as estruturas do sistema digestivo desempenham o papel fundamental na caracterização e na qualidade da fala, exercendo função articulatória e ressonadora. Assim, o som básico da vibração da mucosa das pregas vocais será modificado pelo fenômeno de ressonância provocado pelo trato vocal que consiste na amplificação de certas faixas de freqüência e no amortecimento de outras dependendo das características de cada ressonador, como mostra a figura 5 (STEVENS; HOUSE, 1961; TITZE, 2000). Desde o ponto de vista de um sistema fonte-filtro, as pregas vocais serão a fonte sonora e o trato vocal o filtro, tendo como resultante o sinal acústico da voz humana (RABINER; JUANG, 1993).
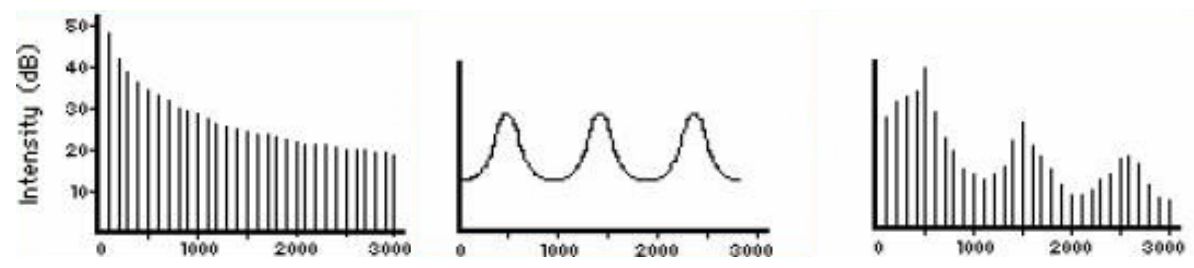

Figura 5 - Desenho esquemático do espectro de frequiências do som fundamental, seguido da curva de ressonância do trato vocal e do espectro resultante da freqüência fundamental com a ressonância do trato vocal

\subsection{DEGLUTIÇÃO E VOZ}

Segundo Andrade e Camargo (2004) a fonação é uma função adaptada que depende da ação conjunta das estruturas dos sistemas respiratório e digestório, cuja interação pode estar prejudicada no caso de disfagia.

Principalmente nos casos neurológicos, a disfonia tem sido associada com a disfagia, pois muitas das condições que causam dificuldade de comunicação como as doenças neurológicas e demências não-tratáveis, podem resultar em disfagia (CLARK, 1994). Isto porque os processos fonoarticulatórios e de deglutição são dinâmicos e depende de vários fatores, como a integridade do sistema nervoso central, além da mobilidade e sensibilidade das estruturas orofaríngeas envolvidas (ANDRADE; CAMARGO, 2004). 
As disfunções neurológicas podem afetar a ação muscular responsável pelo transporte do bolo alimentar da cavidade oral para o esôfago, ocorrendo na maioria dos casos alterações ao nível oral e/ou faríngeo. Isto pode ocorrer de forma isolada em uma das fases da deglutição ou em várias delas, o que é comum em pacientes neurológicos (QUINTELLA; SILVA; BOTELHO, 1999). Para Buchholz (1994), ela pode decorrer de uma fraqueza na musculatura dos lábios, língua, véu palatino, faringe e do esôfago devido a lesão cortical, subcortical e/ou tronco cerebral, podendo ainda somá-las a incoordenação dos movimentos, falha na sensibilidade das regiões oral e faríngea que interferem com as fases voluntárias e reflexas da deglutição.

As desordens no processo de deglutição e/ou alimentação causadas por doença ou trauma neurológico são denominadas disfagias neurogênicas (SANTINI, 1999), que na maioria dos casos, podem ser caracterizadas por presença de alterações funcionais do mecanismo da deglutição, sem que ocorram alterações estruturais (FURKIM; SILVA, 1999), sendo algumas delas:

- Acidente vascular encefálico (AVE), é um déficit neurológico de início súbito, devido presumidamente a um distúrbio local do suprimento sanguíneo no cérebro (XEREZ, 2003), caracterizado por perda de controle motor, alteração da sensibilidade, deficiência cognitiva ou da linguagem, desequilíbrio ou coma (ROTH; HARVEY, 2000);

- Esclerose lateral amiotrófica (ELA), caracterizada pela degeneração progressiva dos neurônios motores inferiores (do corno anterior da medula) e dos superiores (corticais). Há fraqueza progressiva e reflexos de estiramento exacerbados (KIMAN; GOYAL, 1976; SILBINGER et al., 1967). Além disso, a disfonia e disfagia costumam ocorrer durante o curso da doença (KOWACS, 2000);

- Doença de Parkinson, é uma doença progressiva, na qual a perda gradual de neurônios da substância negra leva a um quadro clínico caracterizado por manifestações clínicas como: hipomimia, bradicinesia, desequilíbrio, tremor em repouso, entre outros (KOWACS, 2000).

Vários pesquisadores mostraram a relação dos transtornos de deglutição e voz em pacientes com alterações neurológicas. Carrara-de-Angelis (2000) caracterizou os aspectos vocais laríngeos, bem como correlacionou os achados das avaliações clínica fonoarticulatória, acústica da voz, laringoestroboscópica e videofluoroscópica da deglutição em 24 pacientes 
com Doença de Parkinson, verificando-se que as medidas de perturbação da freqüência fundamental mostraram associação significante com penetração laríngea. Com isso, os dados sugerem relação entre voz e deglutição, reforçando a importância de avaliações objetivas vocais e de deglutição em indivíduos com Doença de Parkinson.

Segundo os resultados do estudo de Warms e Richards (2000), as características da voz molhada não estão associada com a penetração ou aspiração do material em via aérea. Embora o estudo tenha avaliado a característica de umidade de forma isolada dos outros sinais clínicos de disfagia, mas confirma que pode ser indicativo de aglomeradas características que tentam identificar risco de aspiração (LINDEN; SIEBENS, 1983; LINDEN; KUHLEMEIER; PATTERSON, 1993) e que a voz molhada pode ser um desses (LINDEN; KUHLEMEIER; PATTERSON, 1993).

No estudo de Ryu, Park e Choi (2004), 93 pacientes realizaram a videofluoroscopia da deglutição e a análise vocal (analisando a média da frequiência fundamental, média relativa à perturbação, porcentagem do shimmer, relação ruído-harmônico e índice de turbulência vocal) antes e depois do estudo da videofluoroscopia. Visava-se determinar o diagnóstico pelo controle da análise vocal de pacientes com risco clinicamente significativo de aspiração, sendo concluído que a análise vocal apresenta-se um instrumento seguro e de confiança para pacientes com disfagia, podendo detectar indivíduos com alto risco clinicamente significativo para aspiração.

Os sinais acústicos e perceptivos da qualidade vocal mostraram-se concordantes as alterações de deglutição, demonstrando que a avaliação vocal pode complementar a compreensão dos casos de disfagia (ANDRADE; CAMARGO, 2004).

De Paula et al. (2002) referem que seguramente as lesões cerebrais (traumatismo crânio-encefálico, episódios isquêmicos e hemorrágicos) constituem a maioria das causas de disfagia. Estudos realizados em adultos referem que o desconhecimento da patologia da disfagia ou a subestimação dos fatos pode acarretar graves consequiências clínicas, como a desidratação, desnutrição e pneumopatias aspirativas (SMITH et al., 1999).

Segundo Zenner, Losinski e Mills (1995), durante a fase faríngea se a laringe não se fecha apropriadamente pode-se ter a penetração e aspiração de alimento para as vias aéreas inferiores, o que pode causar sons anormais como estridor, "som molhado" da respiração, 
descarga de material antes ou durante a deglutição, além de tosse, limpeza da garganta e "voz molhada". Um estridor pós-deglutição ou fonação com "som molhado" poderiam resultar de penetração com ou sem aspiração (McKAIG, 1999). Para Andrade e Camargo (2004), estudos examinaram a presença de tosse após a deglutição e/ou alteração de fonação, como a rouquidão, que têm sugerido a variação de voz e distúrbios laríngeos como a possibilidade de penetração laríngea.

\subsection{AVALIAÇÃO DO PACIENTE NEUROLÓGICO}

O mecanismo funcional da laringe é complexo e apresenta um sofisticado sistema de controle neurológico, assim os distúrbios neurológicos podem acarretar efeitos na voz, como no mecanismo da respiração e deglutição (CERVANTES, 2002). A continuação serão apresentados alguns testes utilizados em pacientes com alteração neurológica.

\section{- Avaliação clínica e videofluoroscópica da deglutição}

Após a investigação da queixa e do histórico do paciente, é realizada a avaliação clínica, verificando-se inicialmente as características anatômicas e funcionais da musculatura envolvida na deglutição, e posteriormente o funcionamento da deglutição durante a alimentação (PILZ, 1999). A realização da ausculta cervical ocorre por meio do estetoscópio ou microfone sobre a laringe que ajuda avaliar a fase faríngea da deglutição, principalmente a competência da deglutição e respiração, onde os sons do trânsito do bolo alimentar podem ser verificados e avaliados (ARVEDSON, 1993; BOSMA, 1997; MCKAIG, 1999). Ela é uma técnica simples e apresenta-se como um promissor método de diagnóstico e monitoramento terapêutico, mas sendo um método subjetivo (ALMEIDA, 2004).

Em pacientes com história de pneumonias de repetição compatíveis com aspiração, tosse ou engasgos relacionados com a alimentação deve-se realizar a investigação clínica e laboratorial, utilizando a videofluoroscopia e/ou a nasofibroscopia da deglutição, sendo altamente sensíveis à detecção da disfagia orofaríngea (ISOLA, 1999). 
A videofluoroscopia é definida por vários autores como "padrão ouro" para a avaliação da deglutição, permitindo a interpretação da fisiologia e fisiopatologia da deglutição, devido à análise das fases da deglutição e a inter-relação entre elas de forma dinâmica (COSTA et al., 1999; OLIVEIRA, 2003). Além disso, este procedimento possui vantagens como à análise dinâmica, precisa e imediata da deglutição, antes, durante e após o disparo do reflexo faríngeo e em diversas posições. Entretanto, possui algumas desvantagens como exposição do paciente à radiação; utilização de contraste de bário que, por apresentar moléculas grandes, se aspirado, não será absorvido pela corrente sanguínea (GONÇALVES; VIDIGAL, 1999).

A aspiração laringotraqueal é definida como a presença de materiais contrastados abaixo do plano das pregas vocais. Este parâmetro de avaliação da deglutição tornou-se um poderoso sinal de comprometimento funcional, da segurança da deglutição e da disfagia orofaríngea (EKBERG; OLSSON, 1997). A aspiração pode apresentar-se com discreta sintomatologia, na ausência ou diminuição do reflexo de tosse, ocorrendo silenciosamente, em decorrência da diminuição da sensibilidade laríngea e do próprio distúrbio neurológico (MIRRETT et al., 1994). A penetração seria a entrada de conteúdo orofaríngeo na laringe distal, sem associação com uma inspiração, não atingindo os pulmões (ISOLA, 1999).

Assim, visto que as complicações mais comuns que advêm da disfagia são queda no estado nutricional e pneumonia aspirativa, podendo resultar em morte; e que freqüentemente os pacientes com alteração neurológica aspiram durante o processo de alimentação ou até mesmo a própria saliva; a detecção e caracterização da aspiração, que ocorre na fase faríngea, são primordiais para o prognóstico e reabilitação destes pacientes.

\section{- Avaliação perceptivo-auditiva}

A avaliação perceptivo-auditiva e a acústica é uma prática comum de fonoaudiólogos, que possuem como finalidade explorar o comportamento e a dinâmica do sistema vocal de um sujeito. A avaliação perceptivo-auditiva é fundamental na análise da qualidade vocal e da severidade dos desvios, como também na observação de seu impacto nas habilidades de comunicação. Ela é utilizada internacionalmente e empregada em diferentes estudos com elevado grau de confiabilidade (DE BODT; WUYTS; VAN DE HEYNING, 1997). 
Algumas propostas de avaliação vocal perceptiva têm sido apresentadas, sendo as escalas mais difundidas: "Modelo de Descrição da Qualidade Vocal - Fonte e Filtro" (LAVER, 1980), como também a escala "GRBAS", criada pelo Comitê para Testes de Função Fonatória da Sociedade Japonesa de Logopedia e Foniatria (SJLF), em 1969, avaliando a voz em nível glótico; onde G - Grade significa no dicionário da língua portuguesa, Grau; R - Rough, Áspero; B - Breath, Soproso; A - Asthenic, Astênico; S - Strain, Tenso.

A aspereza descreve uma característica vocal associada à rigidez de mucosa, apresentando a qualidade vocal com aspecto de voz seca e sem projeção. A soprosidade caracteriza-se à presença de ruído de fundo, audível. A astenia, relacionada à hipofunção das pregas vocais e pouca energia na emissão; e a tensão associada com o esforço vocal devido ao aumento da adução glótica.

- Avaliação Acústica do sinal de voz.

A acústica é o estudo do som e a acústica da voz pode nos proporcionar informações importantes sobre os movimentos das pregas vocais (COLTON; CASPER, 1996). A análise acústica consiste no método de extração e quantificação de padrões precisamente definidos do sinal vocal por instrumentos objetivos (CARRARA-DE-ANGELIS; CERVANTES; ABRAHÃO, 2001), que se apresenta como um método não invasivo capaz de obter informações quantitativas sobre o aparato vocal (DAJER, 2006).

Segundo Valim et al. (2005), fundamentalmente o sinal de voz possui três características que podem ser analisadas: o período e a amplitude com suas respectivas perturbações, bem como a conformação do sinal.

Para Nieto et al. (1995), é necessária uma distinção no domínio do tempo e da freqüência para a melhor compreensão dos programas de análise de voz. No domínio do tempo a representação gráfica da onda sonora é relacionada à variação da pressão sonora ao longo do tempo, sendo obtidas Freqüência Fundametal, jitter e shimmer. Já para o domínio da freqüência às representações gráficas são relacionadas a variação da amplitude dos componentes espectrais do sinal de voz, sendo obtidos o Espectograma, o Espectro de 
Transformação por Fourier (FFT), traçado de formantes, análise de componentes harmônicas e análise de freqüência fundamental (ANDRADE, 2003).

A frequência de vibração das pregas vocais é chamada de freqüência fundamental (COLTON; CASPER, 1990), que depende da pressão subglótica e configuração do trato vocal (DAVIS, 1979). Segundo (BEHLAU; TOSI; PONTES, 1985) para o português brasileiro, os valores normais médios para os homens são de 80 a $150 \mathrm{~Hz}$ com média de $113 \mathrm{~Hz}$; para as mulheres de 150 a $250 \mathrm{~Hz}$ com média de $204 \mathrm{~Hz}$, e média de $235,8 \mathrm{~Hz}$ para as crianças.

Segundo Hollien, Dew e Philips (1971) existem dados normativos para a freqüência fundamental de homens $(100 \mathrm{e} 150 \mathrm{~Hz})$ e mulheres $(180 \mathrm{a} 250 \mathrm{~Hz})$. A perturbação refere-se à irregularidade da vibração das pregas vocais, chamada jitter ou a variação na amplitude de ciclo a ciclo é chamada shimmer (COLTON; CASPER, 1990), como demonstrado na figura 6. Em falantes normais há pouca variação na perturbação, que pode representar massa nas pregas vocais, tensão ou atividade muscular (BAER, 1979).
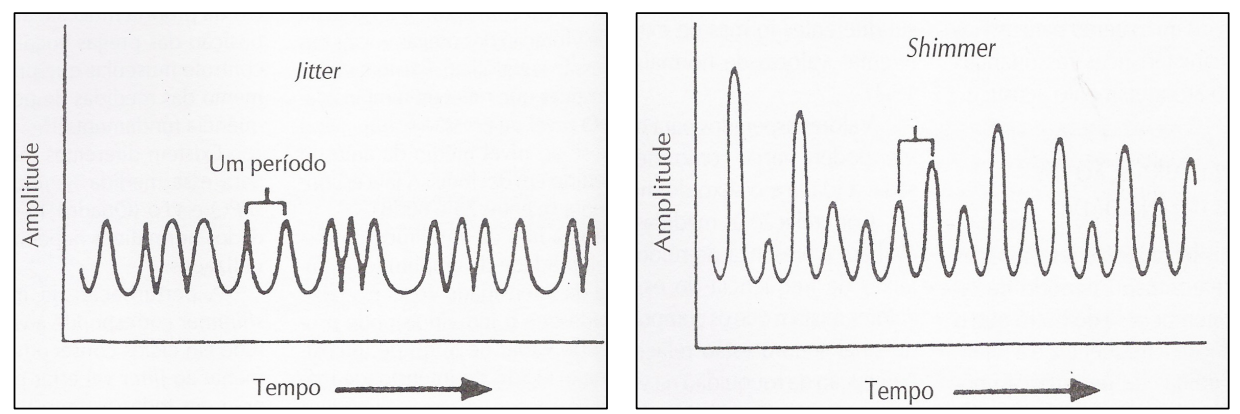

Figura 6 - Representação do jitter e shimmer

Fonte: Barros e Carrara-de-Angelis, 2002

Quando as pregas vocais são afetadas por alterações patológicas sua vibração mostrará aumento da aperiodicidade (HECHER; KREUL, 1971), como mudanças na mucosa, variação na composição das pregas vocais, variação na função muscular e no controle motor da musculatura que controla a vibração (COLTON et al., 1982).

Segundo Krom (1994), o sinal de voz pode ser analisado com estabilidade usando vogais sustentadas. Considerando a não estacionariedade do sinal de voz deve-se buscar uma forma de efetuar as análises sobre as amostras sendo consideradas, por um instante de tempo (entre 100 a 200ms) as medidas desejadas permanecendo estacionárias, como na emissão da 
vogal /a/ sustentada, que apresenta um modelo matemático a partir do trato vocal fixo e totalmente aberto (ANDRADE et al., 2002).

\section{- Técnicas Não Lineares de análise de voz}

Técnicas baseadas em modelos não lineares, como mapa de Pointcaré, dimensão fractal, dimensão de correlação, entropia de Kolmogorov e Expoente de Lyapunov, são capazes de descrever quantitativamente comportamentos caóticos, isto é, descrevem um sistema que é ambos, determinístico e não-linear (LORENZS, 1963; TAKENS, 1980).

Tradicionalmente o sinal de voz tem sido modelado como um processo linear e o instrumento de análise acústica baseado na teoria do sistema linear, no qual os parâmetros acústicos avaliam a perturbação ou ruído contido no sinal de voz (SCALASSARA et al., 2007). Porém este instrumento de modelo linear tem sido realizado durante anos, sendo baseado na suposição que a voz é um fenômeno linear, e que sua produção é um mecanismo complexo que envolve diferentes variáveis apresentando várias não lineares (KUMAR; MULLICK, 1996).

As pregas vocais, juntamente com o fluxo aéreo glótico, constituem um sistema de vibração não-linear, sendo este sistema responsável pela análise da dinâmica não-linear (TITZE; BAKEN; HERZEL, 1993).

\section{- Reconstrução do espaço de fase}

A reconstrução do espaço de fase mostra a vibração das pregas vocais em função do tempo, sendo uma trajetória fechada no sinal periódico e irregular e caótico (RAHN et al., 2005; JIANG, ZHANG, MCGILLIGAN, 2006). Esta análise tem provado ser uma poderosa ferramenta na análise de sinais biológicos como a voz.

Segundo Goldberger (1996), o espaço de fase é definido por variáveis dinâmicas múltiplas compostas de posições e velocidades, cuja técnica de reconstrução é apropriada quando as variáveis dinâmicas múltiplas não podem ser determinadas como nos ciclos vibratórios das pregas vocais que representam um sistema dinâmico, podendo ser descritos 
como uma trajetória no espaço de fase com evolução no tempo. O método tradicional de análise de voz pode ser incerto em vozes, que quando analisadas apresentam algum grau de desordem (HERZEL; BERRY, 1994; GIOVANNI; OUKNINE; TRIGLIA, 1998). Assim, considerando a voz um sistema não linear, pode ser usado a construção do espaço de fase para descrever o comportamento do sistema (DAJER; PEREIRA; MACIEL, 2005).

Aboofazeli e Moussavi (2005) apresentaram a análise quantitativa dos sons da deglutição em 15 indivíduos normais e 11 disfágicos baseados no instrumento da dinâmica não-linear, sendo utilizado o algoritmo Grassberger-Procaccia para calcular a dimensão de correlação como uma medida da complexidade da reconstrução dos atratores. A análise demonstrou uma dinâmica pouco dimensional característica dos sons da deglutição de indivíduos normais e disfágicos. O algoritmo foi capaz de classificar 83\% das deglutições corretamente. Este estudo sugeriu que a análise não-linear é um instrumento promissor para a análise quantitativa dos sons da deglutição e desordens da deglutição.

No estudo de Rahn et al. (2005) aplicou-se à análise da dinâmica não linear e a análise de perturbação em pacientes com doença de Parkinson. A correlação da dimensão $\left(\mathrm{D}_{2}\right)$, jitter e shimmer foram utilizadas para comparação da fonação da vogal sustentada destes sujeitos com o grupo controle. Verificou-se aumento significativo do $\mathrm{D}_{2}$ em mulheres com doença de Parkinson do que nas do grupo controle. Nos homens com doença de Parkinson verificou-se um aumento estatístico do jitter comparados ao grupo controle, mas este não diferiu em $\mathrm{D}_{2} \mathrm{ou}$ shimmer. Assim observou-se que a análise dinâmica não linear pode ser um método valioso no diagnóstico de patologia laríngea do Parkinsoniano. 


\section{3 - MATERIAIS E MÉTODOS}

\subsection{Materiais}

Para a realização da presente pesquisa, o projeto foi previamente enviado ao Comitê de Ética em Pesquisa (CEP) do Hospital das Clínicas da Faculdade de Medicina de Ribeirão Preto - USP (HCFMRP-USP), aprovado de acordo com os processos de $n^{\circ} 3695$ e 3389 (anexos 1 e 2).

Para esta pesquisa foram contemplados dois grupos de análise, sendo um grupo de referencia com 5 indivíduos (1 do sexo masculino e 4 do sexo feminino), com idade média de 28 anos (de 22 a 35 anos), que não apresentam alteração neurológica como também queixas de alteração vocal ou de deglutição; e o grupo de pacientes com alteração neurológica. Neste grupo Foram incluídos indivíduos com idade acima de 15 anos, apresentando alteração neurológica, os quais foram encaminhados ao setor de Fonoaudiologia na área de Neurologia Adulto do Hospital das Clínicas da Faculdade de Medicina de Ribeirão Preto (HCFMRP) USP para a realização da videofluoroscopia da deglutição, no período de dezembro de 2007 a outubro de 2008. Ainda, foram observados todos os quesitos éticos e legais na participação dos sujeitos nesta pesquisa através de assinatura do termo de consentimento.

Foram selecionados para o estudo vinte e seis pacientes de ambos os sexos (sendo 16 homens e 10 mulheres), diagnosticados com alterações neurológicas e com idade média de 53 anos (variando 21 a 77 anos). Como critério de exclusão para este grupo considerou-se indivíduos gravemente comprometidos, cujo estado não permitia a emissão da vogal /a/ ou não compreendia o que lhe era solicitado, bem como indivíduos que não apresentavam comprometimento neurológico.

Os indivíduos selecionados apresentavam como diagnósticos médico: acidente vascular cerebral (5); doença de Parkinson (2); esclerose lateral amiotrófica - ELA (7); ataxia espinocerebelar - SCA (3), demência (1), traumatismo cranioencefálico (1) e outras alterações neurológicas (7). Os dados completos dos sujeitos participantes deste trabalho encontram-se na tabela 1. 
Tabela 1 - Dados do grupo de pacientes com alteração neurológica

\begin{tabular}{|c|c|c|c|}
\hline PACIENTES & SEXO & IDADE & DIAGNÓSTICO \\
\hline 1 & $\mathrm{~F}$ & 55 & Esclerose Lateral Amiotrófica \\
\hline 2 & $\mathrm{~F}$ & 73 & Esclerose Lateral Amiotrófica \\
\hline 3 & $\mathrm{~F}$ & 68 & Esclerose Lateral Amiotrófica \\
\hline 4 & $\mathrm{~F}$ & 38 & Esclerose Lateral Amiotrófica \\
\hline 5 & $\mathrm{M}$ & 69 & AVC \\
\hline 6 & $\mathrm{M}$ & 54 & Outras doenças neurológicas \\
\hline 7 & $\mathrm{~F}$ & 70 & AVC \\
\hline 8 & $\mathrm{M}$ & 67 & Dç Parkinson \\
\hline 9 & $\mathrm{M}$ & 58 & Outras doenças neurológicas \\
\hline 10 & $\mathrm{M}$ & 54 & AVC \\
\hline 11 & $\mathrm{M}$ & 77 & Dç Parkinson \\
\hline 12 & $\mathrm{M}$ & 69 & AVC \\
\hline 13 & $\mathrm{M}$ & 21 & SCA3 \\
\hline 14 & $\mathrm{~F}$ & 72 & Demência \\
\hline 15 & $\mathrm{M}$ & 28 & SCA3 \\
\hline 16 & $\mathrm{M}$ & 51 & TCE \\
\hline 17 & $\mathrm{M}$ & 48 & Outras doenças neurológicas \\
\hline 18 & $\mathrm{M}$ & 64 & Outras doenças neurológicas \\
\hline 19 & $\mathrm{M}$ & 47 & Esclerose Lateral Amiotrófica \\
\hline 20 & $\mathrm{M}$ & 58 & Outras doenças neurológicas \\
\hline 21 & M & 49 & Esclerose Lateral Amiotrófica \\
\hline 22 & $\mathrm{M}$ & 36 & Outras doenças neurológicas \\
\hline 23 & $\mathrm{~F}$ & 39 & Outras doenças neurológicas \\
\hline 24 & $\mathrm{~F}$ & 58 & AVC \\
\hline 25 & $\mathrm{~F}$ & 55 & Esclerose Lateral Amiotrófica \\
\hline 26 & $\mathrm{~F}$ & 25 & SCA3 \\
\hline
\end{tabular}

\subsection{Métodos}

Para a análise da deglutição e análise dos sinais de voz dos 26 pacientes foram utilizados o estudo de videofluoroscopia e os métodos de análise perceptivo-auditiva, análise acústica tradicional e análise de padrões visuais de dinâmica vocal (PVDV). Também participou um grupo de referência de cinco indivíduos sem alteração neurológica e sem queixa vocal e de deglutição.

Os resultados da análise perceptivo-auditiva, análise acústica da voz e PVDV da voz foram comparados aos achados do exame objetivo da deglutição para o estabelecimento de possíveis correlações entre os grupos. Sendo estes comparados antes e após a oferta do 
alimento, bem como a correlação da voz após a oferta do alimento com presença ou não de penetração ou aspiração laringotraqueal.

\subsubsection{Videofluoroscopia}

Procedimento:

Inicialmente o indivíduo foi orientado sobre a pesquisa e recebeu o termo de consentimento livre e esclarecido (anexo 3). Após o seu consentimento, foram colhidos dados referentes à sua identificação, diagnóstico médico e estado atual (anexo 4). Posteriormente, dados de avaliação clínica relacionados à queixa principal, consistência de alimentação, vias alternativas de alimentação, ocorrência de tosses, engasgos e utensílios utilizados.

Após a coleta destes dados foi obtida uma amostra de voz. Posteriormente o indivíduo foi submetido à videofluoroscopia da deglutição. A coleta da amostra de voz foi realizada antes da administração dos alimentos (consistência pastosa e líquida) e após a primeira deglutição da consistência pastosa e da consistência líquida, nos volumes de $3 \mathrm{ml}$ e $7 \mathrm{ml}$.

A videofluoroscopia foi realizada em incidência látero-lateral direita, na qual foram oferecidas as consistências líquida e pastosa, sendo que utilizou-se a água como líquido e para o pastoso utilizou-se uma "papa", que foi preparada pela diluição de $15 \mathrm{ml}$ de espessante alimentar ThicK \& Easy ${ }^{\circledR}$ em 50ml de água, ambos adicionados a $15 \mathrm{ml}$ de sulfato de bário (Bariogel $^{\circledR} 100 \%$, Laboratório Cristália, Itapira, São Paulo). O equipamento utilizado para a realização da videofluoroscopia foi o Angiógrafo Arcomax, da marca Phillips ${ }^{\circledR}$, modelo BV 300.

Os indivíduos foram solicitados a emitir a vogal /a/ sustentada, em nível confortável por aproximadamente 5 segundos. $\mathrm{O}$ microfone estava posicionado a $5 \mathrm{~cm}$ da boca do sujeito, sendo o sinal digitalizado em 16 bits diretamente no computador com freqüência de amostragem de $22.050 \mathrm{~Hz}$. 


\subsubsection{Análise dos sinais de voz}

Os sinais de voz foram analisados através da análise perceptivo-auditiva, da análise acústica tradicional e a análise dos padrões visuais da dinâmica vocal (PVDV). Para utilização das técnicas, os trechos inicial e final do sinal completo de voz foram desprezados (figura 7).

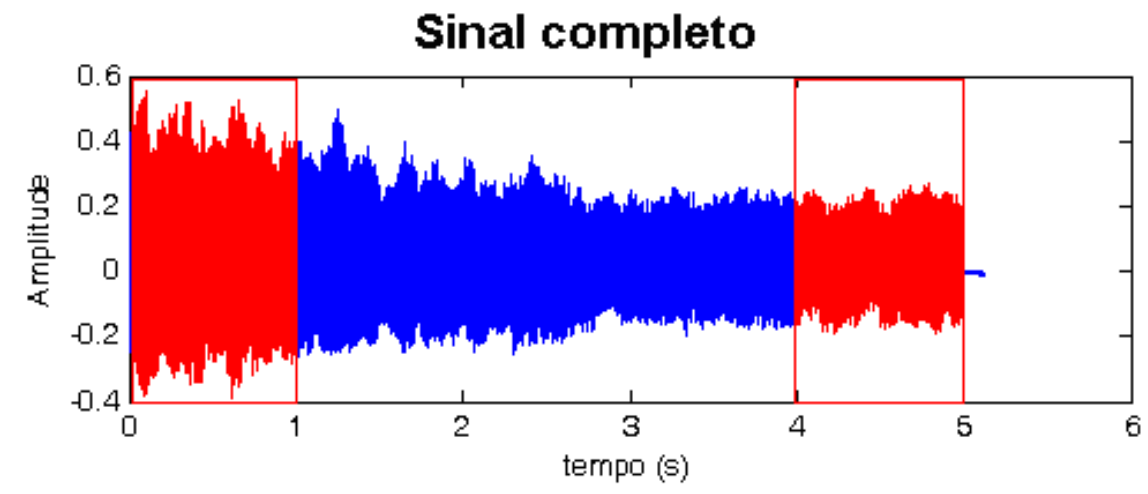

Figura 7 - Exemplo de um sinal de voz completo (vogal/a/), excluindo-se o início e fim do sinal

\subsubsection{Análise perceptivo-auditiva}

Para a análise destas amostras vocais, foram utilizados os parâmetros de rugosidade, soprosidade, tensão, instabilidade e qualidade vocal molhada, sendo que para o grau de comprometimento foi utilizada a graduação, de quatro níveis, originalmente proposta pela escala GRBAS, de acordo com o envolvimento vocal: (0) quando nenhuma alteração vocal é percebida pelo ouvinte; (1) para alterações vocais discretas ou em caso de dúvida se a alteração está presente ou não; (2) quando a alteração é evidente e; (3) para alterações vocais extremas.

A análise perceptivo-auditiva foi realizada por um avaliador, especialista em voz, que não tinha conhecimento da pesquisa (diagnóstico médico, idade e os momentos em que os a amostras vocais foram captadas). As vozes foram apresentadas de forma aleatória para o avaliador e com $15 \%$ de repetição para confiança intra-avaliador, juntamente com um roteiro impresso para marcar a classificação das vozes, sendo que este apresentou $86 \%$ de confiabilidade.

\subsubsection{Análise acústica tradicional}


Os dados foram analisados através do programa Análise de Voz - desenvolvido no Departamento de Engenharia Elétrica da Escola de Engenharia de São Carlos - USP, a partir da dissertação de mestrado: Análise Residual do Sinal de Voz, (MONTAGNOLI, 1998).

Os dois parâmetros de perturbação fornecidos pelo programa, comumente chamados de Jitter e Shimmer, derivam-se da média de perturbação relativa (RAP), (KOIKE, 1973), a partir desse, Davis em 1976 desenvolveu dois novos parâmetros acústicos denominados de quociente de perturbação de pitch (PPQ) e quociente de perturbação de amplitude (APQ).

O parâmetro PPQ ou Jitter indica a perturbação no período do sinal de voz, normalmente ocasionada pela falta de controle das pregas vocais. O parâmetro APQ ou Shimmer muitas vezes está correlacionado a irregularidades nas pregas vocais, como lesões de massas ou redução da resistência glótica.

Nessa nova versão do programa, (MONTAGNOLI, 2009) utiliza a autocorrelação do sinal de voz ao contrário das versões anteriores, as quais utilizavam o sinal residual da voz para definir esses parâmetros. Este programa nos permite visualizar no lado esquerdo superior da tela, o osciloscópio, que mostra a porção do sinal a ser analisado e do lado direito da figura observamos o número de amostras vocais, os três parâmetros acústicos e o analisador do espectro. Os parâmetros de jitter e shimmer são mostrados cor azul, devido a sua natureza progressiva em que o limiar, representado pelo traço branco nos parâmetros, torna-se vermelho quando estes valores são ultrapassados, indicando que o parâmetro esta fora do padrão (figura 8). 


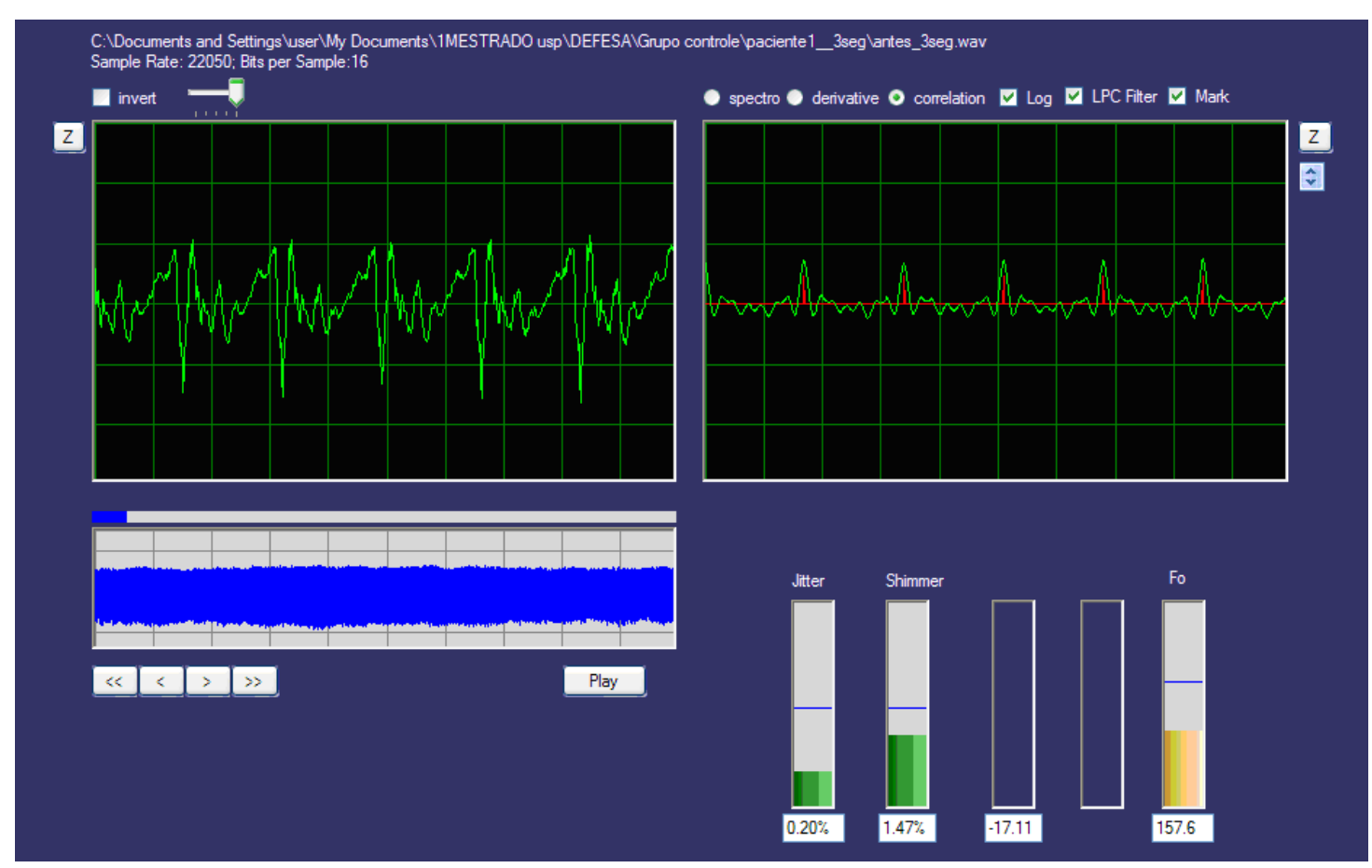

Figura 8 - Tela do programa Voice Analysis 2009 utilizado para análise dos parâmetros acústicos

Neste estudo foi aplicado o teste ANOVA unilateral para analisar a variância dos diferentes grupos (antes da deglutição, após a deglutição de $3 \mathrm{ml}$ e $7 \mathrm{ml}$ de pastoso e após a deglutição de líquido administrado em $3 \mathrm{ml} \mathrm{e} 7 \mathrm{ml}$ ).

\subsubsection{Padrão Visual da Dinâmica Vocal (PVDV)}

Para compreendermos a dinâmica da voz, foi utilizado o PVDV, baseado na técnica de reconstrução do espaço de fase com a técnica de tempo de atraso (TAKENS, 1981), (PACKARD et al., 1980), que mostra o comportamento dinâmico do sinal de voz. Esta rotina de análise foi implementada no MatLab ${ }^{\circledR} 7.0$.

Nesta técnica o sinal de voz, devido suas características dinâmicas, pode ser representado como uma série temporal simples (figura $9-\mathrm{A}$ ) de comprimento $N$, registrado como $x(t i), t i=t 0+i \tau(i=1,2, \ldots, N)$, onde $x(\mathrm{ti}) \in \mathbf{R}, \mathrm{ti}=t 0+i \tau \quad(i=1,2, \ldots, N)$, e $\tau$ o período de amostragem. Com o vetor do tempo de atraso pode-se reconstruir o espaço de fase, que representa um gráfico bidimensional da reconstrução do espaço de fase (figura 9 - B), proporcionando a representação da dinâmica do sistema. 


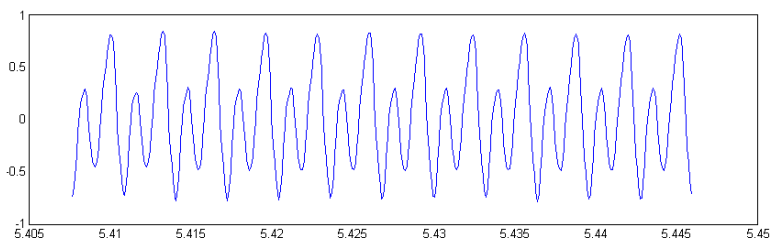

(A)

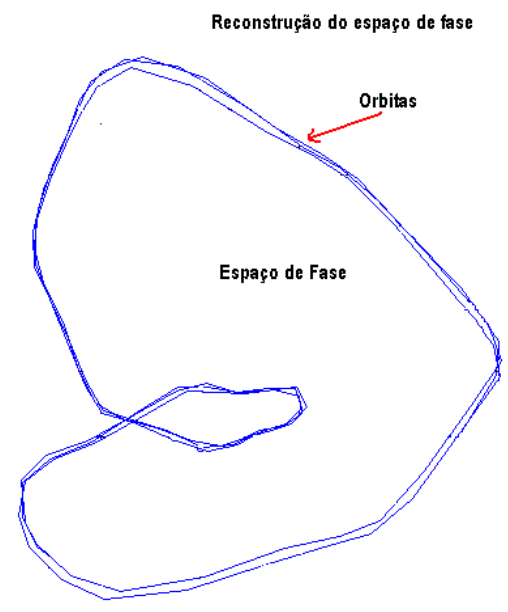

(B)

Figura 9 - Exemplo da série temporal simples (A); e gráfico bidimensional da reconstrução do espaço de fase (B).

Para um melhor entendimento desta técnica, no estudo de Dajer (2006) foram realizados testes com o sinal periódico, sendo testados sinais com uma frequência, com dois componentes, com três harmônicos e com quatro componentes, observando-se que a complexidade de cada Padrão Visual de Dinâmica Vocal aumenta com a presença de harmônicos de maior ordem (figura 10). 


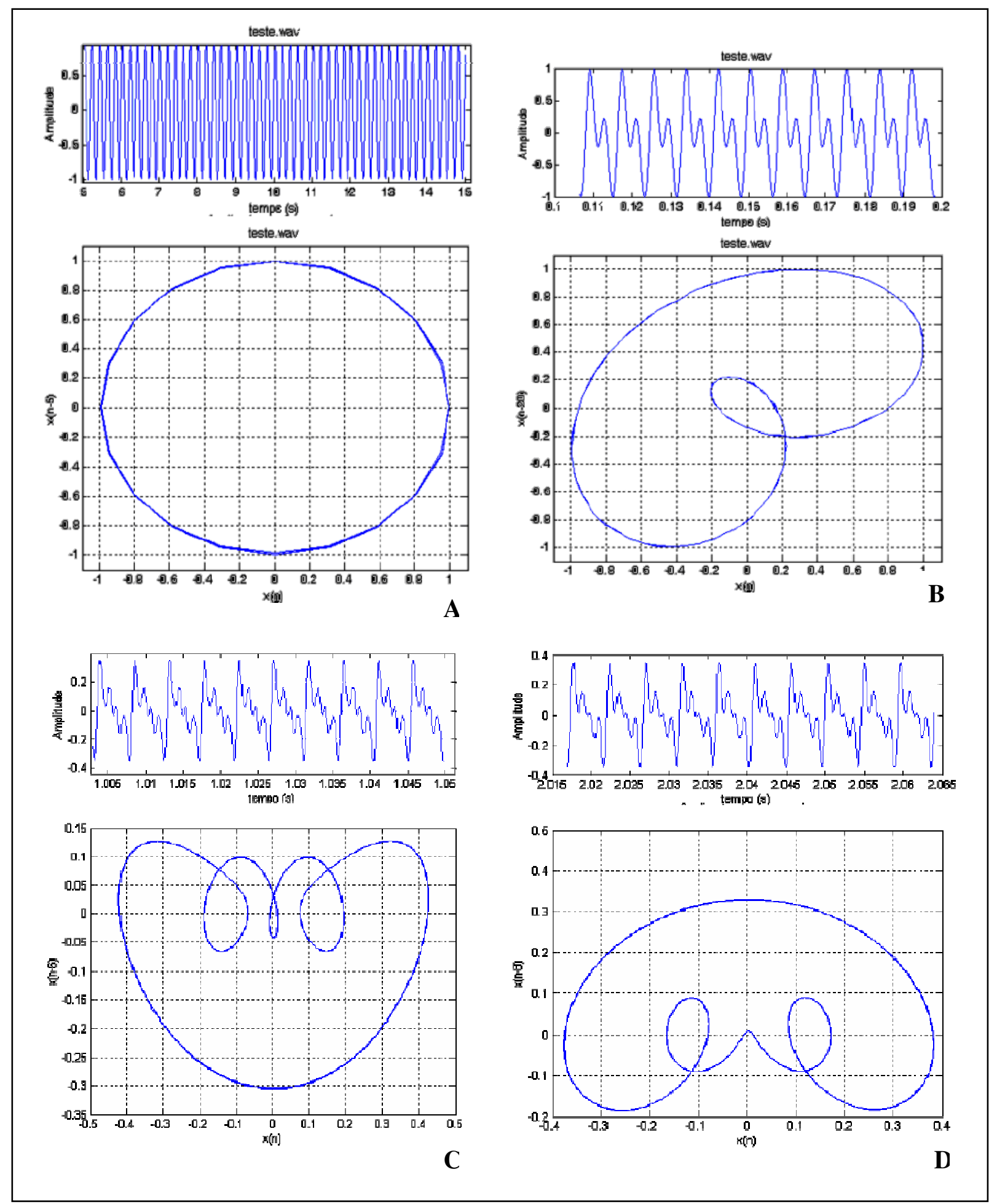

Figura 10 - Exemplo de um sinal periódico com uma frequência fundamental (A); uma frequência e uma harmônica (B); uma frequência e dois harmônicos $(\mathrm{C})$; uma frequência e três harmônicas (D) e na parte inferior o padrão visual da dinâmica vocal do sinal. Adaptada de Dajer (2006).

Na figura 11 foi representado por Dajer (2006) o comportamento de shimmer, que é a presença do espalhamento das órbitas $e$ jitter, caracterizada pela contorção das mesmas. 


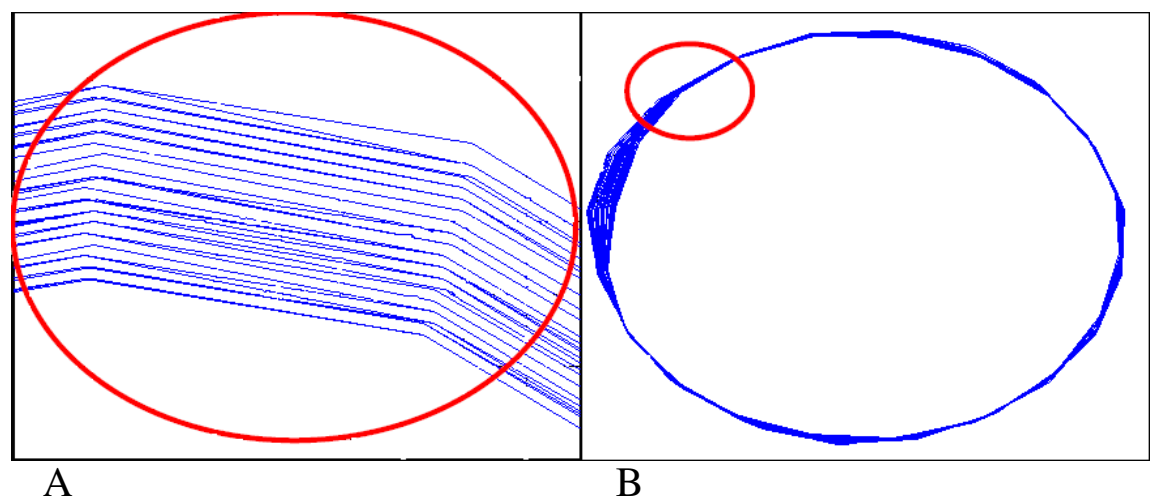

Figura 11 - (A) Padrão Visual da Dinâmica Vocal com shimmer; (B) Padrão Visual da Dinâmica Vocal com jitter. Adaptada de Dajer, 2006

Para este estudo foi realizado uma seleção de trecho dos sinais, utilizando amostras de três segundos para cada sinal (figura 12); para análise mais detalhada dos mesmos, realizou-se a seleção de um trecho de 50 milissegundos da parte inicial, medial e do final da amostra, nos momentos em que apresentaram maior estabilidade na amplitude da onda, conforme apresentado na figura 12. Foram consideradas as três características mais predominantes dos três trechos escolhidos e foi selecionado para análise o PVDV considerado mais representativo para os parâmetros avaliados.

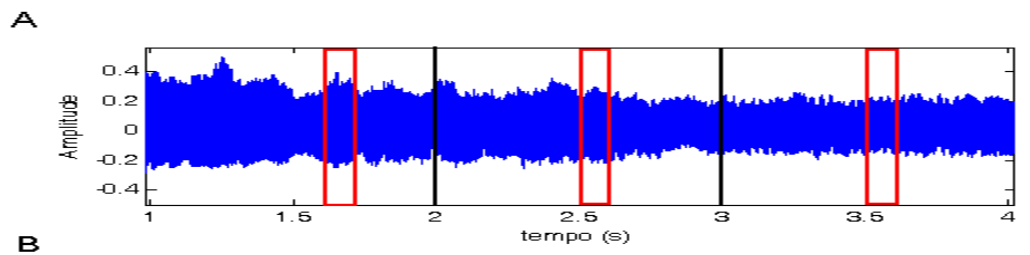

$\mathrm{B}$

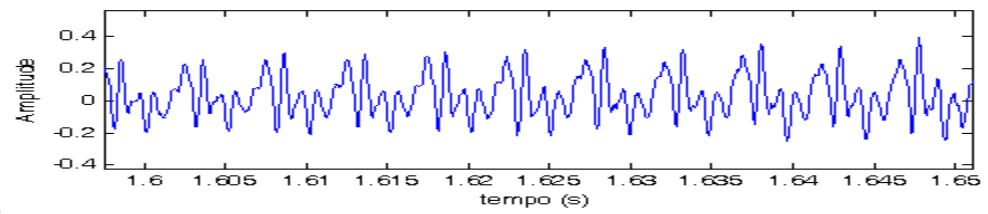

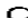

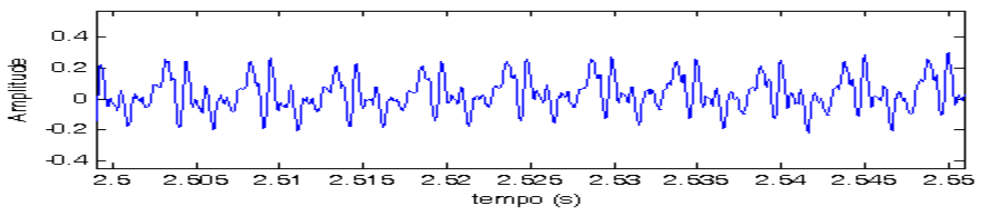

$\mathbf{D}$

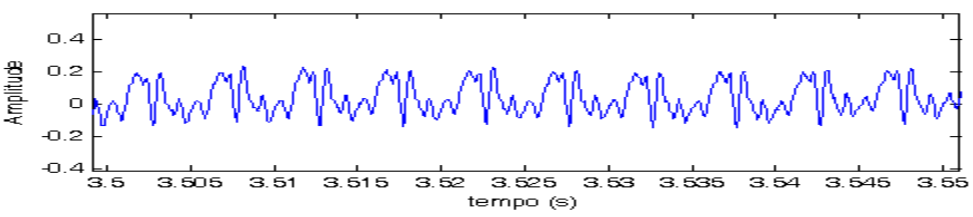

Figura 12 - Trecho selecionado do sinal de voz da vogal /a/ na parte superior (A). As imagens B, C e D são os trechos selecionados em 50 milissegundos 
Na figura 13 observa-se que o sinal de voz pode ser representado através do PVDV, mostrando a dinâmica ponto a ponto do sinal de voz.
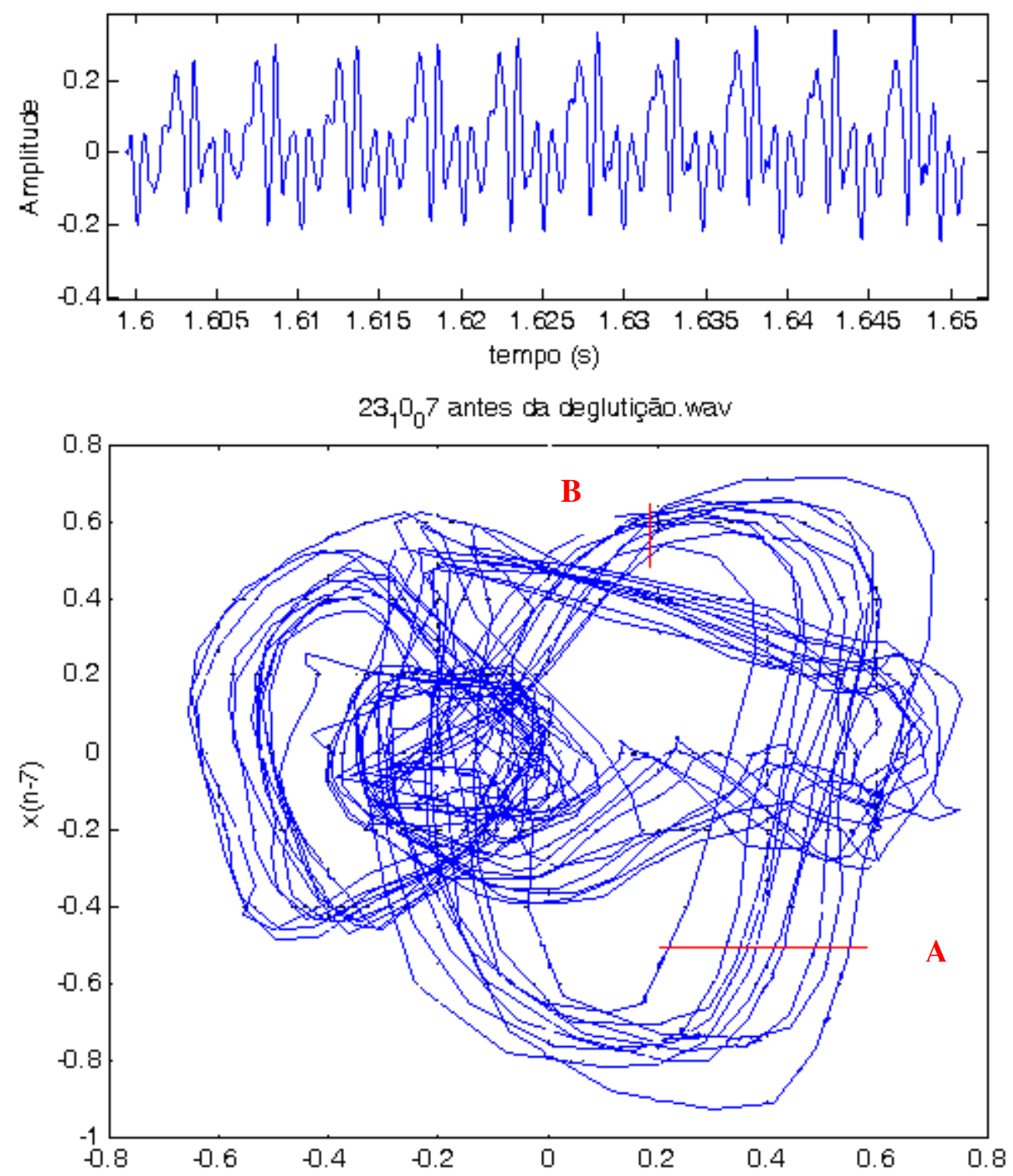

Figura 13 - Na parte superior verifica-se o sinal em amplitude em função do tempo e na parte inferior um exemplo do PVDV do trecho de 50 milissegundos; A) shimmer e B) o jitter

Na figura 13 podemos verificar a partir da técnica de reconstrução do espaço de fase de um trecho de 50 milissegundos, o padrão visual da dinâmica vocal, apresentando o traçado trajetórias espalhadas, sendo este comportamento característico da presença das porcentagens do shimmer alteradas no sinal. Como também há a contorção das órbitas sobre si, indicando alteração do jitter. 
Para melhor avaliação da dinâmica do sinal de voz, nesta pesquisa, foram observadas diferentes características que possibilitam a classificação de: a) número de loops, b) regularidade do traçado e c) convergência das órbitas. Com o objetivo de avaliar estes três aspectos antes da deglutição, após a deglutição da consistência pastosa e da consistência líquida, foram propostos 5 graus para cada um dessas características.

$\mathrm{Na}$ figura 14 esta exemplificada a categorização do número de loops, sendo: 0) para número indefinido de loops; 1) para 1 loop; 2) para 2 loops; 3) para 3 loops e 4) para 4loops ou mais.

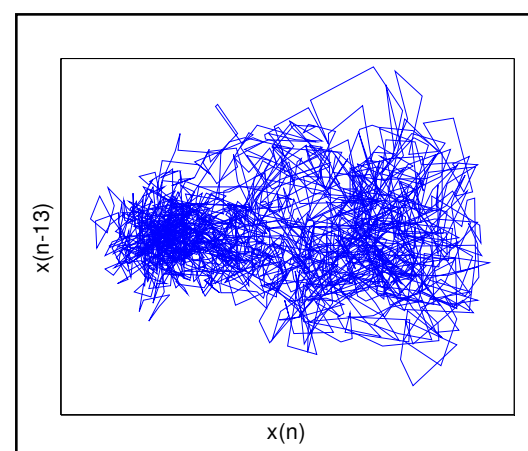

A

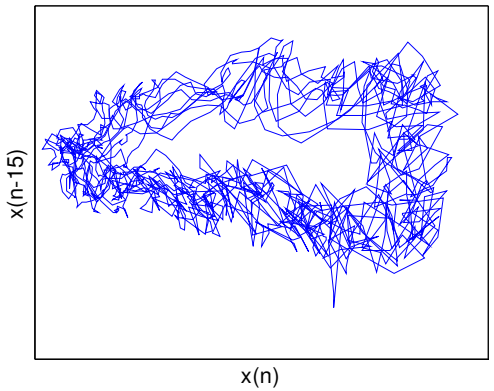

B

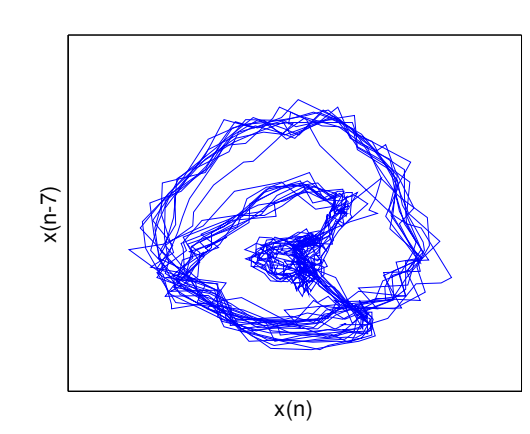

D

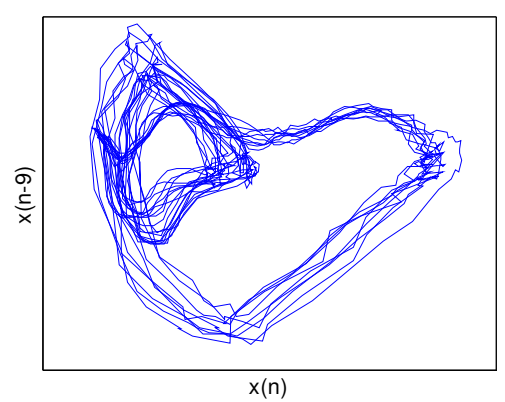

C

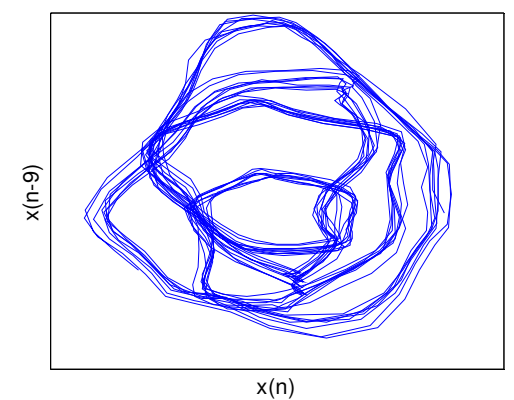

$\mathbf{E}$

Figura 14 - Exemplos de PVDV com os 5 graus de número de loops; A) número indefinido de loops; B) 1 loop; C) 2 loops; D) 3 loops e D) 4 ou mais loops

A regularidade do curso do traçado foi classificada em 5 graus: "0) "regular" para órbitas completamente lisas, sem irregularidades; 1) "regular com porção irregular" órbitas lisas com uma área delimitada de irregularidade 2) "irregularidade intermitente” para órbitas lisas com áreas delimitadas de irregularidades; 3) "levemente irregular" para órbitas irregularmente leve em todo o percurso e 4) "irregular" para órbitas com o traçado completamente imperfeito, conforme demonstrado na figura 15. 


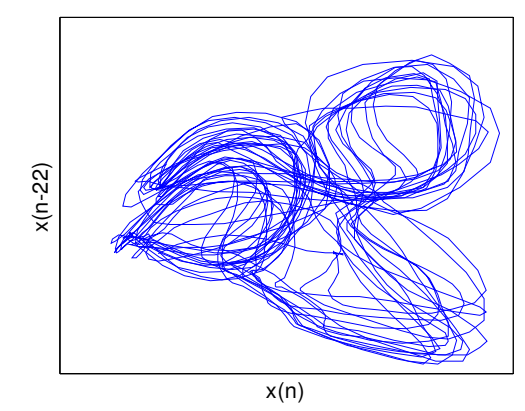

A

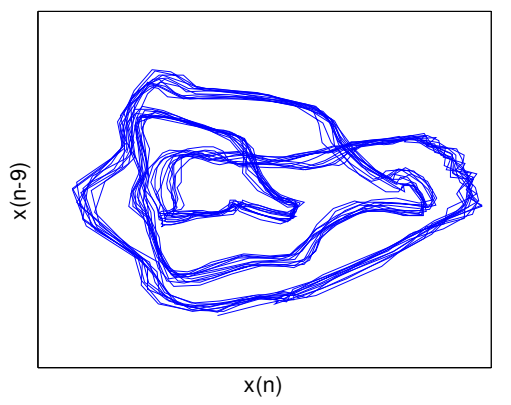

B

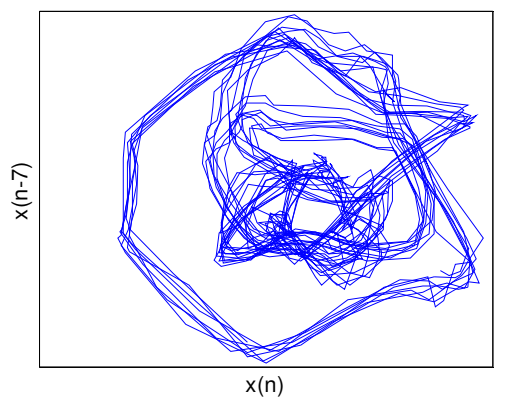

C

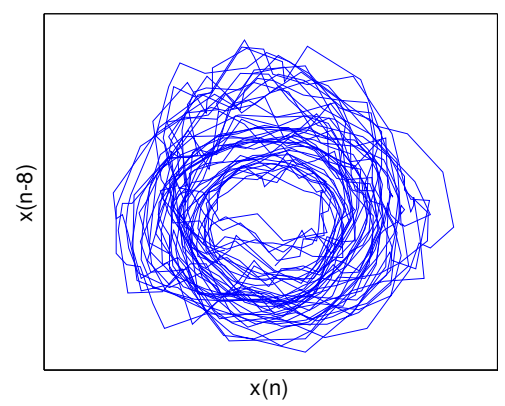

D

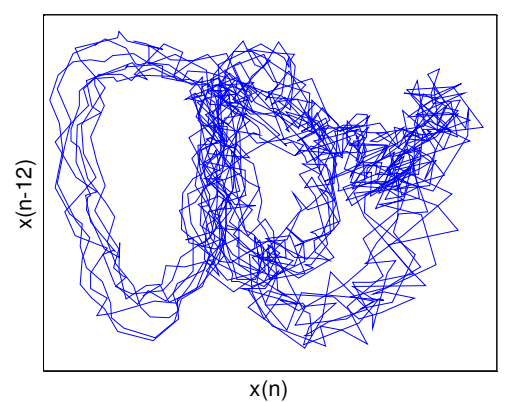

$\mathbf{E}$

Figura 15 - Exemplos de PVDV com os 5 graus de regularidade do traçado; A) regular; B) regular com porção irregular; C) irregularidade intermitente; D) levemente irregular e E) irregular

Para a convergência da trajetória das órbitas, foi proposta uma escala com 5 graus: "forte" convergência para trajetórias sobrepostas ou muito próximas; "forte a média" para pequena dispersão das trajetórias sempre observadas na configuração; 3) "média" para trajetórias mais dispersas, mas que ainda permite distinguir a configuração; 4) convergência "média a fraca" para trajetórias dispersas que desarranjam a configuração; e 5) "fraca" convergência para órbitas muito dispersas que impossibilitam distinguir a configuração do padrão visual. Na figura 16 estão representados os graus de classificação da trajetória das órbitas de diferentes pacientes. 

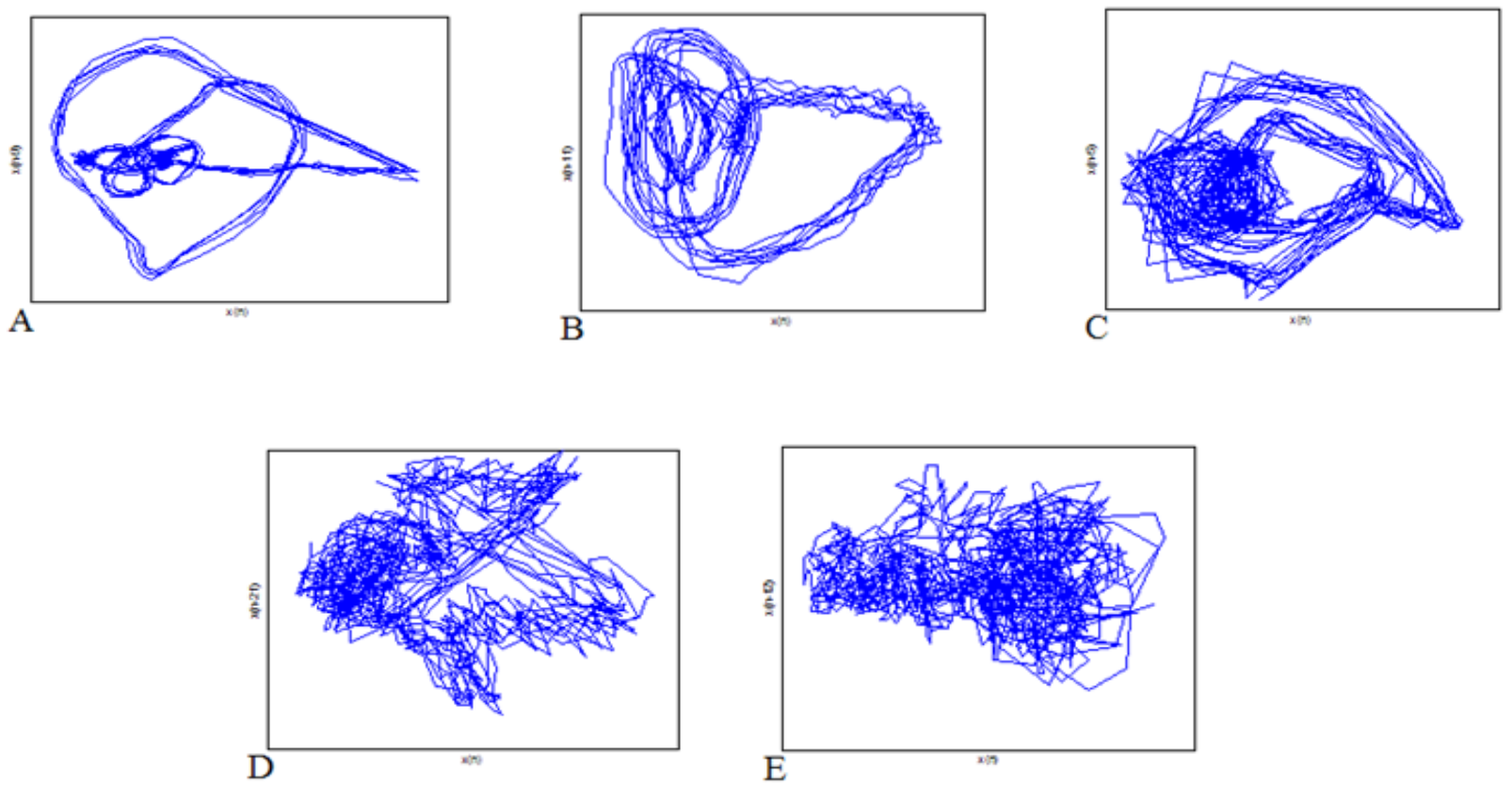

Figura 16 - Classificação da convergência das órbitas; A) forte; B) forte a média; C) média; D) média a fraca e E) fraca convergência

No exemplo da figura 17 se observa o padrão visual da dinâmica vocal de um sinal de voz normal, podendo-se verificar: a) alta complexidade do sinal, devido à presença de harmônicos de uma vogal /a/; b) traçado regular e c) forte distribuição do traçado, já que tratase de um sujeito sem queixa vocal que consegue manter um padrão vibratório de pregas vocais constante (quase periódico) onde um ciclo é muito similar ao seguinte.

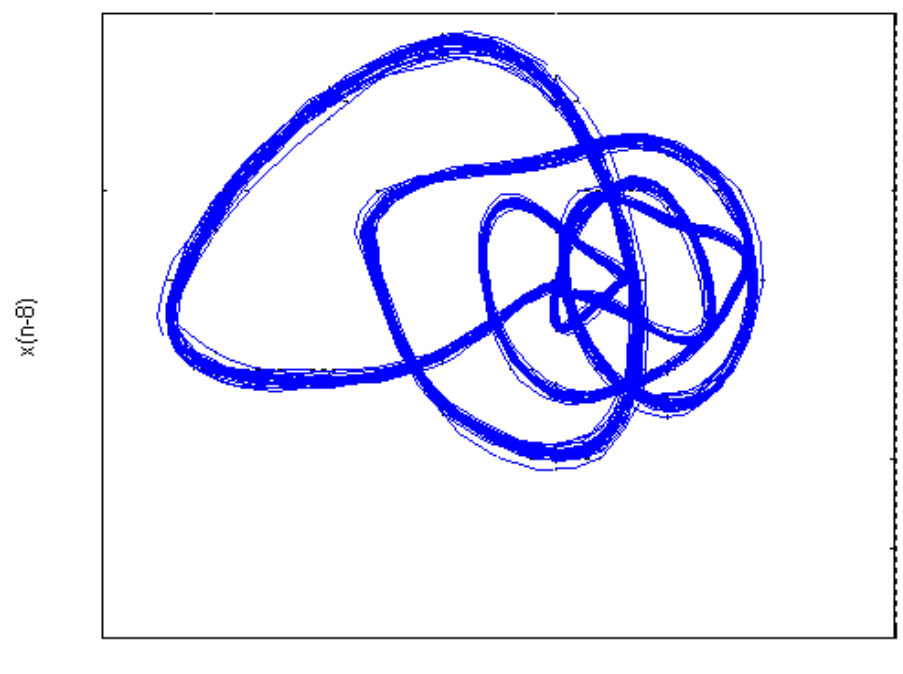

$x(n)$

Figura 17 - Padrão visual da dinâmica vocal de um sinal, de um indivíduo sem alteração vocal. 


\section{4 - RESULTADOS}

Participaram do estudo 31 indivíduos (5 indivíduos sem alteração neurológica - grupo de referência, e 26 com diagnóstico médico de alteração neurológica) que realizaram a videofluoroscopia da deglutição e também coletada a amostra vocal após a deglutição das consistências pastosa e líquida, nos volumes de $3 \mathrm{ml} \mathrm{e} 7 \mathrm{ml}$. Estas amostras foram analisadas pelos métodos de análise perceptivo-auditiva, análise acústica tradicional e análise de padrões visuais de dinâmica vocal (PVDV).

Em cada método analisado inicialmente serão apresentados os resultados do grupo de referência, seguido pelos resultados do grupo de pacientes com alterações neurológicas.

\subsection{Videofluoroscopia da deglutição}

\section{- Grupo de referência}

Foi realizada a videofluoroscopia da deglutição com 5 indivíduos sem alteração neurológica, como também sem queixas vocais e de deglutição.

Observou-se que estes indivíduos não apresentaram resíduo em valécula ou recessos piriformes, como também não apresentaram episódios de penetração e/ou aspiração laringotraqueal.

\section{- Grupo de pacientes com alteração neurológica}

A videofluoroscopia da deglutição foi realizada em 26 pacientes, com alteração neurológica. Segue na tabela 2 os cinco momentos da videofluoroscopia, sendo referido quais pacientes que apresentaram penetração e/ou aspiração laringotraqueal e em qual momento do exame estas alterações ocorreram. 
Tabela 2 - Relação de pacientes que apresentaram resíduo, penetração laríngea e/ou aspiração laringotraqueal

\begin{tabular}{|c|c|c|c|c|}
\hline Pacientes & Pastoso 3ml & Pastoso 7ml & Líquido 3ml & Líquido 7ml \\
\hline 1 & & & & PEN \\
\hline 2 & EV & EV & $\mathrm{RCO}-\mathrm{EV}$ & RCO - EV - ASP \\
\hline 3 & & $\mathrm{RCO}$ & & \\
\hline 4 & & RCO - EV & $\mathrm{RCO}-\mathrm{EV}$ & RCO - EV \\
\hline 5 & & & $\mathrm{RCO}$ & RCO - EV - ASP \\
\hline \multicolumn{5}{|l|}{6} \\
\hline 7 & & RCO - EV & & \\
\hline 8 & EV & & ASP & \\
\hline 9 & & & & ASP \\
\hline $\mathbf{1 0}$ & & $\mathrm{EV}$ & & $\mathrm{EV}$ \\
\hline 11 & RCO - EV & EV & $\mathrm{EV}$ & EV - ASP \\
\hline 12 & EV - RTFE & EV - RTFE & RCO - EV - RTFE - ASP & \\
\hline 13 & & EV & & \\
\hline 14 & RCO - RCP & $\mathrm{RCO}$ & $\mathrm{RCO}$ & RCO - EV - ASP \\
\hline 15 & RTFE & EV - RTFE & $\mathrm{EV}$ & $\mathrm{EV}$ \\
\hline 16 & EV & RTFE & PEN & ASP \\
\hline 17 & & EV & EV & EV \\
\hline 18 & EV - RTFE & EV - PEN & $\mathrm{RCO}$ & PEN \\
\hline 19 & EV & EV - RRP & & RTFE \\
\hline \multicolumn{5}{|l|}{20} \\
\hline \multicolumn{5}{|l|}{21} \\
\hline 22 & EV - RTFE & EV - RTFE & RTFE & RTFE \\
\hline 23 & EV - RTFE & & RTFE & RV - RTFE \\
\hline 24 & & $\mathrm{RCO}$ & & \\
\hline 25 & & PEN & & \\
\hline 26 & & $\overline{E V}$ & & \\
\hline
\end{tabular}

Legenda: RCO- resíduo em cavidade oral; EV - estase em valécula; RRP - resíduo em recessos piriformes; RTFE - resíduo transição faringoesofágica; PEN - penetração e ASP aspiração

Na tabela 3 pode-se verificar que para $3 \mathrm{ml}$ e $7 \mathrm{ml}$ da consistência pastosa, 34,61\% e $50 \%$ (respectivamente) dos pacientes, apresentaram resíduo em valécula; e para $7 \mathrm{ml} \mathrm{de}$ pastoso também verificou-se dois episódios de penetração laríngea. Para $3 \mathrm{ml}$ da consistência líquida, a maioria dos pacientes apresentaram estase valécula $(23,07 \%)$, um episódio de penetração e dois de aspiração laringotraqueal (sendo o exame interrompido devido a presença da aspiração laringotraqueal). Para $7 \mathrm{ml}$ de líquido, observou-se $37,5 \%$ de pacientes com presença de estase em valécula, três episódios de penetração e seis aspiraram o volume de $7 \mathrm{ml}$ de líquido, 
Tabela 3 - Porcentagem dos pacientes que apresentaram alteração na videofluoroscopia da deglutição

\begin{tabular}{ccccc}
\hline & \multicolumn{2}{c}{ Pastoso } & \multicolumn{2}{c}{ Líquido } \\
& 3ml & $\mathbf{7 m l}$ & $\mathbf{3 m l}$ & $\mathbf{7 m l}$ \\
\hline Resíduo em CO & $7,69 \%(2)$ & $19,23 \%(5)$ & $23,07 \%(6)$ & $16,6 \%(4)$ \\
\hline Estase em valécula & $34,61 \%(9)$ & $50 \%(13)$ & $23,07 \%(6)$ & $37,5 \%(9)$ \\
\hline $\begin{array}{c}\text { Resíduo em recessos } \\
\text { piriformes }\end{array}$ & $3,85 \%(1)$ & $3,85 \%(1)$ & 0 & 0 \\
\hline Resíduo em TFE & $19,23 \%(5)$ & $15,38 \%(4)$ & $11,53 \%(3)$ & $12,5 \%(3)$ \\
\hline Penetração laríngea & 0 & $7,69 \%(2)$ & $3,85 \%(1)$ & $8,33 \%(2)$ \\
\hline $\begin{array}{c}\text { Aspiração } \\
\text { laringotraqueal }\end{array}$ & 0 & 0 & $7,69 \%(2)$ & $25 \%(6)$ \\
\hline
\end{tabular}

Legenda: CO - cavidade oral; TFE - transição faringoesofágica.

\subsection{Análise Perceptivo-Auditiva}

Foi realizada a análise perceptivo-auditiva das vozes dos pacientes com alteração neurológica e cinco indivíduos do grupo de referência, sendo classificadas quanto ao grau de rugosidade, soprosidade, tensão, instabilidade e qualidade vocal molhada, classificadas em uma escala de 0 a 3 sendo que 0 foi utilizada para a voz que não apresenta esta alteração; 1 com leve alteração; 2 moderada e 3 severa alteração.

\section{- Grupo de Referência}

Na tabela 4 foram apresentados os dados da análise, podendo-se observar que apenas um indivíduo apresentou grau leve de rugosidade para $7 \mathrm{ml}$ de líquido; para soprosidade, antes da deglutição e após 3ml de líquido, 80\% dos indivíduos não apresentaram alteração, seguido $60 \%$ dos indivíduos em $3 \mathrm{ml}$ de pastoso e $7 \mathrm{ml}$ de líquido que foram classificados com leve soprosidade. No aspecto de tensão a maioria dos indivíduos foram classificados em grau 0. Com relação a instabilidade, antes da deglutição, pastoso $7 \mathrm{ml}$ e líquido $3 \mathrm{ml}$ e $7 \mathrm{ml}$, a maioria dos indivíduos foram classificados como sem alteração, e em $3 \mathrm{ml}$ de pastoso que $60 \%$ foi classificada com grau 1 de instabilidade. Nenhum indivíduo apresentou a qualidade vocal molhada. 
Tabela 4 - Análise perceptivo-auditiva do grupo de referência

\begin{tabular}{|c|c|c|c|c|c|c|c|c|c|c|c|c|c|c|c|c|c|c|}
\hline & \multicolumn{4}{|c|}{ Rugosidade } & \multicolumn{4}{|c|}{ Soprosidade } & \multicolumn{4}{|c|}{ Tensão } & \multicolumn{4}{|c|}{ Instabilidade } & \multicolumn{2}{|c|}{ Molhada } \\
\hline & $\mathbf{0}$ & 1 & 2 & 3 & $\mathbf{0}$ & 1 & 2 & 3 & 0 & 1 & 2 & 3 & $\mathbf{0}$ & 1 & 2 & 3 & $\mathbf{S}$ & $\mathbf{N}$ \\
\hline $\mathbf{A}$ & $\begin{array}{c}100 \% \\
(5)\end{array}$ & 0 & 0 & 0 & $\begin{array}{c}80 \% \\
\text { (4) }\end{array}$ & $\begin{array}{c}20 \% \\
(1)\end{array}$ & 0 & 0 & $\begin{array}{c}80 \% \\
(4)\end{array}$ & $\begin{array}{c}20 \% \\
\text { (1) }\end{array}$ & 0 & 0 & $\begin{array}{c}80 \% \\
(4)\end{array}$ & $\begin{array}{c}20 \% \\
\text { (1) }\end{array}$ & 0 & & 0 & $\begin{array}{c}100 \% \\
(5)\end{array}$ \\
\hline $\begin{array}{l}\mathbf{P} \\
\mathbf{3} \\
\end{array}$ & $\begin{array}{c}100 \% \\
(5)\end{array}$ & 0 & 0 & 0 & $\begin{array}{c}40 \% \\
(2) \\
\end{array}$ & $\begin{array}{c}60 \% \\
(3) \\
\end{array}$ & 0 & 0 & $\begin{array}{c}60 \% \\
\text { (3) } \\
\end{array}$ & $\begin{array}{c}40 \% \\
(2)\end{array}$ & 0 & 0 & $\begin{array}{l}40 \% \\
(2) \\
\end{array}$ & $\begin{array}{c}60 \% \\
(3) \\
\end{array}$ & $v$ & & 0 & $\begin{array}{c}100 \% \\
(5)\end{array}$ \\
\hline $\begin{array}{l}\mathbf{P} \\
7\end{array}$ & $\begin{array}{c}100 \% \\
(5)\end{array}$ & 0 & 0 & 0 & $\begin{array}{c}60 \% \\
(3)\end{array}$ & $\begin{array}{c}40 \% \\
(2)\end{array}$ & 0 & 0 & $\begin{array}{c}100 \% \\
(5)\end{array}$ & 0 & 0 & 0 & $\begin{array}{c}80 \% \\
(4)\end{array}$ & $\begin{array}{c}20 \% \\
(1)\end{array}$ & 0 & 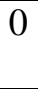 & 0 & $\begin{array}{c}100 \% \\
(5)\end{array}$ \\
\hline $\begin{array}{l}\mathbf{L} \\
\mathbf{3}\end{array}$ & $\begin{array}{c}100 \% \\
(5)\end{array}$ & 0 & 0 & 0 & $\begin{array}{c}80 \% \\
\text { (4) }\end{array}$ & $\begin{array}{c}20 \% \\
(1)\end{array}$ & 0 & 0 & $\begin{array}{c}80 \% \\
(4)\end{array}$ & $\begin{array}{c}20 \% \\
(1)\end{array}$ & 0 & 0 & $\begin{array}{c}60 \% \\
(3)\end{array}$ & $\begin{array}{c}40 \% \\
(2)\end{array}$ & 0 & 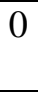 & 0 & $\begin{array}{c}100 \% \\
(5)\end{array}$ \\
\hline $\begin{array}{l}\text { L } \\
7\end{array}$ & $\begin{array}{c}80 \% \\
(4)\end{array}$ & $\begin{array}{c}20 \% \\
(1) \\
\end{array}$ & 0 & 0 & $\begin{array}{c}40 \% \\
(2) \\
\end{array}$ & $\begin{array}{c}60 \% \\
(3) \\
\end{array}$ & 0 & 0 & $\begin{array}{c}100 \% \\
(5) \\
\end{array}$ & 0 & 0 & 0 & $\begin{array}{c}100 \% \\
(5) \\
\end{array}$ & 0 & 0 & 0 & 0 & $\begin{array}{c}100 \% \\
(5)\end{array}$ \\
\hline
\end{tabular}

Legenda: (A) antes; (P3) pastoso 3ml; (P7) pastoso 7ml; (L3) líquido 3ml e (L7) líquido 7ml.

\section{- Grupo de pacientes com alteração neurológica}

Para a $3 \mathrm{ml}$ da consistência líquida foram analisadas 25 vozes, pois um paciente apresentou um sinal ininteligível. Para a $7 \mathrm{ml}$ de líquido foram analisadas 24 vozes, pois devido a presença de aspiração laringotraqueal, o exame foi interrompido, não sendo administrado volume maior da mesma consistência aspirada.

Na tabela 5 as vozes foram classificadas quanto a rugosidade, observou-se que antes da deglutição a maioria dos pacientes não apresentaram esta alteração (grau 0) ou grau 1 de rugosidade. Para a consistência pastosa, a maioria foi classificada com leve alteração, seguida pelo grau 0 . Para $3 \mathrm{ml}$ de líquido, $36 \%$ dos pacientes foram classificados sem esta alteração (grau 0) e com grau 2 de alteração vocal. Para $7 \mathrm{ml} \mathrm{de} \mathrm{líquido} \mathrm{45,8 \%} \mathrm{(11)} \mathrm{apresentaram} \mathrm{leve}$ alteração, seguido por $37,5 \%$ com nenhuma rugosidade.

Tabela 5 - Análise perceptivo-auditiva da rugosidade

\begin{tabular}{lcccc}
\hline & \multicolumn{3}{c}{ Rugosidade } \\
& $\mathbf{0}$ & $\mathbf{1}$ & $\mathbf{2}$ & $\mathbf{3}$ \\
\hline Antes & $46,1 \%(12)$ & $42,3 \%(11)$ & $3,8 \%(1)$ & $7,6 \%(2)$ \\
\hline Pastoso 3ml & $34,6 \%(9)$ & $42,3 \%(11)$ & $19,3 \%(5)$ & $3,8 \%(1)$ \\
\hline Pastoso 7ml & $38,4 \%(10)$ & $46,1 \%(12)$ & $7,6 \%(2)$ & $7,6 \%(2)$ \\
\hline Líquido 3ml & $36 \%(9)$ & $28 \%(7)$ & $36 \%(9)$ & 0 \\
\hline Líquido 7ml & $37,5 \%(9)$ & $45,8 \%(11)$ & $12,5 \%(3)$ & $4,2 \%(1)$ \\
\hline
\end{tabular}


Comparando a análise perceptivo-auditiva com os dados de resíduo, penetração e/ou aspiração laringotraqueal, pode-se verificar que para os 44 pacientes que apresentaram resíduo, apenas 6 apresentaram piora do grau de rugosidade na análise perceptivo-auditiva, quando comparado antes da deglutição com a deglutição de 3 ou $7 \mathrm{ml}$ de pastoso e/ou líquido. Para penetração laríngea, de 5 pacientes apenas 1 apresentou piora e para a aspiração laringotraqueal, de 7 pacientes que aspiraram, 4 apresentaram piora no grau de rugosidade.

$\mathrm{Na}$ tabela 6 as vozes foram classificadas quanto a soprosidade, observando-se que antes da deglutição a maioria dos pacientes com grau 1 de soprosidade. Para a consistência pastosa de $3 \mathrm{ml}, 42,3 \%$ dos pacientes não apresentaram alteração ou com grau 1, e para $7 \mathrm{ml}$ de pastoso a maioria foi classificada no grau 1. Para $3 \mathrm{ml}$ de líquido $36 \%$ dos pacientes não apresentaram esta alteração (grau 0) e 32\% com grau 1 e 2 de soprosidade. Para $7 \mathrm{ml}$ de líquido 50\% (11) não apresentaram alteração.

Tabela 6 - Análise perceptivo-auditiva da soprosidade

\begin{tabular}{|c|c|c|c|c|}
\hline \multicolumn{5}{|c|}{ Soprosidade } \\
\hline & 0 & 1 & 2 & 3 \\
\hline Antes & $34,6 \%(9)$ & $38,4 \%(10)$ & $23 \%(6)$ & $3,8 \%(1)$ \\
\hline Pastoso 3ml & $42,3 \%(11)$ & $42,3 \%(11)$ & $7,6 \%(2)$ & $7,6 \%(2)$ \\
\hline Pastoso 7ml & $46,1 \%(12)$ & $23 \%(6)$ & $19,3 \%(5)$ & $11,5 \%(3)$ \\
\hline Líquido 3ml & $36 \%(9)$ & $32 \%(8)$ & $32 \%(8)$ & 0 \\
\hline Líquido $7 \mathrm{ml}$ & $50 \%(12)$ & $29,1 \%(7)$ & $16,6 \%(4)$ & $4,2 \%(1)$ \\
\hline
\end{tabular}

Comparando a análise perceptivo-auditiva com os dados de resíduo, penetração e/ou aspiração laringotraqueal, verificou-se que para os 44 pacientes que apresentaram resíduo, apenas 6 aumentaram o grau de soprosidade. Para penetração laríngea, de 5 pacientes apenas 1 apresentou piora e para a aspiração laringotraqueal, de 7 pacientes que aspiraram, nenhum apresentou piora no grau de soprosidade.

$\mathrm{Na}$ tabela 7 as vozes foram classificadas quanto a tensão, observando-se antes da deglutição, após a deglutição de $3 \mathrm{ml}$ de pastoso e $3 \mathrm{ml}$ de líquido, a maioria dos pacientes foram classificados com grau 2 de tensão. Para $7 \mathrm{ml}$ de pastoso os pacientes estão distribuídos nos graus 0 , 1 e 2, seguido pelo grau 3 com 19,3\%. Para $7 \mathrm{ml}$ de líquido 37,5\% (9) foram classificados com grau 1, seguido por $33.3 \%$ de grau 2 . 
Tabela 7 - Análise perceptivo-auditiva da tensão

\begin{tabular}{lcccc}
\hline & \multicolumn{4}{c}{ Tensão } \\
& $\mathbf{0}$ & $\mathbf{1}$ & $\mathbf{2}$ & $\mathbf{3}$ \\
\hline Antes & $30,7 \%(8)$ & $19,3 \%(5)$ & $34,6 \%(9)$ & $15,3 \%(4)$ \\
\hline Pastoso 3ml & $15,3 \%(4)$ & $23 \%(6)$ & $46,1 \%(12)$ & $15,3 \%(4)$ \\
\hline Pastoso 7ml & $27 \%(7)$ & $27 \%(7)$ & $27 \%(7)$ & $19,3 \%(5)$ \\
\hline Líquido 3ml & $24 \%(6)$ & $24 \%(6)$ & $40 \%(10)$ & $12 \%(3)$ \\
\hline Líquido 7ml & $16,6 \%(4)$ & $37,5 \%(9)$ & $33,3 \%(8)$ & $12,5 \%(3)$ \\
\hline
\end{tabular}

Na comparação do grau de tensão com os dados de resíduo, penetração e/ou aspiração laringotraqueal, verificou-se que para os 44 pacientes que apresentaram resíduo, 12 apresentaram piora do grau de tensão. Para penetração laríngea, de 5 pacientes, 2 apresentaram piora e para a aspiração laringotraqueal, de 7 pacientes, 2 apresentaram piora no grau de tensão.

Na tabela 8 as vozes foram classificadas quanto ao grau de instabilidade, observandose que antes da deglutição, após a deglutição de $3 \mathrm{ml}$ de pastoso e $3 \mathrm{ml}$ de líquido, a maioria dos pacientes foram classificados com grau 1 de instabilidade. Para o volume de $7 \mathrm{ml}$ de pastoso e de líquido a maioria dos pacientes foram classificados com grau 2 de instabilidade.

Tabela 8 - Análise perceptivo-auditiva da instabilidade

\begin{tabular}{|c|c|c|c|c|}
\hline \multicolumn{5}{|c|}{ Instabilidade } \\
\hline & $\mathbf{0}$ & 1 & 2 & 3 \\
\hline Antes & $19,3 \%(5)$ & $42,3 \%(11)$ & $30,7 \%(8)$ & $7,6 \%(2)$ \\
\hline Pastoso 3ml & $7,6 \%(2)$ & $38,4 \%(10)$ & $34,6 \%(9)$ & $19,3 \%(5)$ \\
\hline Pastoso 7ml & $7,6 \%(2)$ & $38,4 \%(10)$ & $42,3 \%(11)$ & $11,5 \%(3)$ \\
\hline Líquido 3ml & $4 \%(1)$ & $56 \%(14)$ & $32 \%(8)$ & $8 \%(2)$ \\
\hline Líquido 7ml & $8,4 \%(2)$ & $33,3 \%(8)$ & $37,5 \%(9)$ & $20,8 \%(5)$ \\
\hline
\end{tabular}

Na comparação do grau de instabilidade com os dados de resíduo, penetração e/ou aspiração laringotraqueal, verificou-se que para os 44 pacientes que apresentaram resíduo, 23 apresentaram piora do grau de instabilidade. Para penetração laríngea, de 5 pacientes, 2 apresentaram piora e para a aspiração laringotraqueal, de 7 pacientes, 3 apresentaram piora no grau de instabilidade. 
$\mathrm{Na}$ tabela 9 as vozes foram classificadas quanto à presença de qualidade vocal molhada, observando-se que a maioria dos pacientes não apresentou esta característica.

Tabela 9 - Análise perceptivo-auditiva de qualidade vocal molhada

\begin{tabular}{lcc}
\hline & \multicolumn{2}{c}{ Molhada } \\
& S & N \\
\hline Antes & 0 & $100 \%$ \\
\hline Pastoso 3ml & $11,5 \%(3)$ & $88,4 \%(23)$ \\
\hline Pastoso 7ml & $3,8 \%(1)$ & $96,2 \%(25)$ \\
\hline Líquido 3ml & $12 \%(3)$ & $88 \%(22)$ \\
\hline Líquido 7ml & $20,8 \%(5)$ & $79,2 \%(19)$ \\
\hline
\end{tabular}

Na comparação da análise perceptivo-auditiva com a videofluoroscopia, verificou-se que dos 44 pacientes que apresentaram resíduo 7 foram considerados com qualidade vocal molhada ( 3 para $3 \mathrm{ml}$ de pastoso; 1 para $7 \mathrm{ml}$ de pastoso; 2 para $3 \mathrm{ml}$ de líquido e 1 para $7 \mathrm{ml} \mathrm{de}$ líquido). Para os 5 pacientes que apresentaram penetração laríngea, 2 foram classificados com voz molhada para $7 \mathrm{ml}$ de líquido. Para os pacientes que aspiraram, foram classificados com qualidade vocal molhada após a deglutição, um para $3 \mathrm{ml}$ de líquido e 2 para $7 \mathrm{ml}$ de líquido.

\subsection{Análise Acústica Tradicional}

Foram analisados os parâmetros da frequência fundamental (Fo), jitter e shimmer dos sinais de vozes dos indivíduos do grupo de referência e dospacientes com alteração neurológica em diferentes momentos: antes e após a deglutição de $3 \mathrm{ml}$ e $7 \mathrm{ml}$ das consistências pastosa e líquida.

\section{- Grupo de Referência}

Na tabela 10 pode-se observar os valores da Fo do sexo feminino do grupo parâmetro, os valores da média e do desvio padrão da Fo para pacientes do sexo feminino, sendo observado que antes da deglutição os valores variaram de $210,3 \mathrm{~Hz}$ a $222,8 \mathrm{~Hz}$ com a média de 217,3 Hz; para a consistência pastosa os valores de máximo e mínimo, com volume de 
$3 \mathrm{ml}$ variaram de $195 \mathrm{~Hz}$ a 211,7Hz, com média de 205,6Hz; e para o volume de 7ml, o valor médio para o pastoso foi de $207.3 \mathrm{~Hz}$, variando para as mulheres de $201,5 \mathrm{~Hz}$ a $210,6 \mathrm{~Hz}$.

Tabela 10 - Valores em média e desvio padrão da Frequência Fundamental (Fo) para o sexo feminino do grupo de referência

\begin{tabular}{cccccc}
\hline & \multicolumn{3}{c}{ Fo Paciente Feminino (Hz) } & \multicolumn{2}{c}{ Líquido } \\
& Antes & 3ml & Pastoso & 3ml & 3ml \\
\hline Média & 217,3 & 205,6 & 207,3 & 212,1 & 7ml \\
\hline Desvio padrão & 0,301 & 0,309 & 0,614 & 0,576 & 0,425 \\
\hline
\end{tabular}

Para a consistência líquida, quando administrado 3ml, observou-se para o sexo feminino a variação de $204,5 \mathrm{~Hz}$ a $220,8 \mathrm{~Hz}$ (média de $212,1 \mathrm{~Hz}$ ). O volume de $7 \mathrm{ml}$ foi observado que os valores de máximo e mínimo foram de $194,2 \mathrm{~Hz}$ a $220,9 \mathrm{~Hz}$ (média de 210Hz).

Para o sexo masculino houve apenas um indivíduo, apresentando a Fo antes da deglutição de $157,4 \mathrm{~Hz}$, para $3 \mathrm{ml}$ de pastoso $155 \mathrm{~Hz}$ e para $7 \mathrm{ml}$ de pastoso o valor de $155,8 \mathrm{~Hz}$. Para a consistência líquida, para o volume de $3 \mathrm{ml}$ o valor de Fo foi de $155 \mathrm{~Hz}$ e para $7 \mathrm{ml}$ foi de $154,2 \mathrm{~Hz}$.

$\mathrm{Na}$ tabela 11 pode-se verificar a média e o desvio padrão do jitter nos cinco momentos de coleta dos dados. Os valores de jitter antes da deglutição variaram $0,16 \%$ a $0,24 \%$, após a deglutição de $3 \mathrm{ml}$ de pastoso variou de $0,16 \%$ a $0,38 \%$ e após $7 \mathrm{ml}$ os valores apresentaram-se entre $0,16 \%$ a $0,30 \%$. Após a deglutição de $3 \mathrm{ml}$ de líquido verificou-se variação entre $0,16 \%$ a $0,35 \%$ e para $7 \mathrm{ml}$ da consistência líquida de $0,14 \%$ a $0,38 \%$.

Tabela 11 - Valor médio e desvio padrão do jitter antes da deglutição, após a deglutição de $3 \mathrm{ml} \mathrm{e} 7 \mathrm{ml}$ das consistências pastosa e líquida do grupo de referência.

\begin{tabular}{|c|c|c|c|c|c|}
\hline \multicolumn{6}{|c|}{ Jitter (\%) } \\
\hline & \multirow[t]{2}{*}{ Antes } & \multicolumn{2}{|c|}{ Pastoso } & \multicolumn{2}{|c|}{ Líquido } \\
\hline & & $3 \mathrm{ml}$ & $7 \mathrm{ml}$ & $3 \mathrm{ml}$ & $7 \mathrm{ml}$ \\
\hline Média & 0,9 & 0,24 & 0,21 & 0,24 & 0,25 \\
\hline Desvio padrão & 0,014 & 0,107 & 0,04 & 0,044 & 0,055 \\
\hline
\end{tabular}


Na tabela 12 observa-se a média e o desvio padrão do shimmer. Os sinais de vozes analisados antes da deglutição mostraram a variação do shimmer de 1,22\% até 1,53\%; após a deglutição de $3 \mathrm{ml}$ da consistência pastosa variou de $1,44 \%$ a $1,96 \%$ e após a deglutição de $7 \mathrm{ml}$ de pastoso de $1,36 \%$ até $2,03 \%$. Após a deglutição de $3 \mathrm{ml}$ de líquido variou de $1,53 \%$ a $1,81 \%$ e após a administração de $7 \mathrm{ml}$ de líquido a faixa variou de 1,49\% a 2,05\%.

Tabela 12 - Valor médio e desvio padrão do shimmer antes da deglutição, após a deglutição de $3 \mathrm{ml}$ e $7 \mathrm{ml}$ das consistências pastosa e líquida para o grupo de referência

\begin{tabular}{|c|c|c|c|c|c|}
\hline \multicolumn{6}{|c|}{ Shimmer (\%) } \\
\hline & \multirow[t]{2}{*}{ Antes } & \multicolumn{2}{|c|}{ Pastoso } & \multicolumn{2}{|c|}{ Líquido } \\
\hline & & $3 \mathrm{ml}$ & $7 \mathrm{ml}$ & $3 \mathrm{ml}$ & $7 \mathrm{ml}$ \\
\hline Média & 1,38 & 1,67 & 1,63 & 1,67 & 1,80 \\
\hline Desvio padrão & 0,055 & 0,052 & 0,149 & 0,214 & 0,314 \\
\hline
\end{tabular}

\section{- Grupo de pacientes com alteração neurológica}

Na tabela 13 verificamos os valores da média e do desvio padrão da Fo para pacientes do sexo feminino, sendo observado que antes da deglutição os valores variaram de $146,3 \mathrm{~Hz}$ a $300,31 \mathrm{~Hz}$ com a média de $215,9 \mathrm{~Hz}$; para a consistência pastosa os valores de máximo e mínimo, com volume de $3 \mathrm{ml}$ variaram de $113,6 \mathrm{~Hz}$ a 264,2Hz, com média de 196,8Hz; e para o volume de $7 \mathrm{ml}$, o valor médio para o pastoso foi de $199,2 \mathrm{~Hz}$, variando para as mulheres de $135,4 \mathrm{~Hz}$ a $275,6 \mathrm{~Hz}$, apenas oito pacientes foram avaliados, pois o programa não analisou um sinal devido a aperiodicidade do sinal. Para a consistência líquida, quando administrado $3 \mathrm{ml}$, observou-se para o sexo feminino a variação de $138,2 \mathrm{~Hz}$ a $315,9 \mathrm{~Hz}$ (média de 217,2Hz).

O volume de $7 \mathrm{ml}$ foi administrado somente para 24 pacientes (nove mulheres e quinze homens), observando-se os valores de máximo e mínimo foram de $148,7 \mathrm{~Hz}$ a $280,9 \mathrm{~Hz}$ (média de $208,7 \mathrm{~Hz})$.

Tabela 13 - Valores em média e desvio padrão da Frequência Fundamental (Fo) para o sexo feminino

\begin{tabular}{|c|c|c|c|c|c|c|c|}
\hline \multicolumn{8}{|c|}{ Fo Paciente Feminino (Hz) } \\
\hline & \multirow[t]{2}{*}{ Antes } & \multicolumn{2}{|c|}{ Pastoso } & \multicolumn{2}{|c|}{ Líquido } & \multirow{2}{*}{$\begin{array}{c}\text { Pastoso } \\
\mathbf{p} \\
\end{array}$} & \multirow{2}{*}{$\begin{array}{c}\text { Líquido } \\
\mathbf{p}\end{array}$} \\
\hline & & $3 \mathrm{ml}$ & $7 \mathrm{ml}$ & $3 \mathrm{ml}$ & $7 \mathrm{ml}$ & & \\
\hline Média & 215,9 & 196,8 & 199,2 & 217,2 & 208,7 & & \\
\hline Desvio padrão & 22,1 & 14,09 & 20,94 & 11,29 & 16,69 & & 0,984 \\
\hline
\end{tabular}


Na tabela 14 verificamos os valores da média e do desvio padrão da Fo para pacientes do sexo masculino, sendo observado que antes da deglutição os valores variaram de $94,2 \mathrm{~Hz}$ a $259,9 \mathrm{~Hz}$ com média de $157,8 \mathrm{~Hz}$; para a consistência pastosa os valores de máximo e mínimo, com volume de $3 \mathrm{ml}$ variaram de $875 \mathrm{~Hz}$ a $212,05 \mathrm{~Hz}$ com média de $147,2 \mathrm{HZ}$; e para o volume de $7 \mathrm{ml}$, variou de $88,7 \mathrm{~Hz}$ a $199,3 \mathrm{~Hz}$ (média de $1464 \mathrm{~Hz}$ ), para a consistência pastosa e para $3 \mathrm{ml}$ de líquido foi realizada a análise apenas em dezesseis pacientes, pois para um dos pacientes a amostra vocal era insufuciente para a análise. Quando administrado $3 \mathrm{ml}$, os valores ficaram entre $87,3 \mathrm{~Hz}$ a $223 \mathrm{~Hz}$ com média de $145,2 \mathrm{~Hz}$. Para a consistência líquida, volume de $7 \mathrm{ml}$, a análise foi realizada em quinze pacientes, pois para os pacientes que apresentaram aspiração laringotraqueal com o $3 \mathrm{ml}$ de líquido, o exame foi interrompido; os achados foram entre $89,4 \mathrm{~Hz}$ a $217,8 \mathrm{~Hz}$ com média de $148,6 \mathrm{~Hz}$.

Tabela 14 - Valores em média e desvio padrão da Frequência Fundamental para o sexo masculino

\begin{tabular}{cccccccc}
\hline & \multicolumn{9}{c}{ Fo Paciente Masculino (Hz) } & \multirow{2}{*}{ Mastoso } & Líquido \\
& Antes & \multicolumn{2}{c}{ Pastoso } & \multicolumn{2}{c}{ Líquido } & Pastos \\
& & 3ml & $\mathbf{7 m l}$ & 3ml & $\mathbf{7 m l}$ & p & p \\
\hline Média & 157,85 & 147,25 & 146,43 & 145,26 & 148,65 & \multirow{2}{*}{0,618} & \multirow{2}{*}{0,588} \\
\hline Desvio padrão & 2,53 & 8,49 & 16,91 & 14,38 & 8,00 & & \\
\hline
\end{tabular}

No teste ANOVA unilateral foi aplicado nos valores da frequência fundamental do sexo feminino e masculino, nas consistências pastosa e líquida. Na análise da Fo do sexo feminino, para o pastoso, verificou-se que a probabilidade dos grupos antes da deglutição, após a deglutição de $3 \mathrm{ml}$ e $7 \mathrm{ml}$ de pastoso serem iguais é de $68,43 \%$; e para a análise de antes e após deglutição com os volumes de $3 \mathrm{ml}$ e $7 \mathrm{ml}$ de líquido é de 92,88\%. Quando aplicado entre os valores da Fo masculina apresentados antes da deglutição, após a deglutição de $3 \mathrm{ml}$ e $7 \mathrm{ml}$ de pastoso, verificou-se que a probabilidade dos grupos serem semelhantes é de 61,88\%; e para antes com após a deglutição de $3 \mathrm{ml}$ e $7 \mathrm{ml}$ de líquido é de 58,87\% (figura 18 ). 

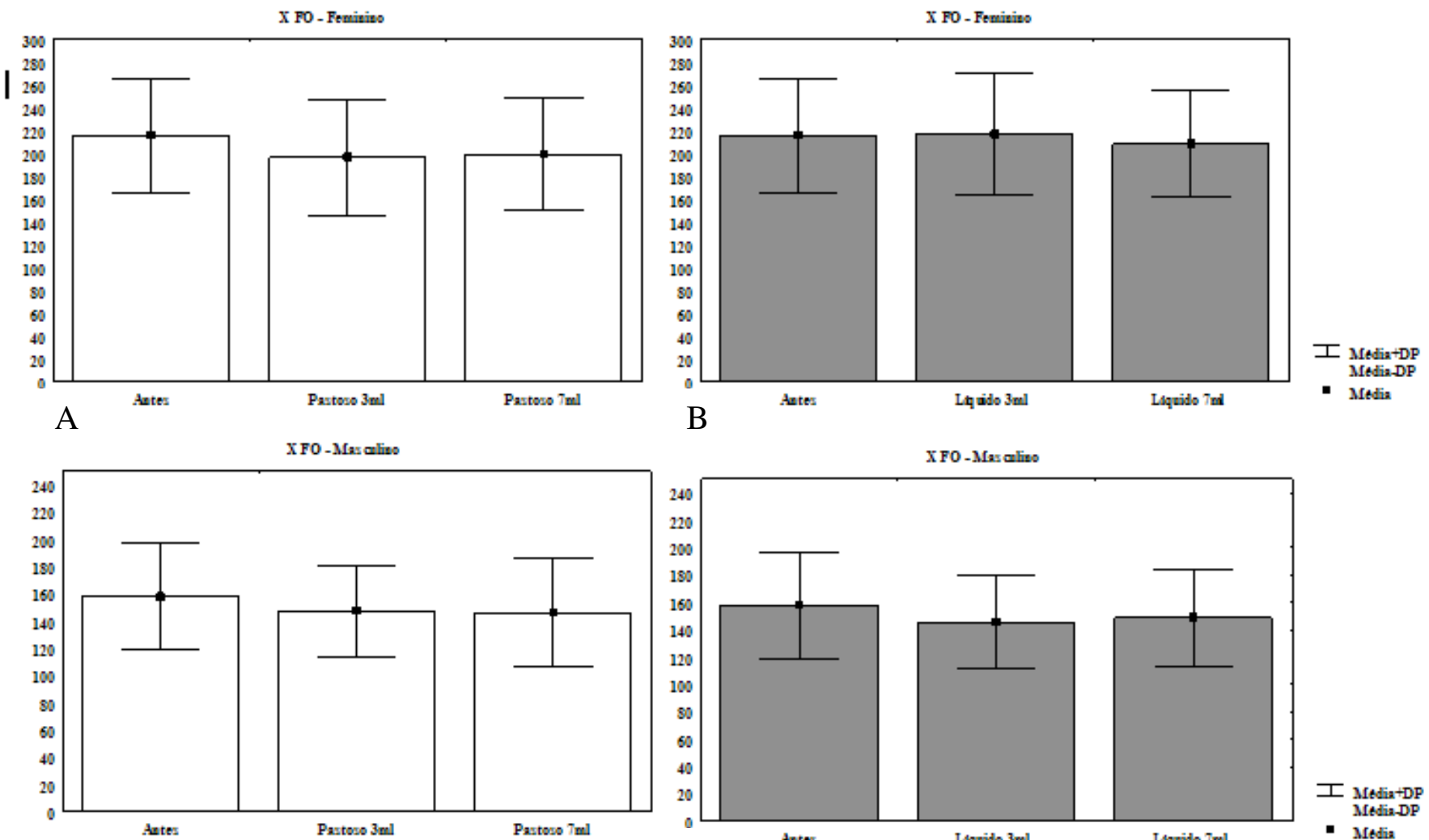

$\mathrm{C}$

$\mathrm{B}$

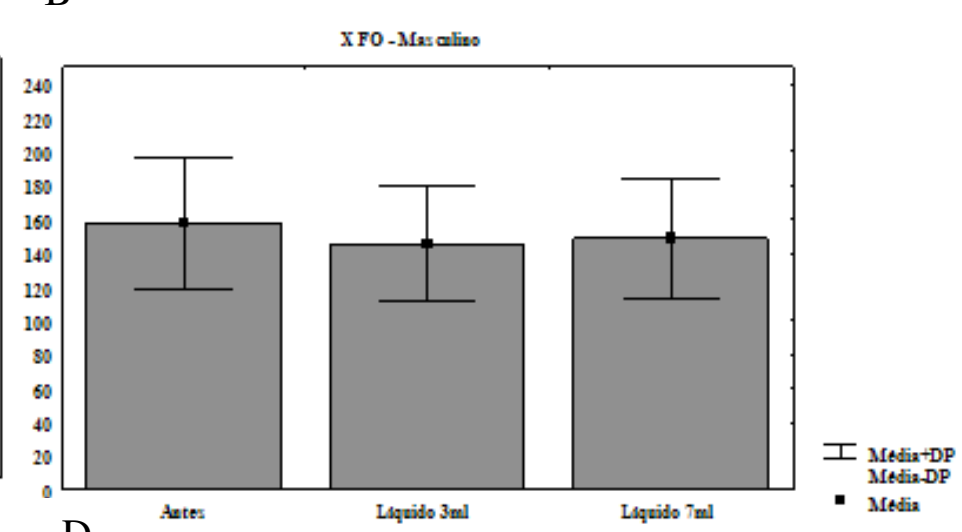

$\mathrm{D}$

Figura 18 - Distribuição para a Fo dos sexos feminino e masculino

Na tabela 15 pode-se verificar a média e o desvio padrão do jitter nos cinco momentos de coleta dos dados. Os valores de jitter antes da deglutição variaram de 0,15\% a 1,18\%, após a deglutição de $3 \mathrm{ml}$ de pastoso variou de $0,17 \%$ a $1,59 \%$ e após $7 \mathrm{ml}$ os valores apresentaramse entre $0,17 \%$ a $1,15 \%$. Após a deglutição de $3 \mathrm{ml}$ de líquido verificou-se variação entre $0,17 \%$ a $3,48 \%$ e para $7 \mathrm{ml}$ da consistência líquida de $0,16 \%$ a $1,62 \%$.

Tabela 15 - Valor médio e desvio padrão do jitter antes da deglutição, após a deglutição de $3 \mathrm{ml}$ e $7 \mathrm{ml}$ das consistências pastosa e líquida

\begin{tabular}{cccccccc}
\hline & \multicolumn{4}{c}{ Jitter (\%) } \\
Antes & \multicolumn{2}{c}{ Pastoso } & \multicolumn{2}{c}{ Líquido } & \multirow{2}{*}{ Pastoso } & Líquido \\
& & 3ml & $\mathbf{7 m l}$ & $\mathbf{3 m l}$ & $\mathbf{7 m l}$ & $\mathbf{p}$ & $\mathbf{p}$ \\
\hline Média & 0,45 & 0,50 & 0,45 & 0,57 & 0,55 & \multirow{2}{*}{0,7701} & \multirow{2}{*}{0,645} \\
\hline Desvio padrão & 0,27 & 0,34 & 0,28 & 0,68 & 0,40 & & \\
\hline
\end{tabular}

Na tabela 16 observa-se a média e o desvio padrão do shimmer. Os sinais de vozes analisados antes da deglutição mostraram a variação do shimmer de 1,18\% até 12,89\%; após a 
deglutição de $3 \mathrm{ml}$ da consistência pastosa variou de $0,16 \%$ a $8,55 \%$ e após a deglutição de $7 \mathrm{ml}$ de pastoso de $0,20 \%$ até $10,7 \%$. Após a deglutição de $3 \mathrm{ml}$ de líquido variou de $1,49 \%$ a $10,5 \%$ e após a administração de $7 \mathrm{ml}$ de líquido a faixa variou de 1,54\% a 13,7\%.

Tabela 16 - Valor em média e desvio padrão do shimmer antes da deglutição, após a deglutição de $3 \mathrm{ml}$ e $7 \mathrm{ml}$ das consistências pastosa e líquida

\begin{tabular}{cccccccc}
\hline & \multicolumn{4}{c}{ Shimmer (\%) } \\
& Antes & \multicolumn{2}{c}{ Pastoso } & \multicolumn{2}{c}{ Líquido } & \multirow{2}{*}{ Pastoso } & \multirow{2}{*}{ Líquido } \\
& & 3ml & $\mathbf{7 m l}$ & 3ml & 7ml & p & P \\
\hline Média & 3,33 & 3,40 & 3,87 & 3,78 & 4,35 & \multirow{2}{*}{0,648} & \multirow{2}{*}{0,357} \\
\hline Desvio padrão & 2,40 & 1,62 & 2,46 & 2,14 & 2,85 & & \\
\hline
\end{tabular}

O teste ANOVA unilateral verificou que o jitter dos grupos antes da deglutição e após a deglutição de $3 \mathrm{ml}$ e $7 \mathrm{ml}$ de pastoso serem semelhantes apresentam probabilidade de $77 \%$; e de $64,87 \%$ para o shimmer. Também verificou a probabilidade do jitter de antes da deglutição com após a deglutição de $3 \mathrm{ml}$ e $7 \mathrm{ml}$ de líquido serem semelhantes é de 64,56\%; e $35,72 \%$ para o shimmer. Na figura 19, pode-se observar a distribuição das amostras dos parâmetros de jitter (A e B) e shimmer (B e C).
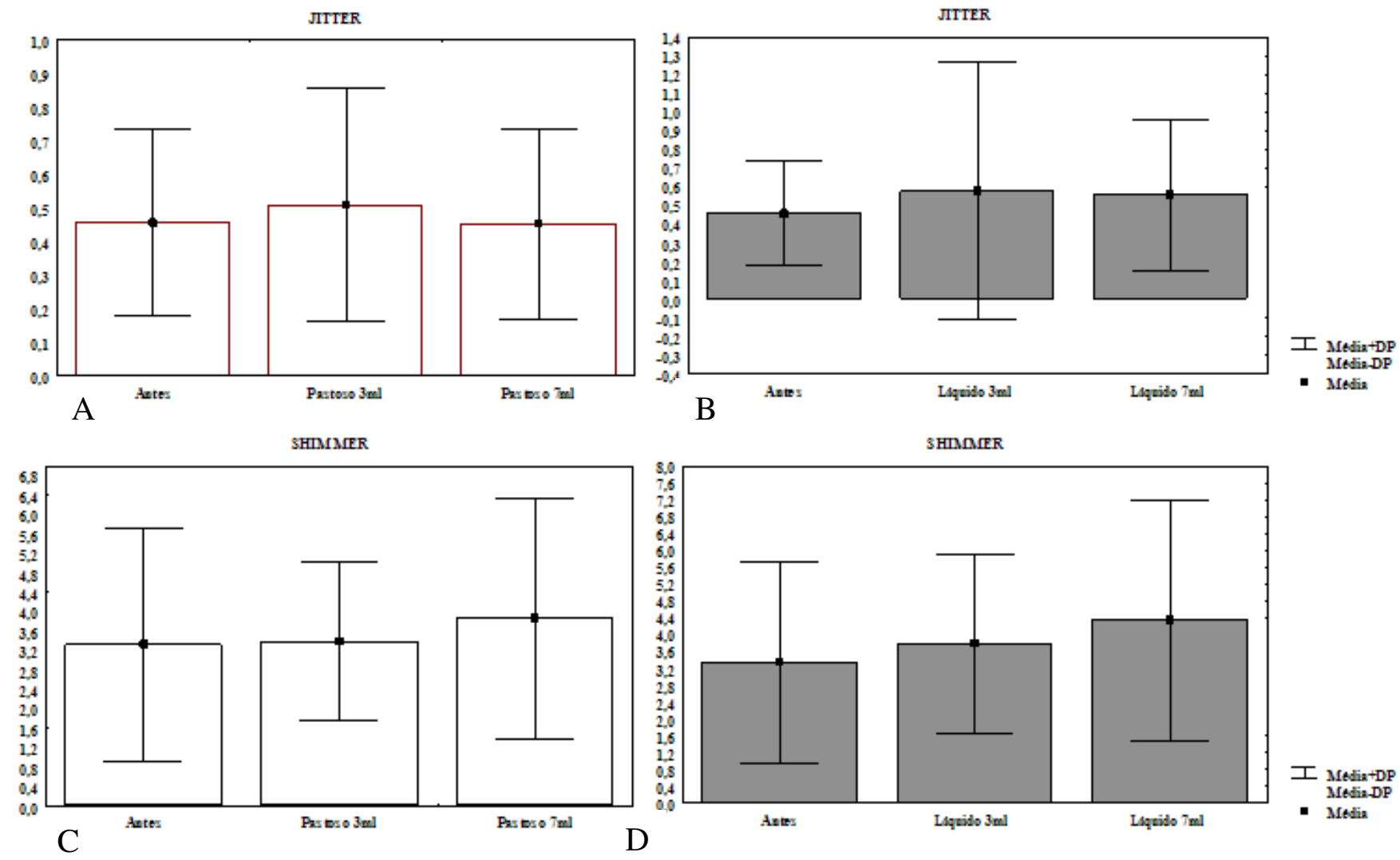

Figura 19 - Gráficos de Distribuição para jitter e shimmer 


\subsection{Análise qualitativa dos padrões visuais da dinâmica vocal}

A voz é única em cada pessoa, e consequentemente este PVDV também será único. Para a análise dos dados foram utilizadas as categorias de loops, regularidade do traçado e convergência das trajetórias.

- Loops

Foi utilizada a categorização do número de loops, sendo: 0) para número indefinido de loops; 1) para 1 loop; 2) para 2 loops; 3) para 3 loops e 4) para 4 loops ou mais.

\section{- Grupo de Referência}

Quanto ao número de loops, pode-se observar que os indivíduos permaneceram na classificação de 3 e 4 loops, e quando realizada a comparação entre antes da deglutição e os diferentes volumes e consistências, como também entre as diferentes consistências, 100\% não apresentaram mudança na complexidade do PVDV após a deglutição das consistências pastosa e líquida nos volumes de 3 e $7 \mathrm{ml}$.

\section{- Grupo de pacientes com alteração neurológica}

$\mathrm{Na}$ tabela 17 pode-se verificar que antes da deglutição, a maioria dos pacientes $(34,6 \%)$ apresentaram categorização 3 , seguido por $27 \%$ classificados em 0 . Para os volumes de $3 \mathrm{ml} \mathrm{e} 7 \mathrm{ml}$ das consistências pastosa e líquida, a maioria dos pacientes apresentaram o padrão visual com grau 0 (46,1\%;42,3\%; 61,5\% e 45,8\%, respectivamente), em outra palavras, a maioria dos PVDV apresentaram configurações desorganizadas com número indefinido de loops. Os resultados completos encontram-se na tabela 17. 
Tabela 17 - Padrão visual do número de loops, antes da deglutição, após a deglutição de pastoso e líquido

\begin{tabular}{|c|c|c|c|c|c|c|c|c|c|c|}
\hline \multirow[b]{2}{*}{ Loops } & \multirow{2}{*}{\multicolumn{2}{|c|}{ Antes }} & \multicolumn{4}{|c|}{ Pastoso } & \multicolumn{4}{|c|}{ Líquido } \\
\hline & & & $\%$ & $3 \mathrm{ml}$ & $\%$ & $7 \mathrm{ml}$ & $\%$ & $3 \mathrm{ml}$ & $\%$ & $7 \mathrm{ml}$ \\
\hline 4 ou mais & $15,4 \%$ & 4 & $7,7 \%$ & 2 & $15,4 \%$ & 4 & $7,7 \%$ & 2 & $8,33 \%$ & 2 \\
\hline 3 & $34,6 \%$ & 9 & $34,6 \%$ & 9 & $27 \%$ & 7 & $27 \%$ & 7 & $33,4 \%$ & 8 \\
\hline 2 & $11,5 \%$ & 3 & $11,5 \%$ & 3 & $15,3 \%$ & 4 & $3,8 \%$ & 1 & $8,33 \%$ & 2 \\
\hline 1 & $11,5 \%$ & 3 & 0 & 0 & 0 & 0 & 0 & 0 & $4,16 \%$ & 1 \\
\hline 0 & $27 \%$ & 7 & $46,1 \%$ & 12 & $42,3 \%$ & 11 & $61,5 \%$ & 16 & $45,8 \%$ & 11 \\
\hline
\end{tabular}

Legenda: os números em vermelho indicam o grau com maior concentração de pacientes.

Foi realizada a comparação dos dados de cada indivíduo, do momento antes da deglutição com após a deglutição das consistências pastosa e líquida nos volumes de 3 e $7 \mathrm{ml}$, como também a comparação entre as consistências e os volumes, para verificar se houve alteração vocal (conforme tabelas). Para a proporção dos dados alterados, considerou-se P0 para quando os dados não apresentavam alteração no grau, nos momentos analisados; P+ para quando o dado apresentava aumento e P- para quando ocorria a diminuição dos valores graus.

Na tabela 18, podemos visualizar a classificação do número de loops, comparados nos diferentes momentos do exame. Pode-se observar que quando comparado antes da deglutição do alimento (parâmetro), com os diferentes volumes e consistências, houve diminuição do número de loops, sendo que o sinal apresentou piora na qualidade quando comparado com os momentos após a deglutição. Também se observou que poucos apresentaram melhora no sinal. Já realizando a comparação do número de loops entre as consistências, verificou-se que os resultados são semelhantes, mostrando que volume e consistência do alimento deglutido (da presença deste em hipofaringe) não interferem na qualidade vocal.

Tabela 18 - Comparação da proporção (em porcentagem) do número de loops antes da deglutição com as consistências pastosa e líquida e com os volumes de 3 e $7 \mathrm{ml}$; comparação entre as consistências e os volumes

\begin{tabular}{|c|c|c|c|c|c|c|c|c|}
\hline \multicolumn{9}{|c|}{ Loops } \\
\hline & A, P3 & A, P7 & A, L3 & A, L7 & P3, P7 & L3, L7 & P3, L3 & P7, L7 \\
\hline $\mathrm{P} 0$ & 38,46 & 34,61 & 38,46 & 33,3 & 57,69 & 70,833 & 73,077 & 45,833 \\
\hline $\mathrm{P}+$ & 19,23 & 26,92 & 11,53 & 25 & 23,07 & 20,833 & 3,846 & 20,833 \\
\hline P- & 42,30 & 38,46 & 50 & 41,66 & 19,231 & 8,333 & 23,077 & 29,166 \\
\hline
\end{tabular}

Legenda: (A) antes; (P3) pastoso 3ml; (P7) pastoso 7ml; (L3) líquido 3ml e (L7) líquido 7ml 
Para uma análise mais detalhada do comportamento de cada paciente e em cada momento do exame, os dados foram apresentados em duas tabelas, sendo a tabela 19 só para a presença de resíduo (resíduo em cavidade oral, estase em valécula, recessos piriformes e transição faringoesofágica) e a tabela 20 para os pacientes que apresentaram penetração laringea e/ou aspiração laringotraqueal.

Na tabela 19 observou-se que de 44 episódios de resíduo, 18 (41\%) apresentaram diminuição do número de loops, seguido pelos momentos que o PVDV não apresentou alteração (17 pacientes; 38,6\%) mesmo com a presença de resíduo e apenas 9 (20,4\%) com o aumento da complexidade do sinal.

Tabela 19 - Número de loops dos pacientes com resíduo

\begin{tabular}{|c|c|c|c|c|c|}
\hline Pacientes & Antes & Pastoso 3ml & Pastoso $7 \mathrm{ml}$ & Líquido 3ml & Líquido 7ml \\
\hline 2 & 4 & 3 & $\overline{0}$ & 0 & 3 \\
\hline 3 & 0 & 3 & 3 & 3 & 3 \\
\hline 4 & 1 & 3 & 3 & 3 & 3 \\
\hline 5 & 0 & 0 & 0 & 0 & 1 \\
\hline 7 & 2 & 0 & 2 & 0 & 0 \\
\hline 8 & 0 & 0 & 0 & 0 & \\
\hline 10 & 3 & 2 & 3 & 0 & 2 \\
\hline 11 & 3 & 3 & 4 & 4 & 4 \\
\hline 12 & 2 & 0 & 4 & 0 & \\
\hline 13 & 4 & 3 & 3 & 3 & 0 \\
\hline 14 & 1 & 0 & 0 & 0 & 0 \\
\hline 15 & 3 & 2 & 2 & 3 & 3 \\
\hline 16 & 3 & 0 & 0 & 0 & 0 \\
\hline 17 & 3 & 3 & 3 & 3 & 3 \\
\hline 18 & 3 & 3 & 2 & 2 & 0 \\
\hline 19 & 0 & 0 & 3 & 0 & 0 \\
\hline 22 & 0 & 0 & 0 & 0 & 0 \\
\hline 23 & 3 & 0 & 0 & 0 & 0 \\
\hline 24 & 1 & 3 & 0 & 3 & 3 \\
\hline 26 & 0 & 0 & 3 & 0 & 0 \\
\hline
\end{tabular}

Legenda: os valores de graus em itálica são de pacientes com resíduo.

$\mathrm{Na}$ tabela 20 esta a relação dos episódios de penetração e/ou aspiração laringotraqueal categorizados quanto ao número de loops, antes e após cada momento da deglutição. Verificando-se que quando há penetração, um manteve o mesmo número de loops e 4 apresentaram diminuição da sua complexidade. Para a aspiração, 5 apresentaram diminuição, 2 aumentaram a complexidade e um manteve-se sem alteração. 
Tabela 20 - Número de loops dos pacientes com penetração e/ou aspiração laringotraqueal

\begin{tabular}{ccccc}
\hline \multicolumn{5}{c}{ Loops } \\
& Antes & P7 & L3 & L7 \\
\hline $\boldsymbol{1}$ & 0 & 0 & 0 & $\mathbf{0}$ \\
\hline $\mathbf{2}$ & 4 & 0 & 0 & $\mathbf{3}$ \\
\hline $\mathbf{5}$ & 0 & 0 & 0 & $\mathbf{1}$ \\
\hline $\boldsymbol{8}$ & 0 & 0 & $\mathbf{0}$ & \\
\hline $\mathbf{9}$ & 3 & 0 & 0 & $\mathbf{2}$ \\
\hline $\mathbf{1 1}$ & 3 & 4 & 4 & $\mathbf{4}$ \\
\hline $\mathbf{1 2}$ & 2 & 4 & $\mathbf{0}$ & \\
\hline $\mathbf{1 4}$ & 1 & 0 & 0 & $\mathbf{0}$ \\
\hline $\mathbf{1 6}$ & 3 & 0 & $\mathbf{0}$ & $\mathbf{0}$ \\
\hline $\mathbf{1 8}$ & 3 & $\mathbf{2}$ & 2 & $\mathbf{0}$ \\
\hline $\mathbf{2 5}$ & 4 & $\mathbf{0}$ & 0 & 0 \\
\hline & & & &
\end{tabular}

Legenda:os valores em azul indicam penetração; os valores em vermelho indicam aspiração

\section{- Regularidade do traçado}

A classificação utilizada para avaliar o traçado foi: "0) "regular" para órbitas completamente lisas, sem irregularidades; 1) "regular com uma porção irregular" órbitas lisas com uma área delimitada de irregularidade 2) “ irregularidade intermitente” para órbitas lisas com áreas delimitadas de irregularidades; 3) "levemente irregular" para órbitas irregularmente leve em todo o percurso; e 4) "irregular" para órbitas com o traçado completamente imperfeito.

\section{- Grupo de Referência}

$\mathrm{Na}$ categorização do traçado deste grupo, 80\% (4 indivíduos) do indivíduos apresentaram traçado regular antes da deglutição, seguido por 20\% (1 indivíduo) em regular com porção irregular, para antes da deglutição e após 3ml de pastoso. Para $7 \mathrm{ml}$ de pastoso, $80 \%$ em regular com porção irregular e $10 \%$ em irregular intermitente. Para $3 \mathrm{ml}$ e $7 \mathrm{ml}$ de líquido, 60\% (3) em levemente irregular, e 10\% em regular com porção irregular e levemente irregular. 
Para o traçado, verificou-se que a maioria dos pacientes estão categorizados em P0, seguido por $\mathrm{P}+$, com aumento da irregularidade do traçado, e somente um indivíduo (20\%), com melhora da irregularidade do traçado (tabela 21).

Tabela 21 - Grau de comparação do traçado (em porcentagem) antes da deglutição com as consistências pastosa e líquida e com os volumes de 3 e $7 \mathrm{ml}$; comparação entre as consistências e os volumes dos indivíduos sem alteração neurológica

\begin{tabular}{ccccccccc}
\hline \multicolumn{7}{c}{ Traçado } \\
\hline & A, P3 & A, P7 & A, L3 & A, L7 & P3, P7 & L3, L7 & P3, L3 & P7, L7 \\
\hline P0 & 100 & 60 & 80 & 80 & 60 & 100 & 80 & 80 \\
\hline & & & & & & & & \\
\hline P+ & 0 & 40 & 20 & 20 & 40 & 0 & 20 & 0 \\
\hline & & & & & & & & \\
\hline P- & 0 & 0 & 0 & 0 & 0 & 0 & 0 & 20 \\
\hline
\end{tabular}

Legenda: (A) antes; (P3) pastoso 3ml; (P7) pastoso 7ml; (L3) líquido 3ml e (L7) líquido 7ml.

\section{- Grupo de pacientes com alteração neurológica}

Na tabela 22 estão apresentados os traçados dos PVDV em cinco diferentes momentos. Antes da deglutição e após a deglutição de $3 \mathrm{ml}$ de pastoso 12 (46,15\%) pacientes estão categorizados em "irregularidade intermitente". Para o volume de $7 \mathrm{ml}$ de pastoso, a maioria dos pacientes estão categorizados como e como "irregularidade intermitente" e "levemente irregular". Já para a consistência líquida para ambos os volumes, os dados apresentam-se na categoria de "irregularidade intermitente".

Tabela 22 - Regularidade do traçado, antes da deglutição, após a deglutição de pastoso e líquido

\begin{tabular}{|c|c|c|c|c|c|c|c|c|c|c|}
\hline \multirow{2}{*}{ Traçado } & \multirow{2}{*}{\multicolumn{2}{|c|}{ Antes }} & \multicolumn{4}{|c|}{ Pastoso } & \multicolumn{4}{|c|}{ Líquido } \\
\hline & & & $\%$ & $3 \mathrm{ml}$ & $\%$ & $7 \mathrm{ml}$ & $\%$ & $3 \mathrm{ml}$ & $\%$ & $7 \mathrm{ml}$ \\
\hline Regular & 0 & 0 & 0 & 0 & 0 & 0 & 0 & 0 & 0 & 0 \\
\hline $\begin{array}{l}\text { Regular com } \\
\text { porção irregular }\end{array}$ & $15,4 \%$ & 4 & $15,4 \%$ & 4 & $11,6 \%$ & 3 & $7,7 \%$ & 2 & $8,33 \%$ & 2 \\
\hline $\begin{array}{l}\text { Irregularidade } \\
\text { intermitente }\end{array}$ & $46,15 \%$ & 12 & $46,15 \%$ & 12 & $34,6 \%$ & 9 & $38,5 \%$ & 10 & $41,7 \%$ & 10 \\
\hline $\begin{array}{l}\text { Levemente } \\
\text { irregular }\end{array}$ & $19,23 \%$ & 5 & $19,23 \%$ & 5 & $34,6 \%$ & 9 & $34,6 \%$ & 9 & $25 \%$ & 6 \\
\hline Irregular & $19,23 \%$ & 5 & $19,23 \%$ & 5 & $19,23 \%$ & 5 & $19,23 \%$ & 5 & $25 \%$ & 6 \\
\hline
\end{tabular}

Legenda: valores me vermelho indicam grau de maior concentração de pacientes. 
Na tabela 23, esta o grau de regularidade do traçado somente dos pacientes que apresentaram resíduo em hipofaringe, verificando-se que de 44 episódios, 20 (45,4\%) mantiveram o mesmo grau, seguido por $15(34,1 \%)$ com aumento da irregularidade, e 9 $(20,4 \%)$ com menor grau de irregularidade embora apresentem resíduo em hipofaringe.

Tabela 23 - Grau da regularidade dos traçados dos pacientes com resíduo em hipofaringe,

\begin{tabular}{|c|c|c|c|c|c|}
\hline Pacientes & Antes & Pastoso 3ml & Pastoso 7ml & Líquido 3ml & Líquido $7 \mathrm{ml}$ \\
\hline 2 & 1 & 2 & 3 & 2 & 3 \\
\hline 3 & 2 & 2 & 2 & 2 & 2 \\
\hline 4 & 2 & 2 & 2 & 2 & 2 \\
\hline 5 & 3 & 3 & 3 & 3 & 4 \\
\hline 7 & 2 & 4 & 4 & 4 & 4 \\
\hline 8 & 4 & 3 & 4 & 4 & \\
\hline 10 & 3 & 4 & 3 & 3 & 4 \\
\hline 11 & 2 & 1 & 1 & 2 & 2 \\
\hline 12 & 4 & 2 & 1 & 3 & \\
\hline 13 & 2 & 2 & 2 & 2 & 2 \\
\hline 14 & 4 & 4 & 4 & 4 & 4 \\
\hline 15 & 3 & 3 & 2 & 2 & 3 \\
\hline 16 & 2 & 2 & 3 & 3 & 3 \\
\hline 17 & 1 & 2 & 2 & 2 & 2 \\
\hline 18 & 3 & 2 & 3 & 3 & 3 \\
\hline 19 & 4 & 4 & 3 & 3 & 4 \\
\hline 22 & 2 & 3 & 3 & 4 & 4 \\
\hline 23 & 1 & 1 & 2 & 2 & 2 \\
\hline 24 & 4 & 1 & 4 & 1 & 1 \\
\hline 26 & 2 & 2 & 2 & 2 & 2 \\
\hline
\end{tabular}

Legenda: os valores de graus em itálica são de pacientes com resíduo.

$\mathrm{Na}$ tabela 24 esta a relação de pacientes que apresentaram penetração e/ou aspiração laringotraqueal categorizados quanto ao traçado. Verificou-se que para os pacientes com penetração, 2 mantiveram-se na mesma categoria de antes da deglutição e 3 aumentaram a irregularidade de traçado. Para aspiração laringotraqueal, 4 permaneceram na mesma categoria e 4 aumentaram a irregularidade de traçado. 
Tabela 24 - Grau do traçado dos pacientes com penetração e/ou aspiração laringotraqueal

\begin{tabular}{ccccc}
\hline \multicolumn{5}{c}{ Traçado } \\
& Antes & P7 & L3 & L7 \\
\hline $\mathbf{1}$ & 2 & 4 & 4 & $\mathbf{3}$ \\
\hline $\mathbf{2}$ & 1 & 3 & 2 & $\mathbf{3}$ \\
\hline $\mathbf{5}$ & 3 & 3 & 3 & $\mathbf{4}$ \\
\hline $\boldsymbol{8}$ & 4 & 4 & $\mathbf{4}$ & \\
\hline $\mathbf{9}$ & 2 & 3 & 3 & $\mathbf{2}$ \\
\hline $\mathbf{1 1}$ & 2 & 1 & 2 & $\mathbf{2}$ \\
\hline $\mathbf{1 2}$ & 4 & 1 & $\mathbf{3}$ & \\
\hline $\mathbf{1 4}$ & 4 & 4 & 4 & $\mathbf{4}$ \\
\hline $\mathbf{1 6}$ & 2 & 3 & $\mathbf{3}$ & $\mathbf{3}$ \\
\hline $\mathbf{1 8}$ & 3 & $\mathbf{3}$ & 3 & $\mathbf{3}$ \\
\hline $\mathbf{2 5}$ & 2 & $\mathbf{3}$ & 3 & 3 \\
\hline & & & &
\end{tabular}

Legenda: os valores em azul indicam penetração; os valores em vermelho indicam aspiração

Na tabela 25 também foi realizada a comparação antes da deglutição, com as diferentes consistências e volumes e a comparação entre as consistências e os volumes, do comportamento do traçado. Pode-se observar que a maioria dos pacientes já iniciou com um traçado irregular, mantendo-se assim após a deglutição das consistências e volumes (P0), sendo observado que nem as consistências nem os volumes interferiram neste parâmetro. Esta proporção foi seguida por $\mathrm{P}+$, verificando-se que houve a piora do traçado após a deglutição.

Tabela 25 - Comparação do grau de irregularidade do traçado (em porcentagem) antes da deglutição com as consistências pastosa e líquida e com os volumes de 3 e $7 \mathrm{ml}$; comparação entre as consistências e os volumes

\begin{tabular}{|c|c|c|c|c|c|c|c|c|}
\hline \multicolumn{9}{|c|}{ Traçado } \\
\hline & A, P3 & A, P7 & A, L3 & A, L7 & P3, P7 & L3, L7 & P3, L3 & P7, L7 \\
\hline $\mathrm{P} 0$ & 50 & 46,15 & 50 & 41,66 & 57,69 & 58,33 & 53,84 & 54,16 \\
\hline $\mathrm{P}+$ & 26,92 & 34,61 & 34,61 & 45,83 & 23,07 & 25 & 34,61 & 29,16 \\
\hline $\mathrm{P}-$ & 23,07 & 19,23 & 15,38 & 12,5 & 19,23 & 16,66 & 11,58 & 16,66 \\
\hline
\end{tabular}

Legenda: (A) antes; (P3) pastoso 3ml; (P7) pastoso 7ml; (L3) líquido $3 \mathrm{ml} \mathrm{e} \mathrm{(L7)} \mathrm{líquido} \mathrm{7ml.}$ 


\section{- Convergência}

Para a análise da convergencia foi utilizada uma escala com 5 graus: "forte" convergencia para trajetórias sobrepostas; "forte a média" para pequena convergência das trajetórias sempre observadas na configuração; 3) convergência "média" para trajetórias mais espalhadas, mas que ainda permite distinguir a configuração; 4) convergência "média a fraca" para trajetórias dispersas que desarranjam a configuração; e 5) "fraca" convergência para órbitas muito espalhadas que impossibilitam distinguir a configuração do padrão visual.

\section{- Grupo de Referência}

Neste aspecto, quando analisado antes da deglutição, após a deglutição de $3 \mathrm{ml}$ e $7 \mathrm{ml}$ das consistências pastosa e líquida, observou-se que 80\% (4 indivíduos) dos pacientes foram classificados com forte a média convergência, seguido por $20 \%$ (1 indivíduo) com forte convergência.

Para a convergência, $100 \%$ dos indivíduos permaneceram em P0, na categoria de 0 e 1, não apresentando alteração do espalhamento das órbitas após a deglutição dos diferentes volumes e consistências.

Na figura 20 esta representada o PVDV de um indivíduo do grupo de referência em todos os momentos do exame. 


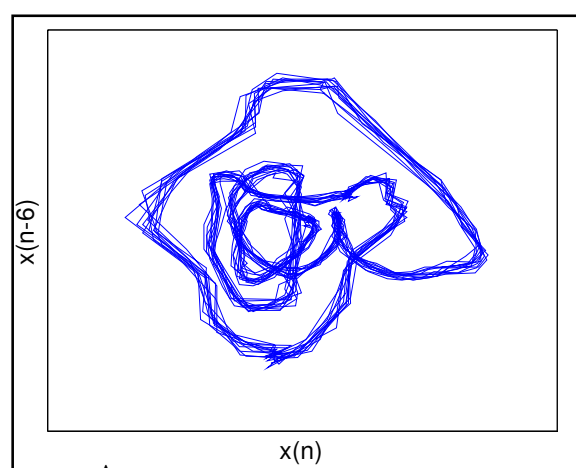

A

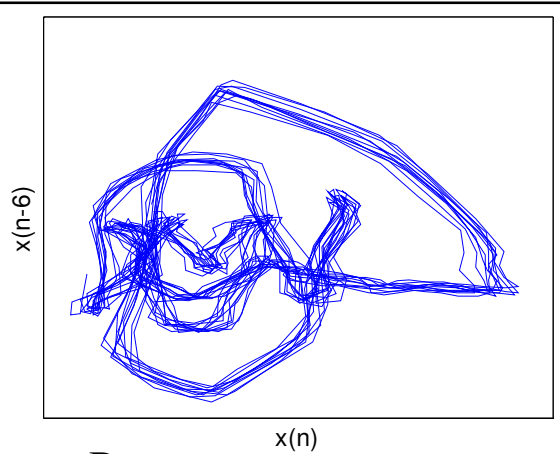

$\mathrm{B}$

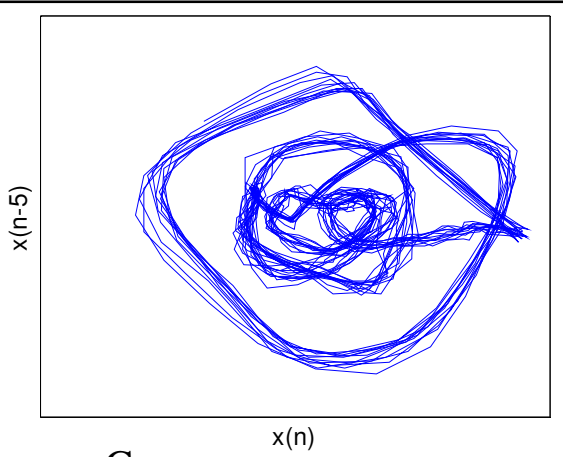

$\mathrm{C}$
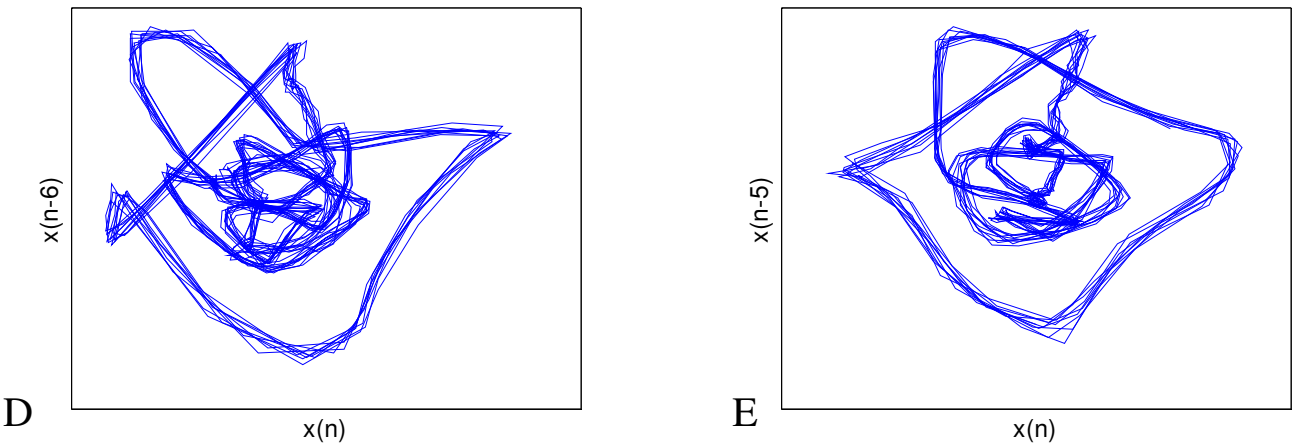

Figura 20 - Padrão Visual da Dinâmica Vocal de um indivíduo do grupo de referência, (A) antes da deglutição; (B) após deglutição de $3 \mathrm{ml}$ de pastoso; (C) após deglutição de $7 \mathrm{ml}$ de pastoso; (D) após a deglutição de $3 \mathrm{ml}$ de líquido e (E) após a deglutição de $7 \mathrm{ml}$ de líquido.

\section{- Grupo de pacientes com alteração neurológica}

Na tabela 26 estão os resultados da convergência do PVDV nos cinco momentos do teste. De acordo com a classificação proposta, nos momentos do teste de antes da deglutição (9 pacientes), após a deglutição de $3 \mathrm{ml}$ (10 pacientes), $7 \mathrm{ml}$ de pastoso (11 pacientes) e líquido $3 \mathrm{ml}$ (9 pacientes), pode-se observar que a maioria dos pacientes estavam na categoria de forte a média convergência, embora a maior parte da amostra esteja classificada em graus de maior alteração. Apenas para $7 \mathrm{ml}$ de líquido que a maior concentração de pacientes esta categorizada em média a fraca convergência (10 pacientes). 
Tabela 26 - Grau de convergência das trajetórias antes da deglutição, após a deglutição de pastoso e de líquido

\begin{tabular}{lcccccccccc}
\hline \multirow{2}{*}{ Convergência } & \multirow{2}{*}{ Antes } & \multicolumn{4}{c}{ Pastoso } & \multicolumn{3}{c}{ Líquido } \\
& & & $\%$ & $3 \mathrm{ml}$ & $\%$ & $7 \mathrm{ml}$ & $\%$ & $3 \mathrm{ml}$ & $\%$ & $7 \mathrm{ml}$ \\
\hline Forte & $3,84 \%$ & 1 & 0 & 0 & $0 \%$ & 0 & 0 & 0 & 10 & 0 \\
\hline Forte a Média & $34,61 \%$ & 9 & $38,46 \%$ & 10 & $42,4 \%$ & 11 & $34,61 \%$ & 9 & $29,16 \%$ & 7 \\
\hline Média & $30,76 \%$ & 8 & $23,1 \%$ & 6 & $7,7 \%$ & 2 & $19,23 \% \%$ & 5 & $20,83 \%$ & 5 \\
\hline Média a Fraca & $26,92 \%$ & 7 & $19,23 \%$ & 5 & $30,76 \%$ & 8 & $30,76 \%$ & 8 & $41,6 \%$ & 10 \\
\hline Fraca & $3,84 \%$ & 1 & $19,23 \%$ & 5 & $19,23 \%$ & 5 & $15,3 \%$ & 4 & $8,33 \%$ & 2 \\
\hline
\end{tabular}

Legenda: valores me vermelho indicam grau de maior concentração de pacientes.

Na tabela 27 foi realizada a comparação antes da deglutição, com as diferentes consistências e volumes, e a comparação entre as consistências e os volumes, observando-se o comportamento da convergência das órbitas. Pode-se observar que quando comparado antes da deglutição com a consistência pastosa e nos volumes de $3 \mathrm{ml}$ e $7 \mathrm{ml}$ e líquida para $7 \mathrm{ml}$, a maioria dos pacientes apresentaram aumento da convergência, já para $3 \mathrm{ml}$ de líquido, o espalhamento manteve-se. Quando comparadas as consistências, todas apresentaram-se em P0 (mantendo a categoria), seguido por P+ (aumento da categoria). Verificou-se que tanto as consistências quanto aos volumes não interferiram neste parâmetro.

Tabela 27 - Grau de comparação da convergência do traçado (em porcentagem) antes da deglutição com as consistências pastosa e líquida e com os volumes de 3 e $7 \mathrm{ml}$; comparação entre as consistências e os volumes

\begin{tabular}{|c|c|c|c|c|c|c|c|c|}
\hline \multicolumn{9}{|c|}{ Convergência } \\
\hline & A, P3 & A, P7 & A, L3 & A, L7 & P3, P7 & L3, L7 & P3, L3 & P7, L7 \\
\hline $\mathrm{P} 0$ & 34,61 & 38,46 & 42,30 & 29,16 & 65,38 & 58,33 & 50 & 62,5 \\
\hline $\mathrm{P}+$ & 46,15 & 42,30 & 38,46 & 45,83 & 19,23 & 25 & 26,92 & 20,83 \\
\hline P- & 19,23 & 19,23 & 19,21 & 25 & 15,35 & 16,66 & 23,07 & 16,66 \\
\hline
\end{tabular}

Legenda: (A) antes; (P3) pastoso 3ml; (P7) pastoso 7ml; (L3) líquido 3ml e (L7) líquido 7ml.

Na tabela 28 estão apresentados somente os pacientes que apresentaram resíduo em hipofaringe classificados quanto à convergência das órbitas. Observou-se que de 44 episódios, 21 apresentaram aumento da convergência, seguido por 13 mantiveram a mesma classificação 
de convergência, e 10 com melhora da sobreposição das orbitas quando apresentam resíduo em hipofaringe.

Tabela 28 - Grau de convergência do traçado dos pacientes com resíduo em hipofaringe

\begin{tabular}{cccccc}
\hline Pacientes & Antes & Pastoso 3ml & Pastoso 7ml & Líquido 3ml & Líquido 7ml \\
\hline 2 & 1 & $\mathbf{2}$ & $\mathbf{3}$ & $\mathbf{2}$ & 3 \\
\hline 3 & 2 & 2 & $\mathbf{1}$ & 1 & 1 \\
\hline 4 & 2 & 1 & $\mathbf{1}$ & $\mathbf{2}$ & $\mathbf{1}$ \\
\hline 5 & 3 & 4 & 4 & $\mathbf{3}$ & 3 \\
\hline 7 & 1 & 3 & $\mathbf{3}$ & 4 & 3 \\
\hline 8 & 4 & $\mathbf{4}$ & 4 & 4 & \\
\hline 10 & 2 & 3 & $\mathbf{3}$ & 3 & $\mathbf{3}$ \\
\hline 11 & 2 & $\mathbf{2}$ & $\mathbf{2}$ & $\mathbf{1}$ & 2 \\
\hline 12 & 1 & $\mathbf{3}$ & $\mathbf{1}$ & 3 & \\
\hline 13 & 1 & 1 & $\mathbf{1}$ & 2 & 3 \\
\hline 14 & 3 & $\mathbf{4}$ & $\mathbf{4}$ & $\mathbf{4}$ & 4 \\
\hline 15 & 2 & $\mathbf{1}$ & $\mathbf{1}$ & $\mathbf{1}$ & $\mathbf{1}$ \\
\hline 16 & 2 & $\mathbf{3}$ & $\mathbf{3}$ & 2 & 3 \\
\hline 17 & 0 & $\mathbf{1}$ & $\mathbf{1}$ & $\mathbf{1}$ & $\mathbf{1}$ \\
\hline 18 & 1 & $\mathbf{1}$ & 1 & $\mathbf{1}$ & 2 \\
\hline 19 & 3 & $\mathbf{4}$ & $\mathbf{2}$ & 3 & $\mathbf{3}$ \\
\hline 22 & 2 & $\mathbf{4}$ & $\mathbf{4}$ & $\mathbf{4}$ & $\mathbf{4}$ \\
\hline 23 & 3 & $\mathbf{3}$ & 3 & $\mathbf{3}$ & $\mathbf{3}$ \\
\hline 24 & 3 & 1 & $\mathbf{4}$ & 1 & 1 \\
\hline 26 & 3 & 1 & $\mathbf{1}$ & 2 & 2 \\
\hline
\end{tabular}

Legenda: os valores de graus em itálica são de pacientes com resíduo.

Na tabela 29, esta a relação de pacientes que apresentaram penetração e/ou aspiração laringotraqueal categorizados quanto à convergência do traçado, verificou-se que para os pacientes com penetração, 3 mantiveram-se na mesma categoria de antes da deglutição e 2 aumentaram a convergência do traçado. Para aspiração laringotraqueal, 3 permaneceram na mesma categorização e 5 aumentaram o espalhamento do traçado. 
Tabela 29 - Grau da convergência do traçado dos pacientes com penetração e/ou aspiração laringotraqueal

\begin{tabular}{ccccc}
\hline \multicolumn{5}{c}{ Convergência } \\
& Antes & P7 & L3 & L7 \\
\hline $\boldsymbol{1}$ & 2 & 3 & 3 & $\mathbf{2}$ \\
\hline $\mathbf{2}$ & 1 & 3 & 2 & $\mathbf{3}$ \\
\hline $\mathbf{5}$ & 3 & 4 & 3 & $\mathbf{3}$ \\
\hline $\boldsymbol{8}$ & 4 & 4 & $\mathbf{4}$ & \\
\hline $\boldsymbol{9}$ & 1 & 1 & 1 & $\mathbf{3}$ \\
\hline $\boldsymbol{1 1}$ & 2 & 2 & 1 & $\mathbf{2}$ \\
\hline $\mathbf{1 2}$ & 1 & 1 & $\mathbf{3}$ & \\
\hline $\mathbf{1 4}$ & 3 & 4 & 4 & $\mathbf{4}$ \\
\hline $\mathbf{1 6}$ & 2 & 3 & $\mathbf{2}$ & $\mathbf{3}$ \\
\hline $\mathbf{1 8}$ & 1 & $\mathbf{1}$ & 1 & $\mathbf{2}$ \\
\hline $\mathbf{2 5}$ & 1 & $\mathbf{3}$ & 3 & 3 \\
\hline
\end{tabular}

Legenda: os valores em azul indicam penetração; os valores em vermelho indicam aspiração

A figura 21 demonstra o padrão visual da dinâmica vocal em amostras de 50 milissegundos cada, antes da deglutição, após a deglutição de $3 \mathrm{ml}$ e $7 \mathrm{ml}$ da consistência pastosa e $3 \mathrm{ml}$ e $7 \mathrm{ml}$ de líquido da paciente de número 2.

Nas figuras A, B e D, verificamos 5 loops e com presença de área de irregularidade no traçado. Em A, as órbitas apresentam-se na classificação de baixa convergência, e nas figuras $\mathrm{B}$ e $\mathrm{C}$ com baixa a média convergência. Em $\mathrm{C}$, as órbitas apresentaram alta convergência, dificultando distinguir a configuração do padrão visual, devido a alteração do shimmer. A figura E apresenta média complexidade, com traçado todo irregular e com baixa a média convergência das órbitas. 


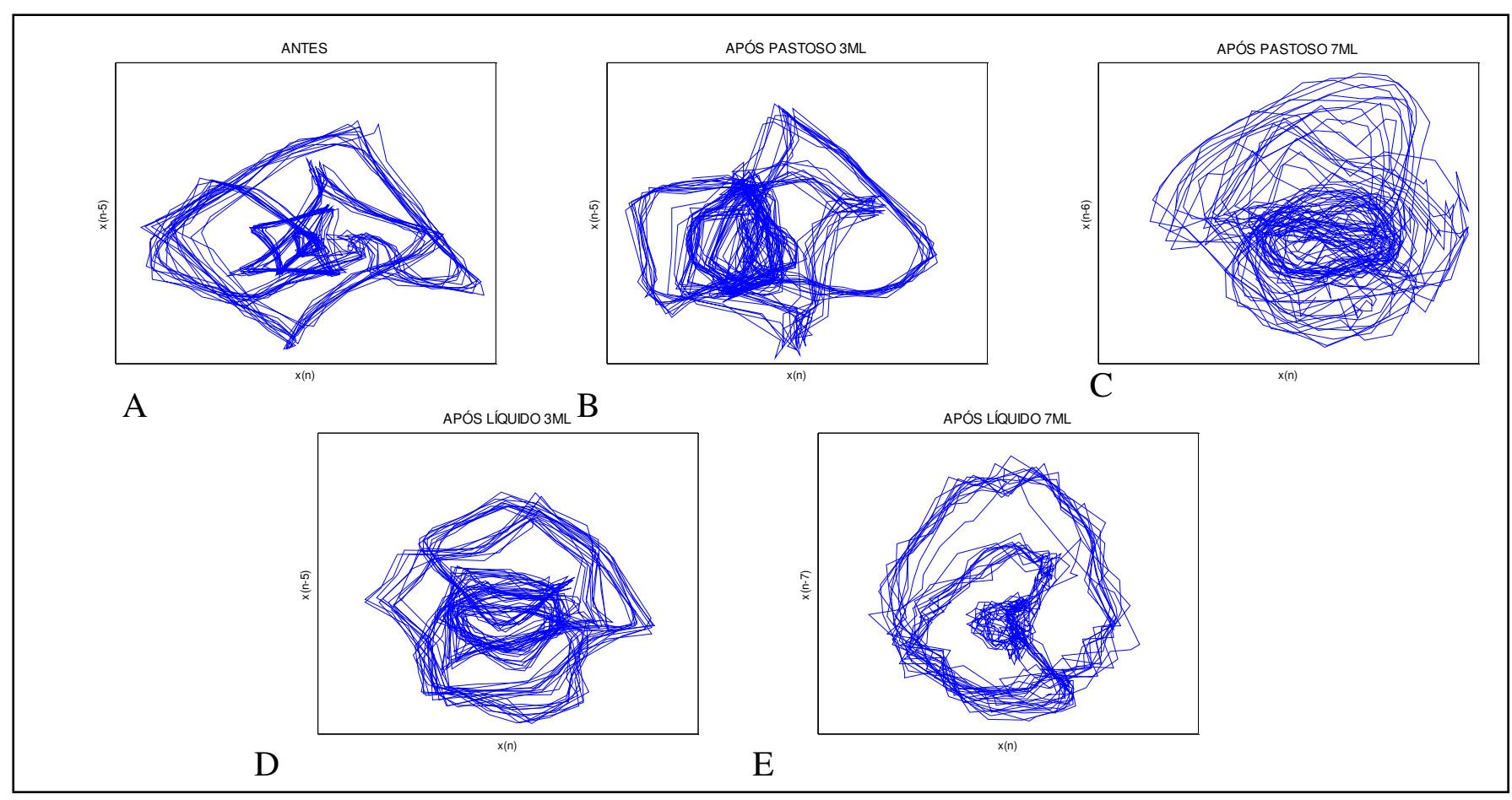

Figura 21 - Padrão Visual da Dinâmica Vocal com amostras de 50 milissegundos; (A) antes da deglutição; (B) após deglutição de $3 \mathrm{ml}$ de pastoso; (C) após deglutição de $7 \mathrm{ml}$ de pastoso; (D) após a deglutição de $3 \mathrm{ml}$ de líquido e (E) após a deglutição de $7 \mathrm{ml}$ de líquido 


\section{5- DISCUSSÃO}

\section{- Videofluoroscopia da deglutição}

A videofluoroscopia é importante devido o esclarecimento da presença de aspiração laringotraqueal ou microaspiração, como também possibilita a observação da dinâmica das estruturas associadas à deglutição durante suas fases (GONÇALVES; VIDIGAL, 1999). É considerada como o padrão ouro para avaliar a aspiração, mas não é universalmente disponível nem apropriada para todos os pacientes (MANN; HANKEY; CAMERON, 2000).

Para Barros et al 2006, é o fonoaudiólogo que através da avaliação clínica, verifica a necessidade da realização de um exame objetivo, e sendo contra-indicando em pacientes com grave estado clínico, nível de consciência rebaixado e/ou com evidências quanto ao risco de aspiração laringotraqueal. Também sendo importante a detecção não somente da aspiração, mas também dos fatores de risco que poderiam contra-indicar a alimentação segura do paciente por via oral (McCOLLOUGH; WERTZ; ROSENBEK, 2001; SILVA; GATTO; COLLA, 2003).

Em indivíduos normais a capacidade para adaptação a viscosidade do bolo garante a segura transferência do bolo direto a faringe sem impedimento (RAUT, MCKEE, JOHNSTON, 2001). A deglutição é influenciada pela consistência, volume e também pela temperatura do bolo deglutido (DANTAS et al, 1990; ADELEYE, 2007), mas também pelas características anatômicas e pela integridade dos músculos e nervos envolvidos (BASS,1997).

O volume contribui fortemente para mudanças na deglutição orofaríngea, incluindo o prolongamento da função da válvula faríngea com o aumento do volume, como também a viscosidade muda o mecanismo da deglutição por aumento na pressão gerada com o aumento da viscosidade do bolo (RADEMAKER, PAULOSKI, COLANGELO;1998).

Raut, McKee e Johnston (2001) referem que indivíduos com disfunção faríngea, o aumento da pressão requerida para a transferência do bolo viscoso pode não ser adequadamente gerada, resultando em resíduo faríngeo e aspiração. Como neste estudo que houve resíduo principalmente em valécula, sendo um estudo realizado com pacientes que 
apresentam alterações neurológicas, onde ocorrem lesões no sistema nervoso central que podem afetar o controle neuromotor da deglutição (ZAFFARI,2004)

Andrade (2004) referiu que com o aumento do volume ofertado, os indivíduos com disfagia pós AVC apresentaram maior dificuldade em realizar a limpeza faríngea acarretando no aumento do resíduo em valéculas e recessos piriformes e, apresentando a fonação sustentada com voz molhada em toda emissão, na parte central da avaliação videoendoscópica da deglutição. Neste estudo a alteração mais relacionada com os pacientes que apresentaram resíduos foi a instabilidade durante a emissão da vogal /a/ sustentada. Para os pacientes com AVC agudo, verifica-se que muitos deles apresentam mais problemas na deglutição de líquido do que de semi-sólidos, assim é essencial avaliar a capacidade de deglutição de semi-sólidos antes do líquido, pois este procedimento passo-a-passo diminui o risco de aspiração durante o teste e identifica pacientes que toleram a ingesta de semi-sólidos e não de líquidos (TRAPL et al. 2007). Esta dificuldade maior com a consistência líquida também foi verificada neste estudo, sendo que para esta consistência houve maior porcentagem de aspiração laringotraqueal.

\section{- Análise perceptivo-auditiva}

Neste estudo, através da análise perceptivo-auditiva, pode-se observar que os parâmetros que apresentaram valores mais alterados foram tensão e instabilidade. Rugosidade e soprosidade não foram detectadas como os aspectos mais desviados da qualidade vocal de pacientes com alteração neurológica.

Em comparação com os achados da videofluoroscopia da deglutição, a tensão e instabilidade foram os parâmetros apresentaram maior correlação com os achados de resíduo e penetração laríngea, concordando com Andrade e Camargo (2000) em que a contração excessiva do trato vocal pode afetar a atividade do sistema supralaríngeo, como tentativa de proteger as vias aéreas, resultando numa qualidade vocal estrangulada. Para Painter (1986), o esforço vocal com constrição supraglótica associado com constrição na fase faríngea da deglutição é encontrado nas alterações vocais com hipertensão, envolvendo a qualidade vocal tensa. A instabilidade é um parâmetro que esta relacionado com a idade e em pacientes com alterações neurológicas (CARRARA-DE-ANGELIS, 2002); pois indica que há uma redução 
na estabilidade de emissão vocal em função das modificações musculares, teciduais e do sistema respiratório (LINVILLE,1996).

Rambaldi (1998) também refere que um gesto motor alterado, como a projeção anterior de língua nas deglutições atípicas, podem contribuir com o aumento da tensão muscular na laringe, provocando um desequilíbrio funcional e um sistema hipercinético, atuando especificamente na coaptação entre as pregas vocais e na pressão sub-glótica.

Para um possível mecanismo de proteção de aspiração, ocorreria a hiperconstrição da musculatura intrínseca da laringe acarretando a maior aproximação das pregas vestibulares, o que permitiria o fechamento supraglótico, protegendo as vias aéreas da aspiração. Tendo como resultado desta constrição excessiva as alterações das características vocais, (FURKIM et al., 1998).

A soprosidade e o estrangulamento, no estudo de Andrade e Camargo (2004), tornaram-se mais intensos ao final do exame, e também aumentaram após a aspiração, podendo indicar que as estruturas das vias aéreas digestivas superiores levaram um tempo para a recuperação da atividade habitual; de forma que a ausência de umidade na voz não significa que as estruturas tenham retomado seu padrão habitual de atividade.

Neste estudo a qualidade vocal molhada foi considerada em alguns pacientes que apresentaram resíduo, penetração e/ou aspiração laringotraqueal, podendo-se concordar com Vale-Prodomo, Carrara-de-Angelis e Barros (2009) que referem que as secreções não necessariamente estão localizadas sobre as pregas vocais, mas podem estar em todo trato vocal, caracterizando a produção vocal como "molhada". Para Murray et al (1996), o acúmulo de secreção no vestíbulo laríngeo produz a qualidade vocal molhada. E segundo Kendall, Leonard ( 2001) com a identificação de voz molhada, o clínico deve estar atento aos sinais de redução da freqüência de deglutição combinada com a fraqueza faríngea, como também deve prestar atenção à pobre limpeza faríngea após sua constrição incompleta.

No estudo de Warns, Richards e GradDip (2000), os resultados não contra-indicam completamente a noção de que a voz molhada é importante, mas que pode ser um indicador de que há risco de aspiração de algum material que permaneceu na região cervical.

Na pesquisa desenvolvida por Warns e Richads (2000), verificando a relação da presença de voz molhada na laringe ou traquéia com penetração e/ou aspiração após a 
videofluoscopia da deglutição, revelou que não houve associação da voz molhada com resíduo ou ingestão de material na área orofaríngea. Não sendo a voz molhada considerada como indicativa para a detecção de penetração e/ou aspiração laringotraqueal, argumentandose que a qualidade "úmida" poderia ser um sinal de estase de saliva e/ou secreção na via aérea e não indicativo de bolo alimentar na mesma. Os autores salientaram que a dúvida ainda permanece, questionando qual condição fisiológica causaria a característica da voz molhada. Vale-Prodomo, Carrara-de-Angelis e Barros (2009), referem que a presença de secreção ou saliva durante a produção vocal é outro fator importante a ser observado, pois é o que caracteriza a qualidade vocal "molhada".

Segundo Andrade e Camargo (2000), a entrada de alimento nas vias aéreas afeta a atividade do sistema respiratório, prejudicando o suprimento aéreo necessário para desencadear os mecanismos de ação laríngea, o que favorece a redução de loudness vocal, com produção de voz astênica, e escape maior de ar, com produção de voz soprosa, o que não foi observado neste estudo como um parâmetro sensível para evidenciar estas alterações.

Andrade (2004) inferiu que a queda da freqüência fundamental sofreu maior influência com a penetração laríngea do que com a aspiração. Assim, o alimento nas pregas vocais ou acima destas, perturba diretamente a atividade das pregas vocais, e que neste estudo aspecto mais sensível da análise perceptivo-auditiva foi a rugosidade nos pacientes que apresentaram aspiração laringotraqueal.

Os indivíduos com disfagia pós AVC desempenham mobilizações no plano laríngeo (fonatório) e supralaríngeo (articulatório) como mecanismo de proteger das vias aéreas durante a fonação semelhante à fisiologia da fase faríngea da deglutição e da produção dos sons faríngeos. Assim, os sinais clínicos do comportamento vocal (voz molhada associada com um conjunto de ajustes da qualidade vocal) foram relevantes para hipóteses relacionadas à presença de resíduos de bolo alimentar ou de estase salivar na região glótica e/ou supraglótica, penetração laríngea e risco de aspiração (ANDRADE, 2004). 


\section{- Análise acústica tradicional}

Os achados da análise acústica tradicional demonstraram que as amostras não apresentaram diferença estatisticamente significativa, quando analisadas entre as consistências pastosa e líquida e nos volumes de $3 \mathrm{ml}$ e $7 \mathrm{ml}$, para os parâmetros de Fo, jitter e shimmer.

Carrara-de-Angelis (2000) caracterizou os aspectos vocais laríngeos, bem como correlacionou os achados das avaliações clínica fonoarticulatória, acústica da voz, laringoestroboscópica e videofluoroscópica da deglutição em 24 pacientes com Doença de Parkinson, verificando-se que as medidas de perturbação da freqüência fundamental mostraram associação significante com penetração laríngea. De modo contrario em nosso estudo esta associação não foi observada, isto pode ter sido devido ao tipo de programa de análise utilizado ou a diversidade de patologias contempladas.

No estudo de Andrade e Camargo (2004), realizado com dois indivíduos, os valores de shimmer mostraram uma grande variação após a aspiração laringotraqueal, e para o jitter uma grande variação após a aspiração e no pré-exame; mas os autores referem que ambos os parâmetros são utilizados para sinais de voz normais e às vezes sinais com pequenos indícios de aperiodicidade e, portanto não auxiliam para o estudo de vozes patológicas. A aperiodicidade do sinal está relacionada à não linearidade na voz humana que tem sido atribuída à tensão (propriedades viscoelásticas dos tecidos) das pregas vocais, a não linearidade associada com a colisão das pregas vocais e a não linearidade da pressão do fluxo na glote (TITZE, 1993).

\section{- Padrão visual da dinâmica vocal}

Segundo Titze (1995) e Karnel (1997) os parâmetros tradicionais de análise como jitter e shimmer que têm sido empregados, parecem ser imprecisos para analisar vozes aperiódicas, e que segundo Titze (1995) as técnicas não-lineares se apresentam como ferramentas promissoras para analisar sinais com aperiodicidade como é o sinal de voz.

Com relação à análise do padrão visual da dinâmica vocal, neste estudo pode-se verificar o comportamento de toda a amostra através da presença de irregularidades no traçado, alteração no número de loops e na convergência das órbitas, pois esta ferramenta nos 
possibilita visualizar de forma dinâmica o sinal de voz, analisando-o ponto a ponto, o qual apresenta melhor resolução quando comparada com a análise acústica, que é realizada através dos valores médios do sinal que muitas vezes mascaram os resultados.

Os dados de análise acústica tradicional são, em alguns casos, insuficientes para refletir à dinâmica do sinal de voz. Já a técnica de reconstrução do espaço de fase como uma ferramenta de análise do sinal vocal, possibilita visualizar dados que ficam encobertos nos cálculos de outras ferramentas através de padrões visuais. Utilizando esta técnica podemos visualizar parâmetros acústicos convencionais como jitter e shimmer (DAJER, 2006).

Dajer, Pereira e Maciel (2005) referem que em sinais de voz com jitter elevado apresentam - em um plano bidimensional - trajetórias que mudam de direção sobre elas mesmas mostrando-se alternativamente dispersas e concentradas em algumas regiões do PVDV. Os autores também referem que um sinal de voz periódico produz o espaço de fase com trajetórias fechadas, quando o sinal é aperiódico observamos irregularidades e trajetórias confusas. Comparando com este estudo, a maioria das vozes dos pacientes com alteração neurológica, foram classificadas na categoria de irregularidade intermitente, devido a presença de ruído nos sinais, assim também como foram classificadas com convergência de média a fraca devido a alteração de shimmer.

No estudo de Rahn et al. (2005), os achados da análise da dinâmica não linear nos sujeitos com doença de Parkinson apresentaram um significativo aumento dos valores do jitter em relação ao grupo controle.

Na análise do PVDV do grupo de referência, observou-se categorização de 3 a 4 loops; na convergência, a maioria dos indivíduos permaneceram em forte a média convergência, sendo ambos os aspectos com 100\% em P0. Para o aspecto da regularidade do traçado houve maior variação das classificações, pois indivíduos com leve alteração (grau 1) de soprosidade, tensão e/ou instabilidade, causam alteração na regularidade do traçado, possibilitando ser visualizado no PVDV discretas mudanças percebidas pela análise perceptivo-auditiva.

Na comparação do PVDV antes e após a administração dos diferentes volumes e consistências, observou-se que a classificação do número de loops antes da deglutição manteve-se no grau 3, modificando-se para grau 0 após a ingestão de diferentes volumes e 
consistências, observando-se perda da complexidade. Para a regularidade do traçado, antes da deglutição a maioria dos PVDV foram classificados com irregularidade intermitente, mantendo-se assim após a administração dos alimentos. Para a convergência, a maioria dos pacientes foram classificados com forte a média convergência antes da deglutição, após $3 \mathrm{ml}$ e $7 \mathrm{ml}$ de pastoso e $3 \mathrm{ml}$ de líquido; com média a fraca em $7 \mathrm{ml}$ de líquido, observando-se que 4 pacientes apresentaram aspiração laringotraqueal, alteração do shimmer, geralmente com a presença de ruído na emissão vocal e descritos perceptivamente como rouquidão e soprosidade (DAJER,2006). Desta forma perturbações da freqüência como shimmer e jitter, assim também como características perceptivas como a rouquidão e a soprosidade encontram seu correlato visual na análise dos PVDV.

Na relação da videofluoroscopia da deglutição com o PVDV, a convergência mostroualteração na maioria dos pacientes que apresentaram resíduo. Para os pacientes com penetração laríngea, houve um menor número de loops evidenciando a menor complexidade do sinal; e para a aspiração laringotraqueal as categorizações do número de loops e convergência caracterizaram melhor esta alteração. A regularidade do traçado pode não ter apresentado muita variação, pois as vozes analisadas já apresentavam alteração significativa antes da oferta das consistências, sendo observado na análise perceptivo-auditiva, alterações como rugosidade, soprosidade, tensão ou instabilidade, provocando irregularidades evidenciadas no PVDV.

Para possibilitar a leitura do PVDV, como é realizada no eletrocardiograma, são necessários mais estudos, para permitir a caracterização das alterações observadas neste método, como também ser incorporado como uma ferramenta utilizada em consultórios, hospitais, entre outros, para a análise do sinal de voz, auxiliando na avaliação e acompanhamento dos pacientes com disfagia. 


\section{6- CONCLUSÃO}

- Na análise perceptivo-auditiva, as classificações de tensão e instabilidade apresentaram-se como os mais sensíveis dos cinco aspectos utilizados, quando verificada a presença de resíduo e penetração laríngea. Em relação à aspiração laringotraqueal, o aspecto da rugosidade também apresentou-se mais sensível;

- A qualidade vocal molhada mostrou-se como um indicativo de penetração laríngea, aspiração laringotraqueal e principalmente de resíduo alimentar;

- A análise acústica tradicional não apresentou diferença estatisticamente significativa quanto aos volumes de $3 \mathrm{ml}$ e $7 \mathrm{ml}$ e as consistências pastosa e líquida;

- Na análise qualitativa dos PVDV verificou-se que na comparação das consistências e volumes, não apresentam alteração na classificação, podendo-se considerar que a deglutição de diferentes consistências e volumes não interferem na qualidade vocal.

- Na comparação antes da deglutição com após a deglutição dos volumes e consistências, observou-se que ocorre a diminuição do número de loops evidenciando a menor complexidade do sinal de voz.

- Para a regularidade do traçado, podemos verificar que antes da administração do alimento o traçado já se apresentava em categorias mais alteradas mantendo-se no mesmo patamar após a administração do alimento; e para convergência, o espalhamento foi maior apenas para $7 \mathrm{ml}$ de líquido.

- Na análise do padrão visual da dinâmica da voz observou-se que os aspectos mais sensíveis para as alterações apresentadas na videofluoroscopia foram:

- Para presença de resíduo, a maior parte dos pacientes apresentaram aumento da convergência;

- Para penetração laríngea, o aspecto que apresentou maior modificação foi o número de loops, ocorrendo a diminuição deles e a conseqüente diminuição da complexidade do sinal;

- Para aspiração laringotraqueal, diminuição do número de loops e aumento da convergência. 
- Os resultados mostraram que nas vozes do grupo de referência, discretas alterações verificadas na análise perceptivo-auditiva podem ser visualizadas pelo padrão visual da dinâmica vocal através da convergência das órbitas e/ou regularidade do traçado.

- O PVDV apresenta-se como uma técnica que possibilita a visualização ponto a ponto das alterações do sinal de voz. A análise qualitativa dos PVDV associada à análise perceptivo-auditiva e a videofluoroscopia da deglutição fornece informações representando uma ferramenta não-invasiva e útil para a avaliação e clínica fonoaudiológica para pacientes com transtornos neurológicos.

\section{Sugestões para trabalhos futuros:}

a) Caracterizar os padrões visuais da dinâmica vocal conforme a alteração evidenciada na videofluoroscopia;

b) Realizar a análise com grupos de pacientes com o mesmo diagnóstico médico. 


\section{7- REFERÊNCIAS BIBLIOGRÁFICAS}

ABOOFAZELI, M.; MOUSSAVI, Z. Analysis and classification of swallowing sounds using reconstrucyed phase space features. IEEE, p. 421-424, 2005.

ADELEYE B, RACHEL C. Comparison of the rheological properties of ready-to-serve and powdered instant food-thickened beverages at different temperatures for dysphagic patients. $\mathbf{J}$ Am Diet Assoc.;107, 2007, p.1176-82.

ALMEIDA, S. T. Detecção dos sons da deglutição através da ausculta cervical. In: JACOBY, J. S.; LEVY, D. S.; SILVA, L. M. C. Disfagia: avaliação e tratamento. Rio de Janeiro: Revinter, 2004. p. 373-381.

ANDRADE, L. M. O. Determinação dos limiares de normalidade dos parâmetros acústicos da voz. 2003. 63f. Dissertação (Mestrado em Bioengenharia) - Escola de Engenharia de São Carlos, Universidade de São Paulo, São Carlos, 2003.

ANDRADE, L. G. C. Estudo da correlação entre qualidade vocal e disfagia pós-acidentes vascular cerebral: aspectos acústicos, fisiológicos e perceptivos. 2004. 155f. Dissertação (Mestrado em Linguistica Aplicada a Estudos da Linguagem) - Universidade Católica de São Paulo, São Paulo, 2004.

ANDRADE, L. G. C; CAMARGO, Z. Estudo preliminar da relação entre qualidade vocal e disfagia - uma abordagem acústica. [trabalho de conclusão de curso]. São Paulo: pontifícia Católica de São Paulo; 2000.

ANDRADE, L. G. C.; CAMARGO, Z. Estudo preliminar da relação entre qualidade vocal e disfagia - uma abordagem acústica. In: JACOBY, J. S.; LEVY, D. S.; SILVA, L. M. C. Disfagia: avaliação e tratamento. Rio de Janeiro: Revinter, 2004. p. 345-364.

ANDRADE, M. O. et al. Medidas de perturbação da voz: um novo enfoque. Revista Fonoaudiologia, v.2, n.2, p. 39-46. dez. 2002. 
ARVEDSON, J. C. Oral motor and feeding assessment. In: ARVEDSON, J. C.; BRODSKY, L. Pediatric swallowing and feeding: assessment and management. San Diego: Singular Publishing Group, Inc, 1993. p. 249-292.

BAER, T. Vocal jitter: A neuromuscular explanation. In: Transcripts of the eighth symposium: Care of professional voice (Part II). New York: The voice foundation, 1979. p. 19-22.

BARROS, A. P. B; CARRARA-DE-ANGELIS, E. Análise acústica da voz. In: DEDIVITIS, R. A; BARRoS, A. P. B. Métodos de Avaliação e Diagnóstico de Laringe e Voz. São Paulo: Lovise, 2002. p. 200-221.

BARROS, A. F. F.; OKUBO, P. C. M. I.; DOMENIS, D. R.; RICZ, H. M.; MELLO-FILHO, F. V. Comparação entre a avaliação clínica e objetiva da deglutição em pacientes com disfagia orofaríngea neurogênica. Revista da Sociedade Brasileira de Fonoaudiologia, v. 11, n. 2, p. 90-95, 2006.

BASS, N.H. The neurology of swallowing. In: Groher ME, editor. Dysphagia-diagnosis and management. 3rd ed. Boston: Butterworth- Heinemann; 1997. p. 7-35.

BEHLAU, M.; TOSI, O.; PONTES, P. Determinação da frequiência fundamental e suas variações em altura (jitter), em intensidade (shimmer) para falantes do português brasileiro. Acta AWHO, v. 4, p. 5-9, 1985.

BOSMA, J. F. Development and impairment of feeding in infancy and childhoad. In: GHROHER, M. Dysphagia: diagnosis and management. 3 ed. London: ButterworthHeinemann, 1997.

BRANCATISANO, A.; DODD, D. S.; ENGEL, L. A. Posterior cricoarytenoid activity and glottic size during hyperpnea in humans. J. Appl. Physiol, v. 71, p. 977-982, 1991.

BUCHHOLZ, D. W. Neurogenic dysphagia: what is the cause when the cause is not obvious? Dysphagia, v. 9, p. 245-55, 1994. 
CARRARA-DE-ANGELIS, E. Deglutição, configuração laríngea, análise clínica e acústica computadorizada da voz de pacientes com Doença de Parkinson. 2000. 144f. Tese (Doutorado em Fonoaudiologia) - Escola Paulista de Medicina, São Paulo, 2000.

CARRARA-DE-ANGELIS, E. Disartrofonias (Avaliação dos componentes funcionais do mecanismo de produção fonoarticulatória). In: DEDIVITIS RA, BARROS APB. Métodos de avaliação e diagnóstico de laringe e voz. São Paulo: Lovise; 2002. p.223-39.

CARRARA-DE-ANGELIS, E.; CERVANTES, O.; ABRAHÃO, M. Necessidades de medidas objetivas da função vocal: avaliação acústica da voz. In: FERREIRA, L. P.; COSTA, H. O. Voz Ativa - falando sobre a clínica fonoaudiológica. São Paulo: Roca, 2001, p. 5372.

CERVANTES, O. Doenças neurológicas. In: DEDIVITIS, R. A; BARROS, A. P. B. Métodos de Avaliação e Diagnóstico de Laringe e Voz. São Paulo: Lovise, 2002, p. 145-175.

CLARK, L. W. Communication disorders: What to look for, and when to refer, Geriatrics, v. 449. p. 51-57, 1994.

COLTON, R. H.; CASPER, J. K. Compreendendo os problemas de voz: uma perspective fisiológica ao diagnóstico e ao tratamento. São Paulo: Artes Médicas Sul Ltda, 1990.

COLTON, R. H.; REED, G.; SAGERMAN, R.; CHUNG, C. An investigation of voice change after radiotherpy. Grant, National Cancer Institute. National Institutes of Health, Bethesda, 1982.

COSTA, M. M. B.; NOVA, J. L. L.; CARLOS, M. T.; PEREIRA, A. A.; KOCH, H. A. Videofluoroscopia: um novo método. In: MACEDO FILHO, E.; PISANI, J. C.; CARNEIRO, J.; GOMES, G. Disfagia: abordagem multidisciplinar. 3.ed.,São Paulo: Frontis, 1999, p. 85-99.

COTES, C. S. G; SILVA, A. A; MELO, L. G; BEHLAU, M. Análise da constrição do vestíbulo laríngeo em diferentes alterações das pregas vocais. In: BEHLAU, M. A voz do especialista. Rio de Janeiro: Revinter, 2001. p. 183-190. 
DAJER, M. E. Padrões visuais de sinais de voz através da técnica de análise não linear. 2006. 103f. Dissertação (Mestrado em Bioengenharia) - Universidade de São Paulo, Campus São Carlos, 2006.

DAJER, M. E.; PEREIRA, J. C.; MACIEL, C. D. Nonlinear dynamical analysis of normal voices. In: Seventh Ieee International Symposium on Multimedia. 2005, Irvine, Ca, USA, IEEE Computer Society, p. 765-771.

DANTAS RO, KERN MK, MASSEY BT, DODDS WJ, KAHRILAS PJ, BRASSEUR JG, et al. Effect of swallowed bolus variables on oral and pharyngeal phases of swallowing. Am J Physiol.258, 1990,p. 675-81.

DAVIS, S. B. Acoustic characteristics of normal and pathological voices. Academic Press Inc, Santa Barbara, CA, 1976.

DAVIS, S. B. Acoustic characteristics of normal and pathological voices. In: LASS, N. J. Speech and Language: Advances in basic research and pratice, New York: Academic Press. v. 1, 1979, p. 271-335.

DE BODT, M.; WUYTS, F. L.; VAN DE HEYNING, P. H. Test-retest study of the GRBAS scale: influence of experience and professional back ground on perceptual rating of voice quality. J. Voice, v. 11, p. 74-80, 1997.

DE PAUlA, A.; BOTELHO, I.; SILVA, A. A.; REZENDE, J. M. M.; FARIAS, C.; MENDES, L. Avaliação da disfagia pediátrica através da videoendoscopia da deglutição. Rev. Bras. Otorrinolaringol, v. 68, n. 1, São Paulo, 2002.

DEDIVITIS, R. A. Anatomia da Laringe. In: DEDIVITIS, R. A; BARROS, A. P. B. Métodos de Avaliação e Diagnóstico de Laringe e Voz. São Paulo: Lovise, 2002, p. 6-37.

DEDIVITIS, R. A.; BARROS, A. P. B. Fisiologia laríngea. In: DEDIVITIS, R. A.; BARROS, A. P. B. Métodos de Avaliação e Diagnóstico de Laringe e Voz. São Paulo: Lovise, 2002, p. 39-52. 
ESTRELA, F., MOTTA, L., ELIAS, V. S. Deglutição e processo de envelhecimento. In: In: JOTZ, G. P.; CARRARA-DE-ANGELIS, E.; BARROS, A. P. B. Tratado de deglutição e disfagia. Rio de Janeiro: Revinter, 2009, p.54-58.

EKBERG, O.; OLSSON, R. Dynamic radiology of swallowing disorders. Endoscopy, v. 29, p. 439-446, 1997.

FURKIM, A. M.; MATTANA, A. Fisiologia da deglutição orofaríngea. In: FERREIRA, L. P.; BEFI-LOPES, D. M.; LIMONGI, S. C. Tratado de Fonoaudiologia, São Paulo: Roca, 2004, p. 212-218.

FURKIM AM, PELAS S, MARIQUE D, CHIARI B, PERISSINOTO J. Disfagia e Disatrofonia pós AVCI: Relato de um caso. Revista de Atualização Científica Pró-Fono, 10(2),1998. p. 3-7.

FURKIM, A. M.; SILVA, R. G. Programa de reabilitação em disfagia neurogênica. São Paulo: Frôntis Editorial, 1999. p. 51.

GIOVANI, A.; OUAKNINE, M.; TPING YU, B. G.; ZANARET, M.; TRIGLIA, J. M. Nonlinear Behavior of Vocal Fold Vibration: The Role of Coupling Between the Vocal Folds. Journal of Voice, v. 13, n. 4, p. 465-476, 1998.

GOLDBERGER. A. L. Non-linear dynamics for clinicians: chaos theory, fractals, and complexity at the bedside. The Lancet, p. 1312-14, 1996.

GONÇALVES, M. I. R.; VIDIGAL, M. L. N. Avaliação videofluoroscópica das disfagias. In: FURKIM, A. M.; SANTINI, C. S. Disfagias Orofaríngeas. Carapicuiba: Pró-fono, 1999. p. 61-96.

HECKER, M. H.; KREUL E. J. Descriptions of the speech f patients with câncer of the vocal folds. Measures of the fundamental frequency. J Acoust Soc Am, v. 49, p. 1275-1282, 1971.

HEGGER, R.; KANTZ, H.; SCHEREIBER, T. Practical implementation of nonlinear time series methods: The TISEAN package. Chaos, v. 9, n. 2, p. 413-435, 1999. 
HERZEL, H.; BERRY, D.; Analysis of vocal disorders with methods from nonlinear dynamics. J Speech Hear Res, v. 37, p. 1008-1019, 1994.

HOLLIEN, H.; DEW, D.; PHILIPS, P. Phonational frequency ranges of adults. J Speech Hear Res, v. 14, p. 755-760, 1971.

ISOLA, A. M. Complicações no sistema respiratório do paciente disfágico. In: FURKIM, A. M.; SANTINI, C. S. Disfagias orofaríngeas. Carapicuiba: Pró-fono, 1999. p. 157-169.

JIANG, J. J; ZHANG, Y.; MCGILliGAN, C. Chaos in Voice, From Modeling to Measurement. Journal of Voice, v. 20, p. 2-17, 2006.

KARNELL, M. P.; CHANG, A.; SMITH, A.; HOFFMAN, H. Impact of signal type on validity of voice perturbation measures. NCVS Status and Progress Report, v. 11, p. 91-94. 1997.

KAWASAKI, A.; FUKUDA, H.; SHIOTANI, A.; KANZAKI, J. Study of movements of individual structures of the larynx during swallowing. Auris Nasus Larynx, v. 28, p. 75-84. 2001.

KENDALL, K., LEONARD, R.J. Pharyngeal constriction in elderly dysphagic patients compared with young and elderly nondysphagic controls. Dysphagia, 16, p. 272-278.2001.

KILMAN, W. J; GOYAL, R. K. Disorders of pharyngeal and upper esophageal sphincter motor function. Arch Int Med, p. 136-592, 1976

KOIKE, Y. Application of some acoustic measures for the evaluation of laryngeal dysfunction. Studia Phonologica, v. 7, p. 17-23, 1973.

KOWACS, P. A. Causas neurológicas de disfagia em adultos. In: MACEDO-FILHO, E.; PISANI, J. C.; CARNEIRO, J.; GOMES, G. Disfagia: Abordagem multidisciplinar. 2 ed., São Paulo: Frôntis, 2000. p. 11-18. 
KROM, G. Consistency and Reability of Voice Quality Ratings for Different Types of Speech Fragments. Journal of Speech and Hearing Research, v. 37, p. 985-1000, 1994.

KUMAR, A.; MULliCK, S. K. Nonlinear dynamical analysis of speech. J. Acoust. Soc. America, v. 100, n. 1, p. 615-629, 1996.

LAVER, J. The phonetic description of voice quality. Cambridge University Press, Cambridge, 1980.

LINDEN, P.; KUHLEMEIER, K. V.; PATTERSON, C. The probability of correctly predicting subglottic penetration from clinical observations. Dysphagia, v. 8, p. 170-179. 1993.

LINDEN, P.; SIEBENS, A. A. Dysphagia: predicting laryngeal penetration. Arch Phys Med Rehabil, v. 64, p. 281-284. 1983.

LINVILLE SE. The Sound of Senescence. J Voice. 10(2), p. 190-200.1996.

LORENZ, E. N. Deterministic no periodic flow. J Atmos Sci, v. 20, p. 130, 1963.

LUDLOW, C. L. Central nervous system control $f$ the laryngeal muscles in humans. Respiratory physiology \& Neurobiology, v. 147, p. 205-222, 2005.

MACEDO FILHO, E. D. Conceitos e fisiologia aplicada da deglutição. In: MACEDO FILHO, E. D.; PISANI, J. C.; CARNEIRO, J. E.; GOMES, G. Disfagia: abordagem multidisciplinar. 3. ed. Rio de Janeiro: Frontis, 1999. p. 3-8.

MANN, G.; HANKEY, G. J.; CAMERON, D. Swallowing disorders following acute stroke: prevalence and diagnostic accuracy. Cerebrovascular Disease. v. 10, p. 380-386, 2000. 
MARCHESAN, I. Q. O que se considera normal na deglutição. In: JACOBY, J. S.; LEVY, D. S.; SILVA, L. M. C. Disfagia: avaliação e tratamento. Rio de Janeiro: Revinter, 2004. p. 317.

McCUlLOUGH, G. H.; WERTZ, R. T.; ROSENBEK, J. C. Sensitivity and specificity of clinical/bedside examination signals for detecting aspiration in adults subsequent to stroke. Journal of Communication Disorders. v.34, p. 55-72, 2001.

MCKAIG, T. N. Ausculta - cervical e torácica. In: FURQUIM, A. M.; SANTINI, C. S. Disfagias orofaríngeas. Carapicuíba: Pró-Fono, 1999. p. 171-187.

MENEGHELLI, U. G.; OLIVEIRA, R. B.; FERNANDES, M. I. M. Organização, regulação e desenvolvimento das atividades motoras do tubo digestivo. In: BARBIERE, D.; KODA, Y. K. L. Doenças gastroenterológicas em Pediatria. São Paulo: Atheneu, 1996. p. 1-15.

MIRRETT, P. L.; RISKI, J. E.; GLASCOTT, J.; JOHNSON, V. Videofluoroscopic assessment of dysphagia in children with severe spastic cerebral palsy. Dysphagia, v. 9, n. 3, p. 174-9, 1994.

MONTAGNOLI, N. A. Análise Residual do sinal de voz. 1998. Dissertação -Universidade de São Paulo, Campus de São Carlos. 1998.

MONTAGNOLI, A. N. Software: Voice Analysis. São Carlos, 2009.

MURRAY, J.; LANGMORE, S. E.; GINSBERG, S.; DOSTIE, A. The significance of oropharyngeal secretions and swallowing frequency in predicting aspiration. Dysphagia, 11:99-103, 1996.

NIETO, A.; DEL PALACIO, A. J.; LORENZO, A. J.; VEGAS, A.; COBETA, I. Los ordenadores en el análises de la voz: aplicaciones clínicas. Acta Otorrinolaringologica Española. v. 46, n. 4, p. 241-245, 1995.

OLIVEIRA, M. C. B. Atendimento hospitalar ao paciente disfágico. In: OLIVEIRA, S. T. Fonoaudiologia hospitalar. São Paulo: Lovise, 2003. p. 117-122. 
PACKARD, N. H.; CRUTCHFIELD, J. P.; FARMER, J. D.; SHAW, R. S. Geometry from a time series. Phys Rev Lett, v. 45, p. 712, 1980.

PAINTER, C. The laryngeal vestibule and voice quality. Arch Otorhinolaryngol, v. 243, p. 329-337, 1986.

PILZ, W. Distúrbios da deglutição na infância. Monografia apresentada ao CEFAC para obtenção do título de especialista em Motricidade Oral, Porto Alegre, 1999.

QUINTEllA, T.; SILVA, A. A.; BOTELHO, M. I. M. R. Distúrbio da deglutição (e aspiração) na infância. In: FURKIM, A. M; SANTINI, C. S. Disfagias orofaríngeas. Carapicuíba: Pró-Fono, 1999. p. 61-96.

RABINER, L. R.; JUANG, B. H. Fundamentals of Speech Recognition. Prentice Hall Inc., 1993.

RADEMAKER, A.W., PAULOSKI, B.R., COLANGELO, L.A. Age and volume effects on liquid swallowing function in normal women. J Speech Lang Hear Res, 41, p.275-284. 1998

RAHN, D. A.; CHOU, M.; JIANG, J. J; ZHANG, Y. Phonatory Impairment in Parkinson's Disease: Evidence from Nonlinear Dynamic Analysis and Perturbation Analysis. Journal of Voice, v. 21, p. 64-71. 2005.

RAMBALDI, L. B. Estudo comparativo do comportamento laríngeo: na deglutição alterada e não-alterada. Dissertação. São Paulo, Universidade Federal de São Paulo Escola Paulista de Medicina, 1998.

RAUT, V.V; MCKEE, G.J; JOHNSTON, B.T. Effect of bolus consistency on swallowing does altering consistency help? Eur Arch Otorhinolaryngol, 258,p.49-53. 2001

ROTH, E. J.; HARVEY, R. L. Rehabilitation of stroke syndromes. In: BRADDON, R.L. Physical Medicine \& Rehabilitation. 2 ed., Philadelphia: W. B. Sanunders, v. 60, 2000. p. 1.117. 
RYU, J. S; PARK, S. R; CHOI, K. H. Prediction of laryngeal aspiration using voice analysis. Am J Phys Med Rehabil, v. 83, n. 10, p. 757-7, oct. 2004.

SANTINI, C. S. Disfagia neurogênica. In: FURKIM, A. M.; SANTINI, C. S. Disfagias orofaríngeas. Carapicuiba: Pró-fono, 1999. p. 19-34.

SASAKI, C. T.; ISAACSON, G. Functional anatomy of the larynx. Otolaryngol. Clin North Am, v. 21, p. 196-9, 1988.

SCALASSARA, P. R.; DAJER, M. E.; MACIEL, C. D.; GUIDO R. C.; PEREIRA, J. C. Relative entropy measures applied to healthy and pathological voice characterization. Applied Mathematics and Computation, v. 10, p. 1-17, nov. 2007.

SHAKER, R.; REN, J.; PDVRSAN, B. et al. Effect of aging and bolus variables on pharyngeal and upper esophageal sphincter motor function. Am J Phisiol, v. 9, p. 427-32. 1993.

SILVA, R. G.; GATTO, A. R.; COLA, P. C. Disfagia orofaríngea neurogênica em adultos avaliação fonoaudiológica em âmbito hospitalar. In: JACOBI, J. S.; LEVY, D. S.; SILVA, L. M. C. Disfagia: avaliação e tratamento. São Paulo: Revinter, p. 181-193, 2003.

SILBINGER, M. L; PIKIELNEY, R.; DONNER, M. W. Neuromuscular disorders affecting the pharynx: cineradiographic analysis. Invest Radiol, p. 2-442, 1967.

SMITH, C. H.; LOGEMANN, J. A.; COLANGELO, L. A.; RADEMAKER, A. W.; PAULOSKI B. R. Incidence and patient characteristics associated with silent aspiration in the acute care setting. Dysphagia, v. 14, p. 1-7, 1999.

STEVENS, K. N.; HOUSE, A.S. Acoustical theory of vowel production and some of its implications. J Speech Hear Res, v. 4, p. 303-20, 1961.

TAKENS F. Dynamical Systems and Turbulence, Warwick. 1980. Lectures Notes in Mathematics. Springer-Verlag, Berlin, 1981. 
TANIGUTE, C. C. Desenvolvimento das funções estomatognáticas. In: MARCHESAN, I. Q. Fundamentos em Fonoaudiologia: aspectos clínicos e em motricidade oral. Rio de Janeiro: Guanabara Koogan, 1998. p. 1-11.

TITZE, I. R. Principles of Voice Production. Prentice Hall. Englewood Cliffs, NJ. 1994.

TITZE, I. R. Workshop on Acoustic Voice Analysis. Denver, CO: National Center for Voice and Speech; 1995. Summary statement 36.

TITZE, I. R, Principles of voice production. 2nd. Iowa City, IA: NCVS; 2000.

TITZE, I. R.; BAKEN, R. J; HERZEL, H. Evidence of chaos in vocal fold vibration. In: TITZE, I. R. Vocal fold physiology. San Diego: Singular Publishing Group, 1993. p. 143185.

TRAPL, M.; ENDERLE, P.; NOWOTNY, M.; TEUSCHL, Y.; MATZ, K.; DACHENHAUSEN, A; BRAININ, M. Dysphagia bedside screening for acute-stroke patients. The gugging swallowing screening. Stroke, 38: 000-000 (published online), 2007.

VALE-PRODOMO, L. P.; CARRARA-DE-ANGELIS, E.; BARROS, A. P. B. Avaliação fonoaudiológica das disfagias. In: JOTZ, G. P; CARRARA-DE-ANGELIS, E.; BARROS, A. P. B. Tratado de deglutição e disfagia Rio de Janeiro: Revinter, 2009. p. 61-67.

VALIM, M. A.; SANTOS, R. S.; MACEDO FILHO, E. D.; ABDULMASSIH, E. M. S.; SERRATO, M. R. F. A Relação entre o Tempo Máximo de Fonação, Frequência Fundamental e a Proteção de Vias Aéreas Inferiores no Paciente com Disfagia Neurogênica. Arq Int Otorrinolaringol, v. 11, n. 3, p. 260-266, 2007.

XEREZ, D. R. Disfagia e Acidente Vascular Encefálico. In: COSTA, M.; CASTRO, L. P. Tópicos em deglutição e disfagia. Rio de Janeiro: Guanabara Koogan, 2003. p. 57-64.

ZAFFARI, R.T. Disfagia orofaríngea neurogênica - orientações para cuidadores e familiares. In: JACOBY, J. S.; LEVY, D. S.; SILVA, L. M. C. Disfagia: avaliação e tratamento. Rio de Janeiro: Revinter, 2004. p. 197-208. 
ZENNER, P. M.; LOSINSKI, D. S.; MILLS, R. H. Using cervical auscultation in the clinical dysphagia examination in long-term care. Dysphagia, v. 10, p. 27-31, 1995.

WARMS, T.; RICHARDS, J. "Wet Voice" as a predictor of penetration and aspiration in oropharyngeal dysphagia. Dysphagia, v. 15, n. 2, p. 84-88, 2000. 


\section{7- ANEXOS}

\section{ANEXO 1}

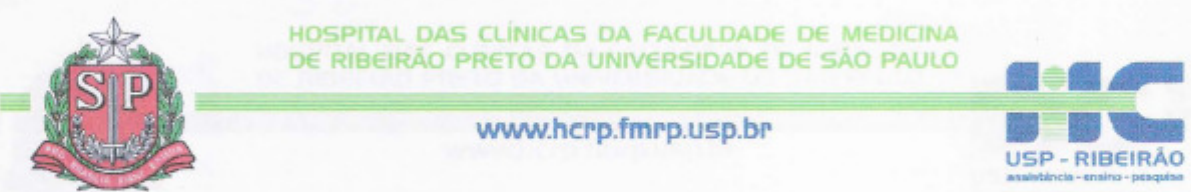

Ribeirão Preto, 24 de outubro de 2007

Oficio $\mathrm{n}^{\circ} 3695 / 2007$

CEP/SPC

Prezada Senhora,

O trabalho intitulado "UTILIZAÇÃo DA ANÁLISE ACÚSTICA COMO INSTRUMENTO PARA O DIAGNÓSTICO DA DISFAGIA EM PACIENTES COM ALTERAÇÕES NEUROLÓGICAS", foi analisado pelo Comitê de Ética em Pesquisa, em sua $257^{a}$ Reunião Ordinária realizada em 22/10/2007, e enquadrado na categoria: APROVADO, bem como o Termo de Consentimento Livre e Esclarecido, de acordo com o Processo HCRP $n^{\circ} 3389 / 2007$.

Lembramos que devem ser apresentados a este CEP, 0

Relatório Parcial e o Relatório Final da pesquisa.

Atenciosamente.

PROF. DR. SÉRGIO PEREIRA DA CUNHA

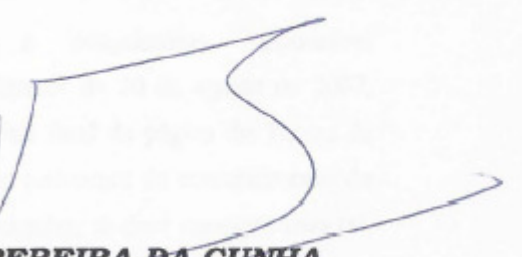

Coordenador do Comitê de Ética em Pesquisa do HCRP e da FMRP-USP

Ilustrissima Senhora

JAMILLE LAYS MARRARA

PROF. DR. ROBERTO OLIVEIRA DANTAS (Co-Orientador)

Depto. de Clínica Médica

Comitê de Ética em Pesquisa HĆ e FMRP-USSP - Campus Universitário FWA - 0000 2733; IRB - 00002186

Fone (16) 3602-2228 - E-mail : cep@hcrp. fimrp.usp. br

Mōnte Alegre 14048-900 Ribeirăo Preto SP 


\section{ANEXO 2}

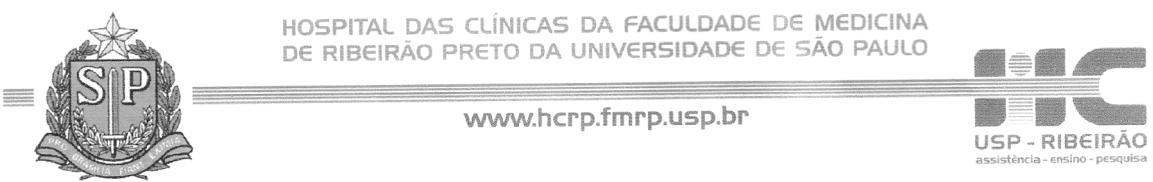

Ribeirão Preto, 29 de setembro de 2008.

Ofício $\mathrm{N}^{\circ} .3544 / 2008$.

$\mathrm{CEP} / \mathrm{MGV}$

\section{PROCESSO HCRP N.3389/2007}

Prezados Pesquisadores,

O Comitê de Ética em Pesquisa, em sua $274^{a}$ Reunião Ordinária, realizada em 22/09/2008, analisou e aprovou o adendo de acréscimo de grupo controle à pesquisa, assim como os Termos de Consentimento Livre e Esclarecido referentes à pesquisa "UTILIZAÇÃO DA ANÁLISE ACÚSTICA COMO INSTRUMENTO PARA O DIAGNÓSTICO DA DISFAGIA EM PACIENTES COM ALTERAÇÕES NEUROLÓGICAS”. O CEP aprovou a continuidade da pesquisa.

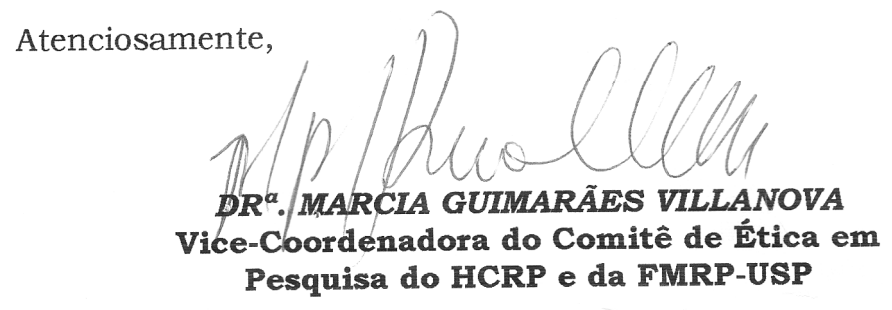

Ilustríssimos Senhores

FGA. JAMILLE LAYS MARRARA

PROF. DR. ROBERTO OLIVEIRA DANTAS

Departamento de Clínica Médica

Comitê de Ética em Pesquisa HCRP e FMRP-USP - Campus Universitário FWA - 0000 2733; IRB - 00002186 - Registro CONEP/SISNEP $n^{\circ} .4$ Fone (16) 3602-2228 - E-mail : cep@hcrp.fmrp.usp.br Mibeirão Preto SP 


\section{ANEXO 3}

Termo de Consentimento Formal de Participação no Projeto intitulado: "Utilização da Análise Acústica como instrumento para o diagnóstico da disfagia em pacientes com alterações neurológicas" Responsáveis da pesquisa:

Orientador: Prof. Dr. José Carlos Pereira

Pesquisadora: Jamille Lays Marrara

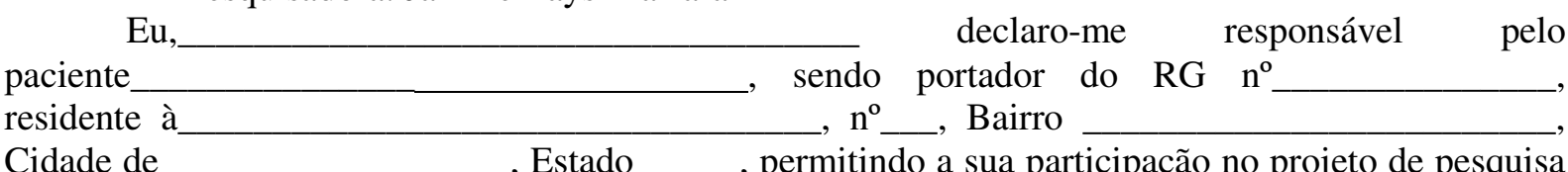

proposto pela fonoaudióloga JAMILLE LAYS MARRARA, CRFa 15001, que tem por finalidade comparar as gravações de voz com o exame de videofluoroscopia da deglutição (no qual o paciente já havia sido encaminhado) e verificar se a mudança na voz esta relacionada com a dificuldade para engolir.

Estou ciente de que inicialmente será solicitado que ele emita, em nível normal de fonação, a vogal /a/ de forma sustentada. Depois ele será encaminhado para o exame normal no ambulatório, onde ficará sentado de lado em um aparelho de Raio X e serão oferecidos os alimentos (nas consistências de "danone" e "água", misturados a um gel, sendo observado em uma televisão o paciente engolindo). Após engolir, o paciente emitirá novamente a vogal /a/ com o mesmo protocolo, para posterior comparação com a que foi gravado antes de engolir o alimento.

Assim, esta pesquisa pretende detectar a penetração e aspiração que pode ocorrer ao engolir e que são importantes para o prognóstico e reabilitação do paciente, visando ser um instrumento utilizado na avaliação clínica fonoaudiológica. A análise acústica da voz é uma técnica não invasiva, sendo um valioso recurso por dispensar o paciente de freqüente exposição à radiação e ser um método de baixo custo.

Declaro que tenho pleno conhecimento dos direitos e das condições que foram assegurados ao paciente, estando relacionados a seguir:

1. A garantia de receber a resposta de qualquer pergunta ou esclarecimento de dúvida a respeito dos procedimentos, riscos e benefícios e de outras situações relacionadas com a pesquisa.

2. A liberdade de retirar meu consentimento, deixando o paciente de participar do estudo a qualquer momento, sem que isso traga prejuízo à continuidade do tratamento.

3. A segurança de que o paciente não será identificado e que será mantido o caráter confidencial da informação relacionada à privacidade do mesmo.

4. O ressarcimento de eventuais despesas, bem como indenização, a título de cobertura material, decorrentes de participação na pesquisa, a ser promovida pela pesquisadora - Jamille Lays Marrara, não cabendo ao Hospital das Clínicas de Ribeirão Preto, qualquer responsabilidade quanto aos referidos pagamentos.

Dúvidas futuras que possam vir a ocorrer poderão ser prontamente esclarecidas com a pesquisadora, Jamille Lays Marrara, tel: (16) 3376-2559. Comitê de Ética em Pesquisa, Av. Bandeirantes, 3.900 - Campus Universitário - Monte Alegre, Ribeirão Preto, tel: (16) 3602-2228, além de haver total liberdade para recusar em prosseguir o projeto, sem que isto acarrete prejuízo ou constrangimento ao paciente.

Ribeirão Preto, de de 


\section{ANEXO 4}

I- Identificação:

\section{Protocolo}

Nome:

RG:

$\mathrm{DN}$ :

Idade:

HD:

\section{II- Dados de avaliação clínica:}

Queixa principal:

Via alternativa de alimentação: ( ) SNE ( ) via oral

$$
\text { ( ) total ( ) parcial }
$$
Consistência de alimentação:
( ) pastoso
( ) líquido
( ) sólido

Utensílios utilizados:
Líquido
( ) copo
( ) canudo
( ) colher
Pastoso

Apresentou:
( ) tosse
( ) antes
( ) durante
( ) após
( ) $\mathrm{P}$ ( ) $\mathrm{L}$
( ) engasgo
( ) antes
( ) durante
( ) após
( ) $\mathrm{P}$ ( ) $\mathrm{L}$
( ) pigarro
( ) $\mathrm{P}$ ( ) $\mathrm{L}$
( ) voz molhada
( ) $\mathrm{P}$ ( ) $\mathrm{L}$

III- Amostra de fala antes e após a administração das consistências:

\begin{tabular}{|l|l|l|l|l|l|}
\hline & & \multicolumn{2}{|c|}{ Pastoso } & \multicolumn{2}{c|}{ Líquido } \\
\hline & Antes & Após - 3ml & Após - 7ml & Após - 3ml & Após - 7ml \\
\hline Jitter & & & & & \\
\hline Shimmer & & & & & \\
\hline SFR & & & & & \\
\hline SFF & & & & & \\
\hline PA & & & & & \\
\hline Ex & & & & & \\
\hline Fo & & & & & \\
\hline
\end{tabular}

\section{IV- Dados da videofluoroscopia da deglutição:}

\begin{tabular}{|l|c|c|c|c|}
\hline \multirow{2}{*}{} & \multicolumn{2}{|c|}{ Pastoso } & \multicolumn{2}{c|}{ Líquido } \\
\cline { 2 - 5 } & $3 \mathrm{ml}$ & $7 \mathrm{ml}$ & $3 \mathrm{ml}$ & $7 \mathrm{ml}$ \\
\hline Resíduo em cavidade oral & & & & \\
\hline Estase em valécula & & & & \\
\hline Resíduo em recessos piriformes & & & & \\
\hline Penetração laríngea & & & & \\
\hline Aspiração laringotraqueal & & & & \\
\hline Resíduo em TFE & & & & \\
\hline
\end{tabular}

